\title{
Diretriz Brasileira de Reabilitação Cardiovascular - 2020
}

Realização: Departamento de Ergometria, Exercício, Cardiologia Nuclear e Reabilitação Cardiovascular da Sociedade Brasileira de Cardiologia

Conselho de Normatizações e Diretrizes (2020-2021): Brivaldo Markman Filho, Antonio Carlos Sobral Sousa, Aurora Felice Castro Issa, Bruno Ramos Nascimento, Harry Correa Filho, Marcelo Luiz Campos Vieira

Coordenador de Normatizações e Diretrizes (2020-2021): Brivaldo Markman Filho

Coordenadores da Diretriz: Tales de Carvalho e Mauricio Milani

Autores da Diretriz: Tales de Carvalho, ${ }^{1,2}{ }^{\oplus}$ Mauricio Milani, ${ }^{3}$ Almir Sergio Ferraz, ${ }^{4}$ Anderson Donelli da Silveira, $, 5,6,7$ Artur Haddad Herdy, ${ }^{1,8,9}$ Carlos Alberto Cordeiro Hossri, ${ }^{4,10}$ Christina Grüne Souza e Silva, ${ }^{11}$ Claudio Gil Soares de Araújo, ${ }^{11}$ Eneas Antonio Rocco, ${ }^{12}$ José Antonio Caldas Teixeira, ${ }^{13}$ Luciana Oliveira Cascaes Dourado, ${ }^{14}$ Luciana Diniz Nagem Janot de Matos, ${ }^{15}$ Luiz Gustavo Marin Emed, ${ }^{16}$ Luiz Eduardo Fonteles Ritt,, 17,18 Marconi Gomes da Silva, ${ }^{19}$ Mauro Augusto dos Santos, ${ }^{20,21}$ Miguel Morita Fernandes da Silva, ${ }^{22}$ Odilon Gariglio Alvarenga de Freitas, ${ }^{23}$

Pablo Marino Corrêa Nascimento, ${ }^{13,21}$ Ricardo Stein, ${ }^{5,6,7}$ Romeu Sergio Meneghelo, ${ }^{4,15}$ Salvador Manoel Serra ${ }^{24}$

Clínica de Prevenção e Reabilitação Cardiosport, ${ }^{1}$ Florianópolis, SC - Brasil

Universidade do Estado de Santa Catarina (Udesc), ${ }^{2}$ Florianópolis, SC - Brasil

Fitcordis Medicina do Exercício, ${ }^{3}$ Brasília, DF - Brasil

Instituto Dante Pazzanese de Cardiologia, ${ }^{4}$ São Paulo, SP - Brasil

Programa de Pós-Graduação em Cardiologia e Ciências Cardiovasculares da Universidade Federal do Rio Grande do Sul (UFRGS), ${ }^{5}$

Porto Alegre, RS - Brasil

Hospital de Clínicas de Porto Alegre, Universidade Federal do Rio Grande do Sul (HCPA/UFRCS), ${ }^{6}$ Porto Alegre, RS - Brasil

Vitta Centro de Bem Estar Físico, ${ }^{7}$ Porto Alegre, RS - Brasil

Instituto de Cardiologia de Santa Catarina, ${ }^{8}$ Florianópolis, SC - Brasil

Unisul: Universidade do Sul de Santa Catarina (UNISUL), ${ }^{9}$ Florianópolis, SC - Brasil

Hospital do Coração (Hcor), ${ }^{10}$ São Paulo, SP - Brasil

Clínica de Medicina do Exercício, Clinimex, ${ }^{11}$ Rio de Janeiro, RJ - Brasil

Hospital Samaritano Paulista, ${ }^{12}$ São Paulo, SP - Brasil

Universidade Federal Fluminense (UFF), ${ }^{13}$ Rio de Janeiro, RJ - Brasil

Instituto do Coração (Incor) do Hospital das Clínicas da Faculdade de Medicina da Universidade de São Paulo (HC-FMUSP), ${ }^{14}$ Rio de Janeiro, RJ - Brasil

Hospital Israelita Albert Einstein, ${ }^{15}$ São Paulo, SP - Brasil

Hospital Cardiológico Costantini, ${ }^{16}$ Curitiba, PR - Brasil

Hospital Cárdio Pulmonar, ${ }^{17}$ Salvador, BA - Brasil

Escola Bahiana de Medicina e Saúde Pública, ${ }^{18}$ Salvador, BA - Brasil

SPORTIF - Clínica do Exercício do Esporte, ${ }^{19}$ Belo Horizonte, MG - Brasil

ACE Cardiologia do Exercício, ${ }^{20}$ Rio de Janeiro, $R J$ - Brasil

Instituto Nacional de Cardiologia, ${ }^{21}$ Rio de Janeiro, RJ - Brasil

Universidade Federal do Paraná, ${ }^{22}$ Curitiba, PR - Brasil

Minascor Centro Médico, ${ }^{23}$ Belo Horizonte, MG - Brasil

Instituto Estadual de Cardiologia Aloysio de Castro (IECAC), ${ }^{24}$ Rio de Janeiro, RJ - Brasil

Esta diretriz deverá ser citada como:

Carvalho T, Milani M, Ferraz AS, Silveira AD, Herdy AH, Hossri CAC, et al. Diretriz Brasileira de Reabilitação Cardiovascular - 2020. Arq Bras Cardiol. 2020; 114(5):943-987.

Nota: estas Diretrizes se prestam a informar e não a substituir o julgamento clínico do médico que, em última análise, deve determinar o tratamento apropriado para seus pacientes.

\section{Correspondência:}

Sociedade Brasileira de Cardiologia - Av. Marechal Câmara, 360/330 - Centro - Rio de Janeiro - CEP: 20020-907.

E-mail: diretrizes@cardiol.br

DOI: https://doi.org/10.36660/abc.20200407 


\begin{tabular}{|c|c|c|c|c|c|c|c|}
\hline \multicolumn{8}{|c|}{$\begin{array}{l}\text { Declaração de potencial conflito de interesses dos autores/colaboradores da Diretriz Brasileira de Reabilitação Cardiovascular - } 2020 \\
\qquad \text { Se nos últimos } 3 \text { anos o autor/colaborador da diretriz: }\end{array}$} \\
\hline $\begin{array}{l}\text { Nomes Integrantes } \\
\text { da diretriz }\end{array}$ & $\begin{array}{l}\text { Participou de estudos } \\
\text { clínicos elou experimentais } \\
\text { subvencionados pela } \\
\text { indústria farmacêutica ou de } \\
\text { equipamentos relacionados } \\
\text { à diretriz em questão }\end{array}$ & $\begin{array}{l}\text { Foi palestrante } \\
\text { em eventos } \\
\text { ou atividades } \\
\text { patrocinadas } \\
\text { pela indústria } \\
\text { relacionados à } \\
\text { diretriz em questão }\end{array}$ & $\begin{array}{l}\text { Foi (é) membro } \\
\text { do conselho } \\
\text { consultivo } \\
\text { ou diretivo } \\
\text { da indústria } \\
\text { farmacêutica ou } \\
\text { de equipamentos }\end{array}$ & $\begin{array}{c}\text { Participou } \\
\text { de comitês } \\
\text { normativos } \\
\text { de estudos } \\
\text { científicos } \\
\text { patrocinados } \\
\text { pela indústria }\end{array}$ & $\begin{array}{l}\text { Recebeu auxílio } \\
\text { pessoal ou } \\
\text { institucional da } \\
\text { indústria }\end{array}$ & $\begin{array}{l}\text { Elaborou textos } \\
\text { científicos em } \\
\text { periódicos } \\
\text { patrocinados } \\
\text { pela indústria }\end{array}$ & $\begin{array}{c}\text { Tem ações } \\
\text { da } \\
\text { indústria }\end{array}$ \\
\hline Almir Sergio Ferraz & Novartis, Amgen, Sanofi & Não & Não & Não & Não & Boehringer & Não \\
\hline Anderson Donelli da Silveira & Não & Não & Não & Não & Não & Não & Não \\
\hline Artur Haddad Herdy & Não & Não & Não & Não & Não & Não & Não \\
\hline $\begin{array}{l}\text { Carlos Alberto Cordeiro } \\
\text { Hossri }\end{array}$ & Não & Não & Não & Não & Não & Não & Não \\
\hline Christina Grüne Souza e Silva & Não & Não & Não & Não & Não & Não & Não \\
\hline Claudio Gil Soares de Araújo & Não & Não & Não & Não & Inbramed & Não & Não \\
\hline Eneas Antonio Rocco & Não & Não & Não & Não & Não & Não & Não \\
\hline José Antonio Caldas Teixeira & Não & Não & Não & Não & Não & Não & Não \\
\hline $\begin{array}{l}\text { Luciana Diniz Nagem Janot } \\
\text { de Matos }\end{array}$ & Não & Não & Não & Não & Não & Não & Não \\
\hline $\begin{array}{l}\text { Luciana Oliveira Cascaes } \\
\text { Dourado }\end{array}$ & Não & Não & Não & Não & Não & Não & Não \\
\hline Luiz Gustavo Marin Emed & Não & Não & Não & Não & Não & Não & Não \\
\hline Luiz Eduardo Fonteles Ritt & Não & Não & Não & Não & Não & Não & Não \\
\hline Marconi Gomes da Silva & Não & Não & Não & Não & Não & Não & Não \\
\hline Mauricio Milani & Não & Não & Não & Não & Não & Não & Não \\
\hline Mauro Augusto dos Santos & Não & Não & Não & Não & Não & Não & Não \\
\hline $\begin{array}{l}\text { Miguel Morita Fernandes } \\
\text { da Silva }\end{array}$ & Não & Não & Não & Não & Novartis & Não & Não \\
\hline $\begin{array}{l}\text { Odilon Gariglio Alvarenga de } \\
\text { Freitas }\end{array}$ & Não & Não & Não & Não & Não & Não & Não \\
\hline $\begin{array}{l}\text { Pablo Marino Corrêa } \\
\text { Nascimento }\end{array}$ & Não & Não & Não & Não & Não & Não & Não \\
\hline Ricardo Stein & Não & Não & Não & Não & Não & Não & Não \\
\hline Romeu Sergio Meneghelo & Não & Não & Não & Não & Não & Não & Não \\
\hline Salvador Manoel Serra & Não & Não & Não & Não & Não & Não & Não \\
\hline Tales de Carvalho & Não & Não & Não & Não & Não & Não & Não \\
\hline
\end{tabular}




\section{Diretrizes}

\section{Lista de Abreviaturas de Acrônimos}

1RM - Teste de 1 repetição máxima

AV - Atrioventricular

AVC - Acidente vascular cerebral

CAVD - Cardiomiopatia arritmogênica do ventrículo direito

CDI - Cardioversor desfibrilador implantável

CRVM - Cirurgia de revascularização do miocárdio

DAC - Doença arterial coronariana

DAOP - Doença arterial obstrutiva periférica

DCV - Doenças cardiovasculares

DRC - Doença renal crônica

DDVE - Diâmetro diastólico final do ventrículo esquerdo

DSVE - Diâmetro sistólico final do ventrículo esquerdo

ECG - Eletrocardiograma

ENM - Eletroestimulação neuromuscular

FC - Frequência cardíaca

FEVE - Fração de ejeção do ventrículo esquerdo

IAM - Infarto agudo do miocárdio

IC - Insuficiência cardíaca

IC 95\% - Intervalo de confiança de 95\%

ICP - Intervenção coronária percutânea

ITB - Índice tornozelo-braquial

HAS - Hipertensão arterial sistêmica
$\mathrm{MCH}$ - Miocardiopatia hipertrófica

MET - Equivalente metabólico

MMII - Membros inferiores

MMSS - Membros superiores

MNC - Miocardiopatia não compactada

MP - Marcapasso cardíaco

MS - Morte súbita

NYHA - New York Heart Association

PA - Pressão arterial

PAD - Pressão arterial diastólica

PAS - Pressão arterial sistólica

pmp - Por milhão da população

PSAP - Pressão sistólica da artéria pulmonar

RCV - Reabilitação cardiovascular

RCVD - Reabilitação cardiovascular domiciliar

RMN - Ressonância magnética nuclear

TCMI - Treinamento contínuo de moderada intensidade

TCPE - Teste cardiopulmonar de exercício

TE - Teste ergométrico

TIAI - Treinamento intervalado de alta intensidade

TMI - Treinamento da musculatura inspiratória

TxC - Transplante cardíaco

$\mathrm{VO}_{2}$ - Consumo de oxigênio

VSA - Vida salva por ano 


\section{Sumário}

1. Introdução.................................................................................. 946

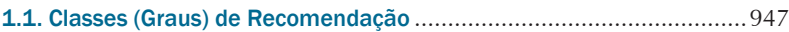

1.2. Níveis de Evidência................................................................. 947

2. Estrutura de um Programa de Reabilitação Cardiovascular................. 947

2.1. Equipe e Responsabilidades dos Profissionais ............................. 947

2.1.1. Médico Assistente ................................................................. 947

2.1.2. Médico-líder no Programa de Reabilitação Cardiovascular......... 947

2.1.3. Outros Profissionais ................................................................. 947

2.1.4. Fisioterapeutas e Profissionais de Educação Física..................... 947

2.1.5. Profissional de Enfermagem..................................................... 947

2.2. Estrutura Física de um Serviço de Reabilitação ................................. 948

2.2.1. Aspectos Gerais ....................................................................... 948

2.2.2. Equipamentos para a Prática de Exercícios Físicos ...................... 948

2.2.2.1. Exercícios Aeróbicos ....................................................................... 948

2.2.2.2. Exercícios de Fortalecimento Muscular ................................. 948

2.2.2.3. Outros Exercícios.................................................................... 948

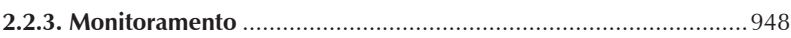

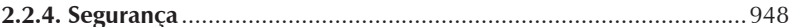

3. Fases da Reabilitação Cardiovascular e Estratificação de Risco .......... 949

3.1. Risco Clínico Alto........................................................... 949

3.2. Risco Clínico Intermediário.................................................................. 950

3.3. Risco Clínico Baixo .......................................................................... 951

4. Custo-efetividade da Reabilitação Cardiovascular .............................952

5. Reabilitação Cardiovascular Domiciliar

6. Reabilitação Cardiovascular Integrando o Tratamento Clínico Pleno das Doenças Cardiovasculares................................................................... 953 6.1. Recomendações Gerais para Incremento da Atividade Física e Prática de Exercícios Físicos............................................................................... 954 6.2. Hipertensão Arterial Sistêmica ........................................................ 955

6.2.1. Benefícios Terapêuticos dos Exercícios Físicos ............................. 955

6.2.2. Indicações de Exercícios Físicos na Hipertensão

Arterial Sistêmica ......................................................................... 956

6.2.3. Avaliação Pré-participação .......................................................... 956

6.2.4. Particularidades na Prescrição e no Acompanhamento dos

Exercícios Físicos .................................................................... 957

6.3. Coronariopatia Estável após Evento Agudo ou Revascularizações ....957

6.3.1. Benefícios Terapêuticos dos Exercícios Físicos ............................. 958

6.3.2. Quando Indicar Reabilitação .................................................. 958

6.3.3. Avaliação Pré-participação e Prescrição de Exercícios................. 959

6.3.4. Particularidades na Prescrição e Acompanhamento dos

Exercícios Físicos ............................................................................ 960

6.3.4.1. Angina Refratária .................................................................... 960

6.3.4.2. Treinamento com Indução de Isquemia Miocárdica .................. 960

6.3.4.3. Ajustes de Fármacos Diante da Assimilação do

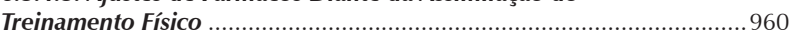

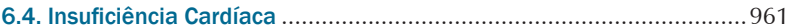

6.4.1. Prescrição dos Exercícios Físicos e Avaliação Pré-participação ... 961

6.4.2. Considerações Finais sobre a Insuficiência Cardíaca .................. 963

6.5. Transplante Cardíaco................................................................... 963

6.5.1. Benefícios dos Exercícios Físicos..................................................... 963

6.5.2. Avaliação Pré-participação e Particularidades ............................. 964

6.5.3. Prescrição do Treinamento Físico ........................................ 964

6.5.4. Reabilitação Cardiovascular Domiciliar........................................ 965

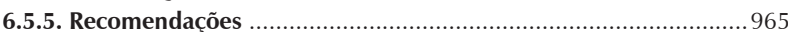

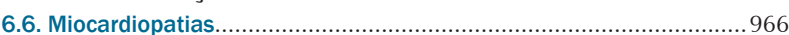

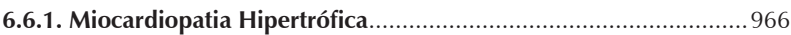

6.6.1.1. Benefícios Terapêuticos do Exercício Físico............................. 966

6.6.1.2. Quando Indicar Exercícios Físicos ........................................... 967

6.6.1.3. Avaliação Pré-participação ................................................. 967

6.6.1.4. Particularidades na Prescrição e no Acompanhamento dos

Exercícios Físicos

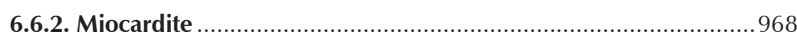

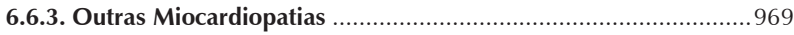

6.6.3.1. Cardiomiopatia Arritmogênica do Ventrículo Direito ............... 969

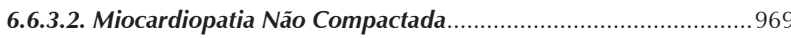

6.7. Valvopatias ......................... 970

6.7.1. Fase Pré-intervenção ................................................................ 970

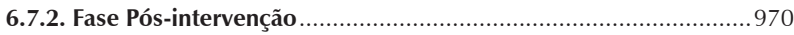

6.7.3. Avaliação Pré-participação ........................................................ 970

6.7.4. Particularidades na Prescrição e no Acompanhamento dos

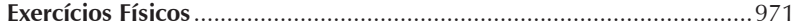

6.8. Portadores de Marcapasso ou Cardioversor

Desfibrilador Implantável ................................................................. 971

6.8.1. Benefícios Terapêuticos dos Exercícios Físicos ........................... 972

6.8.2. Quando Indicar Reabilitação Cardiovascular ............................ 973

6.8.3. Avaliação Pré-participação ................................................................ 973

6.8.4. Particularidades na Prescrição e no Acompanhamento dos

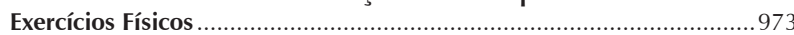

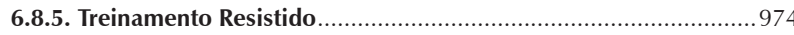

6.8.6. Estimulação Elétrica Neuromuscular....................................... 974

6.9. Doença Arterial Obstrutiva Periférica............................................... 975

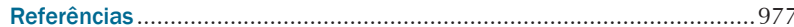

\section{Introdução}

Está cientificamente comprovado, sendo algo incorporado ao senso comum, que ser fisicamente ativo contribui para preservar e recuperar a boa saúde do corpo e da mente. Os efeitos favoráveis da reabilitação cardiovascular (RCV) com ênfase nos exercícios físicos têm sido consistentemente documentados, inclusive em meta-análises de estudos clínicos randomizados, que demonstram significativas reduções da morbimortalidade cardiovascular e global, ${ }^{1}$ bem como da taxa de hospitalização, ${ }^{1,2}$ com expressivo ganho de qualidade de vida, ${ }^{1,2}$ justificando a sua consensual e enfática recomendação pelas principais sociedades médicas mundiais. ${ }^{3-6}$

O sedentarismo, que apresenta elevada prevalência no Brasil e no mundo, está fortemente relacionado às doenças cardiovasculares (DCV) e à mortalidade precoce. ${ }^{7,8}$ Em contrapartida, maiores volumes de atividade física são positivamente associados à melhor qualidade e à maior expectativa de vida, ${ }^{9-13}$ existindo uma forte e inversa associação dos diferentes componentes da aptidão física com a mortalidade por todas as causas e com a ocorrência de eventos cardiovasculares desfavoráveis. Ou seja, quanto menor o nível de aptidão física, maior tende ser a taxa de mortalidade. ${ }^{14-21}$

Portanto, o principal objetivo da RCV com ênfase nos exercícios físicos é propiciar uma melhora dos componentes da aptidão física, tanto aeróbico quanto não aeróbicos (força/ potência muscular, flexibilidade, equilíbrio), algo que exige a combinação de diferentes modalidades de treinamento. Assim, a RCV deve proporcionar os mais elevados níveis de aptidão física passíveis de obtenção, de modo a reduzir o risco de eventos cardiovasculares e promover todos os outros benefícios a serem auferidos pela prática regular de exercícios físicos, culminando com a redução da mortalidade geral. ${ }^{14-21}$

Entretanto, apesar dos benefícios documentados e do excelente significado em termos de custo-efetividade, $22,23 \mathrm{a}$ RCV é mundialmente subutilizada. No Brasil, país de dimensão continental e grande diversidade social e econômica, dentre as inúmeras barreiras ao acesso à $\mathrm{RCV}^{24,25}$ vale destacar como algo presente em praticamente todas as regiões: escassez de 
serviços estruturados, dificuldade de deslocamento (mobilidade urbana ruim) e níveis altos de violência nas cidades..$^{26,27}$ Neste contexto, programas de reabilitação cardiovascular domiciliar (RCVD), em que a maioria das sessões ocorre no ambiente domiciliar sob supervisão indireta, surgem como complemento ou alternativa aos programas tradicionais, nos quais as sessões são sempre realizadas sob supervisão direta ou presencial.

A exemplo do que ocorreu nos documentos anteriormente publicados pela Sociedade Brasileira de Cardiologia sobre o tema, ${ }^{6,28-31}$ esta diretriz aborda exclusivamente a intervenção com base na prática de exercícios físicos direcionadas aos pacientes com DCV, sendo a classe (ou grau) de recomendação sempre fundamentada no nível de evidência encontrado, conforme consta a seguir.

\subsection{Classes (Graus) de Recomendação}

- Classe I: condições para as quais há evidências conclusivas, ou, na sua falta, consenso de que o procedimento é seguro e útil/eficaz;

- Classe II: condições para as quais há evidências conflitantes e/ou divergência de opinião sobre segurança e utilidade/eficácia do procedimento:

- Classe IIA: peso ou evidência/opinião a favor do procedimento. A maioria aprova;

- Classe IIB: segurança e utilidade/eficácia menos bem estabelecida, não havendo predomínio de opiniões a favor.

- Classe III: condições para as quais há evidências e/ou consenso de que o procedimento não é útil/eficaz e, em alguns casos, pode ser prejudicial.

\subsection{Níveis de Evidência}

- Nível A: dados obtidos a partir de múltiplos estudos randomizados de bom porte, concordantes e/ou de meta-análise robusta de estudos clínicos randomizados;

- Nível B: dados obtidos a partir de meta-análise menos robusta, com base em um único estudo randomizado ou em estudos não randomizados (observacionais);

- Nível C: dados obtidos de opiniões consensuais de especialistas.

\section{Estrutura de um Programa de Reabilitação Cardiovascular}

\subsection{Equipe e Responsabilidades dos Profissionais}

A composição das equipes profissionais de RCV deve ajustar-se aos objetivos, à clientela e às disponibilidades de recursos humanos e materiais, respeitadas as características regionais, a modalidade (supervisão direta ou indireta) e o local de realização (hospital, clínica, ambulatório e outros). A equipe multiprofissional habitualmente é composta por médicos, educadores físicos, fisioterapeutas e profissionais de enfermagem, mas outros, como nutricionistas, psicólogos e assistentes sociais, podem compor a equipe..$^{31,32}$

\subsubsection{Médico Assistente}

A RCV compõe o tratamento clínico pleno dos pacientes estáveis com DCV, o que exige a integração do médico assistente, que, ao encaminhar o seu paciente, deve ter conhecimento das indicações e dos benefícios a serem obtidos, adotando as necessárias providências clínicas pré-participação. Tendo em vista o encaminhamento de relatórios, eventuais necessidades de ajustes farmacológicos, intercorrências médicas, entre outros, é de grande relevância que sejam criados mecanismos para uma fácil comunicação entre o médico assistente e a equipe de RCV. ${ }^{31}$

\subsubsection{Médico-líder no Programa de Reabilitação Cardiovascular}

Coordena as ações médicas, sendo no Brasil habitualmente o coordenador geral do programa de RCV. Ele deve conhecer em profundidade a temática de RCV e ter conhecimento para atuar em emergências cardiovasculares. ${ }^{6,32-34}$

Algumas de suas principais atuações são:

a) Executar a avaliação pré-participação, com inclusão de testes de exercício, de modo a subsidiar a programação inicial das sessões de treinamento da RCV; ${ }^{31}$

b) Treinar a equipe para identificar situações de risco e realizar o atendimento apropriado em situações emergenciais;

c) Estabelecer restrições e limites para a prescrição dos exercícios físicos;

d) Liderar e interagir com os demais membros da equipe, com o objetivo de otimizar a qualidade e a segurança da prescrição dos exercícios físicos;

e) Programar reavaliações subsequentes, sempre interagindo com o médico assistente.

\subsubsection{Outros Profissionais}

De modo semelhante aos médicos, os demais membros da equipe, ao executarem suas respectivas funções, devem seguir as normas e regras que norteiam as atividades do programa, respeitando as recomendações de seus respectivos conselhos profissionais. ${ }^{31}$

\subsubsection{Fisioterapeutas e Profissionais de Educação Física}

Atuam diretamente na prescrição e na supervisão dos exercícios físicos, dentro das metas e dos limites definidos na orientação médica, após a avaliação pré-participação e subsequentes reavaliações. Devem ter conhecimentos específicos sobre as DCV e fisiologia do exercício, além de receberem periodicamente treinamento de suporte básico de vida, incluindo o uso de desfibrilador automático externo. Além da atuação nas sessões de exercícios físicos, podem contribuir para as orientações e demais medidas, visando a adoção de hábitos saudáveis.

\subsubsection{Profissional de Enfermagem}

Em um programa de RCV, o profissional de enfermagem pode auxiliar na avaliação clínica, atuando na obtenção e no fornecimento de informações relacionadas à situação 
clínica do paciente, inclusive em contato com os familiares. Pode ser responsável pelas dosagens de glicemia e verificação de pressão arterial (PA), antes e durante as sessões de exercícios. Em caso de intercorrências clínicas, pode participar do atendimento e auxiliar o médico, com eventuais administrações de medicamentos. Deve também estar capacitado para atuar no suporte básico de vida, com uso de desfibrilador automático externo.

\subsection{Estrutura Física de um Serviço de Reabilitação}

\subsubsection{Aspectos Gerais}

Um programa de RCV pode funcionar em vários tipos de instalações, a depender dos objetivos e recursos disponíveis. Mais frequentemente, os programas de RCV são realizados em ambientes fechados e climatizados, sendo também possível realizar as sessões de exercícios físicos em espaços abertos, como pistas de atletismo, quadras, ginásios poliesportivos, parques ou áreas públicas de lazer. ${ }^{29}$

Em ambientes fechados, o espaço para a realização dos exercícios físicos deverá apresentar dimensões e características adequadas, variáveis de acordo com os recursos locais e a capacidade de atendimento. O ambiente deverá ser suficientemente amplo para a realização dos exercícios físicos, com uma altura de pé direito idealmente igual ou superior a 2,5 m. Também deverá ser apropriadamente iluminado e bem ventilado, onde seja possível manter a temperatura entre $22^{\circ} \mathrm{C}$ e $25^{\circ} \mathrm{C}$, além de umidade relativa do ar entre 40 e $65 \%$ durante as sessões de exercício. A área disponível exclusivamente para a realização dos exercícios físicos, desconsiderando vestiários, banheiros, recepção ou sala de espera, varia muito, podendo ir desde $20 \mathrm{~m}^{2}$ a algumas centenas de metros quadrados. É importante que existam locais próprios para a troca de roupas e instalações sanitárias. Para minimizar o risco de acidentes e quedas, o piso deve ter propriedades antiderrapantes. ${ }^{29}$

\subsubsection{Equipamentos para a Prática de Exercícios Físicos}

\subsubsection{Exercícios Aeróbicos}

Os equipamentos mais usados são esteiras rolantes e cicloergômetros de membros inferiores (MMII), mas também podem ser utilizados cicloergômetros de membros superiores (MMSS), remoergômetros, ergômetros de esqui, elípticos, entre outros. ${ }^{29}$

As esteiras rolantes devem ser elétricas, com capacidade de suportar, pelo menos, $100 \mathrm{~kg}$ de peso corporal, com suportes frontal e lateral para as mãos e trava de segurança. Devem também permitir ajuste individualizado dentro de uma faixa ampla de velocidade e inclinação. Os cicloergômetros podem ser de frenagem mecânica ou eletromagnética. Há modelos específicos para MMSS ou ainda para que os quatro membros sejam exercitados simultaneamente. Para os modelos de MMII existem as opções vertical e horizontal. O ideal é que o cicloergômetro possibilite a leitura da cadência ou velocidade e, principalmente, da potência em watts. Há cicloergômetros em que é possível programar a intensidade diretamente em watts, de modo que a resistência do pedal aumenta quando a cadência diminui e vice-versa.
Os remoergômetros, ergômetros de esqui e elípticos podem ser particularmente úteis para os pacientes com menor grau de limitação funcional ou que já tenham tido experiências prévias com tais equipamentos. Eles apresentam como vantagem possibilitar o exercício simultâneo dos MMSS e MMII.

\subsubsection{Exercícios de Fortalecimento Muscular}

Há vários tipos de equipamentos que podem ser utilizados para o fortalecimento muscular. Porém, é possível realizar vários exercícios utilizando somente o peso corporal, que representa um esforço, em geral, suficiente nos pacientes mais debilitados. Um exemplo prático é o exercício de sentar e levantar, cuja realização requer tão somente uma cadeira ou um banco.

O uso de cordas ou faixas suspensas, bem fixadas ao teto ou alto da parede, podem permitir uma ampla variedade de exercícios com a utilização do peso do próprio corpo. Pesos livres, halteres ou caneleiras com pesos variados são frequentemente adotados em programas de RCV e possibilitam uma ampla variedade de movimentos e estímulos adequados de diferentes grupos musculares. Podem ser também utilizados aparelhos específicos, com pesos ligados a cabos e polias. Outros equipamentos que também podem ser usados: barras, bastões, bolas com peso (medicine balls), "bolas suíças" e faixas ou bandas elásticas com diferentes graus de resistência. ${ }^{29}$

Em todos os exercícios deve haver atenção para a correta execução dos movimentos e adequada postura, a fim de evitar lesões osteomusculares. Atenção ao manuseio dos equipamentos também é necessária, com o intuito de evitar acidentes com o material e eventuais lesões corporais.

\subsubsection{Outros Exercícios}

Visando a saúde global, considerando a cardiopatia e doenças associadas, pode ser necessário acrescentar outros tipos de exercícios, como treinamento isométrico manual, treinamento da musculatura inspiratória e exercícios para aprimorar o equilíbrio e a flexibilidade.

\subsubsection{Monitoramento}

Além de esfigmomanômetros e estetoscópios, há vários recursos disponíveis, como cardiofrequencímetros e aplicativos de celulares para monitoramento da frequência cardíaca (FC), glicosímetros e oxímetros digitais. Dependendo da complexidade clínica e do risco de eventos cardiovasculares desfavoráveis, é desejável o monitoramento eletrocardiográfico no repouso e durante o exercício, que pode ser obtido por equipamentos de conexão direta ao paciente ou por sistemas de telemetria, sendo de fundamental importância em caso de eventos cardiovasculares a possibilidade do rápido acesso aos equipamentos, para identificação do quadro clínico e a subsequente conduta médica.

\subsubsection{Segurança}

Apesar de ser extremamente incomum, é importante que o programa tenha um planejamento para o adequado 
atendimento de eventos cardiovasculares graves, como a parada cardiorrespiratória, que, na maioria dos casos em adultos, decorre de fibrilação ventricular ou taquicardia ventricular sem pulso. Portanto, o desfibrilador, manual ou automático, é um equipamento de segurança obrigatório. Ainda devem estar disponíveis outros materiais do suporte básico e avançado de vida, como laringoscópio, tubos orotraqueais de tamanhos variados, máscaras, ambu e oxigenioterapia suplementar.

Para orientação mais detalhada de técnicas, equipamentos e medicamentos, orienta-se consultar diretrizes específicas sobre os respectivos assuntos. ${ }^{35,36}$

\section{Fases da Reabilitação Cardiovascular e Estratificação de Risco}

Tradicionalmente, a RCV é dividida em fases temporais, sendo a fase 1 intra-hospitalar e as fases 2 a 4 ambulatoriais. Nos primórdios, a fase 1 foi destinada à recuperação após infarto agudo do miocárdio (IAM) ou cirurgia de revascularização miocárdica (CRVM). Posteriormente, em contexto atualmente denominado reabilitação cardiopulmonar e metabólica, foram incluídos os pacientes internados submetidos a intervenções coronárias percutâneas (ICP), cirurgias valvares, cirurgias para cardiopatias congênitas e transplante cardíaco (TxC), além dos portadores de insuficiência cardíaca (IC), doença arterial coronariana (DAC), diabéticos, hipertensos, pneumopatas e nefropatas crônicos, assim que estabilizados clinicamente. Portanto, a RCV deve ser iniciada imediatamente após o paciente ter sido considerado clinicamente compensado, como decorrência do tratamento clínico e/ou intervencionista. ${ }^{31}$

Na fase 1 da RCV objetiva-se que o paciente tenha alta hospitalar com as melhores condições físicas e psicológicas possíveis, municiado de informações referentes ao estilo saudável de vida, em especial no que diz respeito ao exercício físico. Propõe-se a combinação de exercícios físicos de baixa intensidade, técnicas para o controle do estresse e programas de educação em relação aos fatores de risco e à cardiopatia. A equipe de atendimento deve ser composta por, pelo menos, médico, fisioterapeuta e enfermeiro, capacitados para atuar em RCV, que não precisam dedicar tempo integral ao programa de reabilitação, podendo exercer outras atividades no hospital. ${ }^{31}$

$\mathrm{O}$ direcionamento às fases ambulatoriais da RCV deve ser realizado na alta da internação. A fase 2 começa imediatamente após a alta hospitalar e tem duração média de 3 meses. A fase 3 costuma ter duração de 3 a 6 meses e a fase 4 tem duração prolongada. Em todas as fases objetiva-se progressão dos benefícios da RCV ou, pelo menos, a manutenção dos ganhos obtidos.

Em uma divisão rígida da RCV em fases temporais, pode-se não levar em consideração que existem pacientes com cardiopatias graves, muito sintomáticos e debilitados, que permanecem por longo prazo em uma reabilitação "fase 2", pois continuam requerendo a supervisão direta dos exercícios físicos, enquanto outros, de baixo risco, desde o início se enquadram em programas de fase 3 ou mesmo de fase 4, sendo potenciais candidatos a uma RCV domiciliar, em que a maioria das sessões ocorrem sob supervisão indireta, à distância. ${ }^{31}$

Portanto, recomenda-se uma estratificação do risco clínico que possibilite o uso mais racional dos programas, com direcionamento individualizado às modalidades de RCV. Nesse contexto, os pacientes de alto risco, com menor capacidade física e mais sintomáticos, devem participar de sessões supervisionadas por tempo indeterminado, enquanto os de menor risco, com maior capacidade física e menos sintomáticos precocemente podem realizar, sem supervisão direta, exercícios mais intensos e diversificados (Figura 1).

A estratificação de risco clínico do paciente em alto, intermediário ou baixo é pautada em recomendações

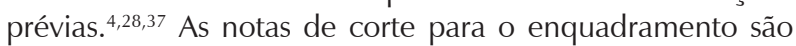
baseadas na opinião de especialistas (evidência nível C), o que possibilita modificações regionais de acordo com a experiência da equipe da RCV e com o julgamento clínico realizado na avaliação médica pré-participação e subsequentes reavaliações (Tabela 1 ).

\subsection{Risco Clínico Alto}

A duração da RCV pode variar conforme o quadro clínico e a evolução do treinamento físico. O enquadramento, a manutenção ou a reclassificação do perfil de risco devem ser determinados pela avaliação médica pré-participação e por reavaliações subsequentes, realizadas pelo médico e demais integrantes da equipe. O modelo dessa avaliação médica pode variar de acordo com a estrutura logística e a experiência do serviço, devendo conter, no mínimo, consulta clínica, exame físico, eletrocardiograma (ECG) de repouso e teste cardiopulmonar de exercício (TCPE) ou teste ergométrico (TE).

\begin{tabular}{|l|l|r|r|}
\hline Risco clínico & Alto & Intermediário & Baixo \\
\hline Capacidade física $\left(\mathrm{MET}, \mathrm{VO}_{2}\right)$ & Menor & & Maior \\
\hline Sintomatologia & Maior & & Menor \\
\hline Necessidade de supervisão dos exercícios & Maior & & Menor \\
\hline
\end{tabular}

Figura 1 - Características gerais dos pacientes em reabilitação cardiovascular ambulatorial, de acordo com a estratificação do risco clínico. MET: equivalente metabólico; $\mathrm{VO}_{2}$ : consumo de oxigênio. 
Tabela 1 - Estratificação do risco clínico dos pacientes em reabilitação cardiovascular ambulatorial

\begin{tabular}{|c|c|c|c|}
\hline Risco & Alto & Intermediário & Baixo \\
\hline \multicolumn{4}{|l|}{ Característica } \\
\hline $\begin{array}{l}\text { Evento cardiovascular, intervenção } \\
\text { cardiovascular ou descompensação clínica }\end{array}$ & Inferior a 8 a 12 semanas & Superior a 12 semanas & Superior a 6 meses \\
\hline Capacidade funcional & $\begin{array}{c}\text { TE: }<5 \mathrm{MET} \\
\text { TCPE: Weber } \mathrm{C} / \mathrm{D} \text { ou } \mathrm{VO}_{2} \text { pico } \\
<60 \% \text { do predito }\end{array}$ & $\begin{array}{c}\text { TE: } 5 \text { a } 7 \text { MET } \\
\text { TCPE: Weber } \mathrm{B} \text { ou } \mathrm{VO}_{2} \text { pico de } 60 \text { a } \\
85 \% \text { do predito }\end{array}$ & $\begin{array}{c}\text { TE: }>7 \text { MET } \\
\text { TCPE: Weber } A \text { ou } \mathrm{VO}_{2} \text { pico }>85 \% \\
\text { do predito }\end{array}$ \\
\hline $\begin{array}{l}\text { Sinais e sintomas de isquemia miocárdica } \\
\text { (limiar isquêmico) }\end{array}$ & $\begin{array}{c}\text { Em baixas cargas } \\
\text { TE: abaixo de } 6 \mathrm{MET} \\
\text { TCPE: abaixo de } 15 \mathrm{ml}^{\mathrm{kg}} \mathrm{kg}^{-1} \cdot \mathrm{min}^{-1}\end{array}$ & $\begin{array}{c}\text { TE: acima de } 6 \mathrm{MET} \\
\text { TCPE: acima de } 15 \mathrm{ml} \cdot \mathrm{kg}^{-1} \cdot \mathrm{min}^{-1}\end{array}$ & Ausente \\
\hline Sintomatologia & $\begin{array}{c}\text { IC: CF III e IV } \\
\text { Angina: CF III e IV }\end{array}$ & $\begin{array}{c}\text { IC: CF I a II } \\
\text { Angina: CF I e II }\end{array}$ & Ausente \\
\hline Outras características clínicas & $\begin{array}{c}\text { IRC dialítica; } \\
\text { queda da saturação de oxigênio } \\
\text { em esforço; } \\
\text { arritmia ventricular complexa }\end{array}$ & $\begin{array}{l}\text { De acordo com o julgamento } \\
\text { clínico na avaliação médica } \\
\text { pré-participação }\end{array}$ & $\begin{array}{l}\text { De acordo com o julgamento } \\
\text { clínico na avaliação médica } \\
\text { pré-participação }\end{array}$ \\
\hline
\end{tabular}

Os pacientes de alto risco, com frequência, podem necessitar de atendimento médico imediato ou a curto prazo (reinternação, intervenções ou ajustes de fármacos). Portanto, requerem maior monitoramento do treinamento pela equipe assistencial, a qual deve ser capaz de identificar sinais e sintomas de situações de risco e atuar no atendimento de intercorrências clínicas, inclusive com material de suporte básico e avançado de vida, com cardiodesfibrilador manual ou automático. É preferencial, inclusive, que esse equipamento esteja dentro da sala de atendimento. A equipe médica deve estar prontamente disponível na localidade, com rápido acesso ao paciente em caso de intercorrências graves.

Ressalte-se que a melhor maneira de prevenir intercorrências durante um programa de reabilitação e, especialmente após eventos e intervenções, consiste na realização de qualificadas avaliações pré-participação e subsequentes, que devem ser sistemáticas.

O programa de exercícios deve ser individualizado em termos de intensidade, duração, frequência, modalidade de treinamento e progressão, de acordo com os testes funcionais realizados inicialmente e no seguimento. Sempre devem ser adotados recursos para a correta determinação da FC e verificação da PA, em repouso e em esforço, além da possibilidade de verificação de saturação de oxigênio, determinação da glicemia capilar e monitoramento eletrocardiográfico.

O atendimento também deve contemplar um programa educacional direcionado à modificação do estilo de vida, com ênfase na reeducação alimentar e em estratégias para cessação do tabagismo, quando necessárias. É importante que o paciente obtenha conhecimentos sobre sua doença e aprendizado de automonitoramento, tanto na execução dos exercícios quanto na identificação de sinais e sintomas de alerta para situações clínicas instáveis ou de risco.

As características clínicas dos pacientes que se enquadrariam inicialmente no risco clínico alto (presença de, pelo menos, uma delas) são:
- Internação por descompensação cardiovascular recente (menos de 8 a 12 semanas) devido a quadros de: IAM ou angina instável; revascularização cirúrgica ou percutânea; arritmias complexas; morte súbita revertida; descompensação de $\mathrm{IC}$;

- Pacientes cardiopatas, com presença ou ausência de evento cardiovascular e/ou intervenções, mas com importantes alterações funcionais ao esforço físico, ou seja:

- Baixa capacidade funcional no TE (menor que 5 equivalentes metabólicos [MET]) ou no TCPE (classificação de Weber C e D ou consumo de oxigênio $\left[\mathrm{VO}_{2}\right.$ ] abaixo de $60 \%$ do predito para idade e sexo);

- Sinais e sintomas de isquemia miocárdica em baixa carga (abaixo de 6 MET ou de $\mathrm{VO}_{2}$ de $15 \mathrm{ml} \cdot \mathrm{kg}^{-1} \cdot \mathrm{min}^{-1}$ );

- Sintomatologia exacerbada (IC com classe funcional III e IV ou angina classe funcional III e IV).

- Outras características clínicas de pacientes com risco aumentado aos exercícios físicos: doença renal crônica (DRC) dialítica, dessaturação de oxigênio em esforço e arritmia ventricular complexa em repouso ou esforço.

Considerando que os pacientes de alto risco frequentemente necessitam de reajustes de fármacos e de reavaliações, com eventuais intervenções (revascularizações ou outros procedimentos), torna-se essencial comunicação constante da equipe assistencial da RCV com o(s) médico(s) assistente(s). É importante destacar que alguns pacientes, devido a intercorrências nas sessões e/ou resultados nas avaliações subsequentes, podem permanecer classificados como de alto risco, mantendo a prática de exercícios físicos sob supervisão direta por tempo indeterminado.

\subsection{Risco Clínico Intermediário}

Os pacientes podem ter cumprido etapas anteriores da RCV, sendo reclassificados, ingressar diretamente nessa categoria sem participações prévias ou ser oriundos de outros programas de exercícios. A duração da RCV sob essa 
classificação também pode ser variável, a depender do quadro clínico e da evolução do treinamento físico, algo a ser definido nas reavaliações subsequentes.

A supervisão de exercícios deve ser feita pelo fisioterapeuta ou professor de educação física, e o serviço deve, idealmente, contar com a coordenação geral de um médico com experiência em RCV. É recomendada a disponibilidade de recursos para a correta determinação da FC e verificação de PA em repouso e esforço e, sempre que necessário, com possibilidade de verificação da saturação de oxigênio, determinação da glicemia e monitoramento eletrocardiográfico.

Para o atendimento de pacientes de risco intermediário, caso não haja médico presente no local das atividades, deve haver possibilidade do seu rápido acionamento remoto. A estrutura do serviço deve apresentar material de suporte básico de vida e profissionais de saúde treinados em reanimação cardiopulmonar, com o uso de desfibrilador automático externo, o qual deve estar presente no local de atendimento.

É fundamental que a equipe médica integrada ao serviço de RCV realize a avaliação pré-participação, com adequada estratificação do risco. O seguimento médico regular e as reavaliações sistemáticas, além dos atendimentos eventuais quando necessários, são fundamentais para garantir a segurança dos exercícios.

As características clínicas dos pacientes com risco intermediário (presença de, pelo menos, uma característica) são:

- Evento cardiovascular ou intervenções com intervalo superior a 12 semanas, com estabilidade do quadro clínico;

- Pacientes cardiopatas que ainda apresentam algumas alterações funcionais em esforço físico:

- Moderada capacidade funcional no TE (entre 5 e 7 MET) ou no TCPE (classificação de Weber B ou VO entre 60 e $85 \%$ do predito para idade e sexo);

- Sinais e sintomas de isquemia em carga acima de 6 MET ou com $\mathrm{VO}_{2}$ acima de $15 \mathrm{ml} \cdot \mathrm{kg}^{-1} \cdot \mathrm{min}^{-1}$;

- Sintomatologia de menor magnitude (IC com classe funcional I e II ou angina classe funcional I e II).

- Outras características clínicas que o médico responsável pela avaliação pré-participação julgue como de risco intermediário aos exercícios físicos.

O principal objetivo da RCV neste perfil de risco ainda é o aprimoramento da aptidão física, tanto aeróbica quanto não aeróbica (força/potência muscular, flexibilidade, equilíbrio), com melhor controle da(s) doença(s). Deve ser considerada a necessidade de promoção de bem-estar, com melhora da qualidade de vida, além de outros procedimentos que contribuam para a redução do risco de complicações clínicas, como é o caso das estratégias para cessação do tabagismo, reeducação alimentar e controle de peso corporal. A ênfase na manutenção e adesão do tratamento farmacológico também é fundamental para evitar a progressão ou instabilização da DCV. A obtenção de conhecimentos sobre a própria doença, possibilitando melhor automonitoramento, aumentam a acurácia na identificação de sinais e sintomas relacionados à progressão da doença ou a situações clínicas instáveis, que podem requerer interrupção do programa de exercícios e reavaliações médicas.
Os pacientes desta categoria, após um período inicial de orientações e de obtenção de conhecimentos sobre os exercícios e o automonitoramento, podem adequar-se a uma RCV domiciliar, na qual a prática de exercício físico é realizada com supervisão indireta, sob a responsabilidade de profissionais do serviço. A avaliação das sessões, com reajustes na prescrição e esclarecimentos de dúvidas, deve ser feita de maneira sistemática, presencial ou virtualmente, conforme o caso.

\subsection{Risco Clínico Baixo}

Assim como os pacientes de risco intermediário, os de baixo risco podem ter sido reclassificados após cumprirem etapas anteriores da RCV, ingressarem diretamente nesta categoria sem participações prévias na RCV, ou serem oriundos de outros programas de exercícios físicos. A duração do treinamento destes pacientes é de longo prazo, visando a manutenção da saúde geral e obtenção dos maiores ganhos possíveis nos componentes da aptidão física, com o objetivo de alcançar ao máximo o potencial de saúde do indivíduo.

Dependendo da disponibilidade e das preferências individuais, os exercícios podem ser realizados sob supervisão presencial ou à distância. Porém, em virtude do menor risco clínico e da menor necessidade de supervisão, os pacientes deste estágio se enquadram perfeitamente em um modelo domiciliar, de modo que a equipe da RCV possa dedicar atenção assistencial presencial principalmente aos pacientes de maior risco clínico.

Os pacientes devem ter reavaliações médicas periódicas, realizadas pelo seu médico assistente e pela equipe da RCV, com TCPE ou TE, cuja periodicidade, a princípio, não deve exceder 12 meses. O objetivo das reavaliações médicas é reajustar a prescrição do treinamento e identificar eventual piora da doença ou sinais de risco para situações instáveis ou eventos cardiovasculares, possibilitando eventuais reajustes do tratamento farmacológico e/ou intervenções cirúrgicas ou percutâneas.

Os pacientes em RCVD devem ser periodicamente avaliados e orientados para a prática dos exercícios, ocasiões em que é recomendável a participação em algumas sessões supervisionadas de exercícios, especialmente para os menos experientes, possibilitando eventuais reajustes na prescrição e esclarecimento de dúvidas. É também recomendável a realização de consultas periódicas com a equipe da RCV, por meio de contatos virtuais e/ou telefônicos, pelo menos uma vez a cada seis meses, para estimular a adesão ao programa de exercícios físicos.

As características clínicas dos pacientes do estágio 4 (presença de todas as características a seguir) são:

- Evento cardiovascular ou intervenções com intervalo superior a 6 meses e estabilidade clínica;

- Pacientes cardiopatas que não apresentam alterações funcionais em esforço físico ou que estas sejam muito discretas quando presentes;

- Os pacientes nessa classificação costumam apresentar as seguintes características:

- Boa capacidade funcional no TE (superior a 7 MET) ou no TCPE (classificação de Weber $\mathrm{A}_{\text {ou }} \mathrm{VO}_{2}$ acima de $85 \%$ do predito para idade e sexo);

- Ausência de sinais e sintomas de isquemia miocárdica ou de outra sintomatologia anormal ao esforço físico. 


\section{Custo-efetividade da}

\section{Reabilitação Cardiovascular}

Segundo a Organização Mundial da Saúde, entre 2000 e 2016 o aumento mundial dos gastos com saúde no mundo foi maior do que o crescimento da economia global, chegando a 7,5 trilhões de dólares em 2016. ${ }^{38} \mathrm{Em}$ relação às DCV, 863 bilhões de dólares foram gastos mundialmente em 2010, estimando-se que em 2030 chegue a 1,04 trilhão de dólares. ${ }^{39}$

No Brasil, onde quase $50 \%$ dos gastos com saúde são financiados pelo governo, ${ }^{40}$ observa-se situação semelhante, pois as DCV constituem o grupo que ocasiona o maior gasto com internações no Sistema Único de Saúde, sendo a principal causa de aposentadorias por invalidez. ${ }^{41-45}$ Em 2015, em relação às DCV, estima-se que o gasto público com internações hospitalares e consultas tenha sido superior a 5 bilhões de reais e o gasto por afastamentos temporários ou permanentes superior a 380 milhões de reais. ${ }^{40}$

Portanto, o impacto econômico provocado pelas DCV, aliado à obrigatoriedade do uso consequente e racional de recursos financeiros, exige a implementação em larga escala de modelos de baixo custo, viabilizando o atendimento de maior número de pacientes. Em coronariopatas estáveis, a RCV é uma estratégia que, em termos de custo-efetividade, supera, com larga margem, procedimentos amplamente utilizados no país, tais como a intervenção coronariana percutânea (ICP). ${ }^{46,47}$ Além disso, sua utilização em maior escala proporcionaria redução nos gastos com saúde, em decorrência da diminuição de novos eventos cardiovasculares, reinternações hospitalares e tratamentos intervencionistas. ${ }^{48,49}$ Assim, sua disseminação deveria ser considerada uma estratégia de saúde pública prioritária.

A determinação da custo-efetividade, que se faz por análise combinada das consequências clínicas (efetividade) e do gasto financeiro do sistema de saúde, é fundamental para avaliar a pertinência da implementação em larga escala de determinado tratamento. ${ }^{50-52}$ De acordo com Georgiou et al., ${ }^{53}$ são consideradas medidas de excelente custo-efetividade as que exigem investimentos inferiores a 20.000 dólares para salvar uma vida por ano (VSA), sendo aceitáveis as que exigem investimentos entre 20.000 e 40.000 dólares e inaceitáveis aquelas que exigem investimentos acima de 40.000 dólares por VSA.

De acordo com os dados disponíveis entre 1985 e 2004, a RCV foi considerada uma intervenção com excelente relação de custo-efetividade, na medida em que a sua adição ao tratamento convencional resultou em um aumento de gastos de 2.193 a 28.193 dólares por VSA. Em 2005, Papadakis et al. ${ }^{23}$ publicaram a primeira revisão sistemática de estudos sobre custo-efetividade da RCV como prevenção secundária em pacientes portadores de DAC e IC. ${ }^{23}$ Em artigo de 2018, ${ }^{54}$ a avaliação de estudos publicados após 2001 mostrou uma relação de custo-efetividade muito semelhante à descrita anteriormente, sendo o aumento dos gastos com a adição da RCV ao tratamento convencional situado entre $2.555 \mathrm{e}$ 23.598 dólares por VSA.

Cabe ainda destacar que, apesar de mais de $75 \%$ das mortes por DCV ocorrerem em países de média e baixa renda per capita, ${ }^{55}$ há uma escassez de dados sobre custo-efetividade da RCV nesses países. ${ }^{56} \mathrm{~A}$ maioria das informações é oriunda de nações de alta renda per capita, como Estados Unidos, Canadá e países europeus, dificultando a extrapolação dos resultados para a realidade brasileira. Entretanto, vale ressaltar que os poucos estudos disponíveis nos países de média e baixa renda mostram a mesma tendência. No Brasil, a incorporação da reabilitação ao tratamento convencional de pacientes com IC resultou em um aumento de gasto de 21.169 dólares por VSA. ${ }^{57}$

No entanto, apesar dos claros benefícios clínicos e econômicos da RCV, o percentual de pacientes elegíveis que efetivamente participam desse tipo de serviço está muito aquém do desejado. Segundo dados internacionais, apenas em torno de $30 \%$ frequentam um programa de RCV e, no Brasil, estima-se que a situação seja ainda pior, estando certamente muito abaixo de $15 \%,{ }^{26,58,59}$ pois na maioria dos estados, inclusive na maior parte das capitais e grandes cidades brasileiras, não existe sequer um único serviço de RCV.

Neste contexto, a utilização de modelos de RCVD tem crescido. Inicialmente, a preocupação quanto à segurança da prática do exercício físico fez com que a RCVD fosse destinada somente a pacientes de baixo risco. No entanto, com a demonstração de que não há inferioridade quanto à segurança e com benefícios clínicos semelhantes em relação à estratégia convencional, ${ }^{60-62}$ além do avanço tecnológico de dispositivos que permitem o monitoramento à distância, tem sido ampliada a utilização deste tipo de serviço para o atendimento de pacientes com perfil de risco mais elevado.

Estudos recentes mostram que a RCVD apresenta efetividade semelhante à tradicional, conforme demonstraram Ades et al., ${ }^{60}$ que compararam os efeitos dos dois modelos em pacientes com DAC de risco leve e moderado em intervenções realizadas por 3 meses, após evento coronariano agudo. Apesar de o grupo de pacientes que atendeu ao programa tradicional ter realizado um volume maior de exercícios físicos, não houve diferença quanto ao ganho em capacidade funcional ou em qualidade de vida entre os dois grupos. Jolly et al. ${ }^{62}$ compararam os desfechos relacionados aos fatores de risco cardiovasculares entre os programas tradicional e domiciliar por um período mais longo, com seguimentos de 6, 12 e 24 meses, e não observaram diferenças nos resultados.

Recentemente, uma revisão sistemática de estudos com pacientes após IAM, CRVM ou IC, realizada por Anderson et al., ${ }^{61}$ também não encontrou diferenças significativas entre as duas propostas em relação aos desfechos morte, eventos cardíacos, capacidade funcional, qualidade de vida e fatores de risco modificáveis, no curto prazo (3 a 12 meses) e no longo prazo (até 24 meses).

Assim, programas de RCVD devem ser considerados como estratégia para facilitar o acesso, a adesão e a consequente disseminação da intervenção. Entretanto, existem apenas poucos estudos demonstrando que a RCVD apresenta um custo semelhante ao dos programas tradicionais, $61,63,64$ havendo uma grande lacuna de pesquisas que possibilitem a comparação das suas propostas em termos de custo-efetividade. ${ }^{65-67}$

Diante dos fatos, é insustentável que países de todos os níveis de renda e, mais preocupantemente os de média e baixa, continuem fornecendo massivamente e sem critérios de indicação mais rigorosos, intervenções terapêuticas de 
alto custo e persistam negligenciando em relação a uma estratégia altamente efetiva, economicamente viável e de grande aplicabilidade como a RCV. Portanto, há necessidade da implementação de políticas de saúde pública, com o objetivo de aumentar a disponibilidade, a participação e a adesão dos pacientes elegíveis aos programas de RCV tradicionais e domiciliares.

Por fim, considerando a relevância da RCV, fundamentada em seu amplo benefício clínico e custo-efetividade, impõe-se a adoção de estratégias que modifiquem a cultura médica e favoreçam a disseminação de programas estruturados. Nesse contexto, torna-se relevante que serviços de referência em cardiologia ofereçam a RCV aos seus pacientes durante a internação e após a alta hospitalar. A disponibilidade de um serviço de RCV deveria inclusive ser considerada como um pré-requisito obrigatório para que uma instituição médica fosse reconhecida ou acreditada como de excelência em cardiologia.

\section{Reabilitação Cardiovascular Domiciliar}

O acesso e a adesão dos pacientes a um programa presencial de RCV apresenta diversas barreiras, ${ }^{24-27,68}$ que, aliadas a um reduzido encaminhamento médico e uma baixa disponibilidade de serviços, conduzem a uma participação efetiva muito reduzida dos pacientes em programas de exercícios físicos supervisionados. Nesse contexto, programas de supervisão indireta, realizados no ambiente domiciliar (RCVD), surgem como alternativa ou complementação aos programas tradicionais e presenciais de RCV. Em virtude da sua maior abrangência, a RCVD pode ser considerada o principal modo de intervenção quando se trata de estratégia de saúde pública, visando à massificação da RCV na população.

Uma revisão sistemática da Cochrane ${ }^{61}$ incluiu 23 estudos com 2.890 pacientes cardiopatas (pós-infarto, pós-revascularização, com angina ou IC) e foram comparados os efeitos das RCV convencional e domiciliar. Não foram encontradas diferenças em mortalidade, capacidade física e qualidade de vida. Portanto, a escolha da participação em programas formais ou domiciliares depende da disponibilidade de serviços e das preferências individuais dos pacientes.

Entende-se como RCVD a prática de exercícios físicos sem supervisão presencial, mas orientada e acompanhada pelos profissionais do serviço de RCV. Por essa razão, também é chamada de reabilitação semi-supervisionada, com supervisão indireta ou à distância. As indicações e os objetivos da RCVD são os mesmos do modelo convencional, exigindo os mesmos cuidados em relação à avaliação pré-participação e à prescrição de exercícios. A maioria das sessões é realizada sob supervisão indireta, mas a participação em algumas sessões presenciais, especialmente no início do programa, é de fundamental importância para consolidar o aprendizado das orientações sobre a prescrição e esclarecer dúvidas. Os exercícios podem ser realizados no próprio domicílio ou em parques, vias públicas, ginásios, academias, entre outros, com automonitoramento pelos pacientes, seguindo as orientações recebidas.

Sendo assim, para se obter uma adequada RCVD como estratégia populacional, primeiramente é necessário ampliar a disponibilidade e capacidade de atendimento de programas presenciais de RCV, a fim de possibilitar avaliação inicial, orientações, prescrição dos exercícios físicos e seguimento das sessões domiciliares, com ajustes periódicos por reavaliações. A estratégia domiciliar deve estar alinhada com a da RCV convencional, pois as duas modalidades são paralelas, com pacientes de diferentes perfis de risco, ou sequenciais, com o mesmo paciente em dois momentos clínicos diferentes.

Portanto, assim como a RCV convencional, a primeira etapa da RCVD é o encaminhamento pelo médico assistente, seguido da avaliação pelo médico da reabilitação e demais profissionais, idealmente com realização do teste de esforço (TCPE ou TE) e/ou outras avaliações de aptidão física. Após a avaliação pré-participação, os pacientes definidos como de alto risco podem ser priorizados para a RCV presencial. Já aqueles de menor risco, capazes de automonitoramento e conforme preferências individuais, podem ser direcionados à RCVD. Após receberem as instruções sobre a prescrição dos exercícios, os pacientes executam as sessões por conta própria, podendo haver documentação dos exercícios em planilhas impressas ou eletrônicas, com utilização de recursos como cardiofrequencímetros, pedômetros ou medidores de velocidade e distância percorrida por GPS. Aplicativos de smartphones podem intermediar a troca de informações entre os pacientes e a equipe assistencial.

Em alguns casos, um programa de RCV combinado, com sessões presenciais e domiciliares, pode ser a opção para pacientes de risco moderado, em aprendizagem sobre o automonitoramento ou com dificuldade de comparecer às sessões presenciais por problemas sociais ou de deslocamento. A proporção dessa combinação pode variar de acordo com as características clínicas do paciente e a estrutura logística do serviço.

Portanto, o foco é tornar os pacientes fisicamente mais ativos, sendo imperativa a redução do sedentarismo e suas nefastas consequências. Para tal, é fundamental a utilização isolada ou combinada dos recursos disponíveis, seja a atividade física informal, a reabilitação domiciliar ou a convencional.

\section{Reabilitação Cardiovascular Integrando o Tratamento Clínico Pleno das Doenças Cardiovasculares}

A RCV deve estar integrada ao tratamento clínico pleno das DCV, que consiste na ação sinérgica das mudanças estruturadas de estilo de vida com o tratamento farmacológico otimizado, com intervenções indicadas quando existe instabilização clínica e/ou refratariedade ao tratamento clínico inicial. Nos pacientes com DAC estável, até mesmo com isquemia moderada ou grave, a adição de tratamentos intervencionistas não têm se mostrado superiores na redução de desfechos maiores (morte cardiovascular, morte por todas as causas, IAM, IC). ${ }^{69,70}$

Para aumentar a eficácia e a segurança da RCV, é importante que o tratamento farmacológico da DCV esteja adequadamente ajustado, visando aumentar a tolerância ao esforço, o que favorece a execução dos exercícios físicos, reduzindo o risco de eventos. ${ }^{3,5,71-73}$ Neste contexto, podem ser necessários ajustes de doses e/ou adição de fármacos previamente ao início do 
programa de exercícios físicos. Por outro lado, após o início da RCV e adequada adesão aos exercícios, alguns pacientes podem requerer retirada ou reduções de doses de fármacos, em virtude da assimilação ao treinamento físico, como, por exemplo, em casos de hipotensão sintomática, bradicardia acentuada e hipoglicemia..$^{74,75}$

\subsection{Recomendações Gerais para Incremento da Atividade Física e Prática de Exercícios Físicos}

Existe associação entre o tempo de sedentarismo, com atividades como assistir à televisão, e maior mortalidade por todas as causas, bem como mortalidade cardiovascular. ${ }^{76}$ Por isso, para a promoção da saúde e prevenção de DCV, as diretrizes médicas têm recomendado, no mínimo, a prática de exercício físico de intensidade moderada por, pelo menos, 150 minutos semanais ou de alta intensidade por 75 minutos semanais (recomendação 1 B). ${ }^{77-83}$ A prática de mais de 300 minutos semanais de exercício de intensidade moderada a alta pode conferir benefício adicional, conforme já foi evidenciado em pacientes com DAC. ${ }^{84}$

De acordo com a avaliação individual, a prescrição dos exercícios físicos pode variar em relação às suas diversas características, como tipo (aeróbico, resistência muscular, flexibilidade), modalidade (caminhada, corrida, bicicleta, dança) e duração (tempo de execução), devendo se considerar a frequência semanal e a intensidade (Tabelas 2 e 3).

Pacientes sedentários devem iniciar os exercícios no limite inferior da prescrição, progredindo gradativamente ao longo das semanas seguintes. A progressão inicial pode ser feita na duração da sessão e, posteriormente, na intensidade dos exercícios. Pacientes já fisicamente ativos podem realizar, desde o início, exercícios em níveis mais intensos, objetivando um mínimo de 75 minutos, divididos em duas ou mais sessões semanais.

Os exercícios de resistência muscular localizada, seja de fortalecimento ou de potência, têm se mostrado bastante benéficos para a saúde geral e para os sistemas cardiovascular e osteomuscular, sendo de fundamental importância nos pacientes com sarcopenia e/ou osteopenia. Devem ser realizados, pelo menos, duas vezes por semana, privilegiando grandes grupos musculares de MMSS, MMII e tronco. Podem ser feitos utilizando o próprio peso corporal do indivíduo ou usando implementos como pesos livres, caneleiras, faixas elásticas, aparelhos de musculação, entre outros recursos. A carga ou peso, para cada exercício ou movimento, deve ser individualmente ajustada, além de se ter a devida atenção à execução dos movimentos para que a técnica e a postura sejam corretas.

Existem diferentes protocolos para exercícios resistidos, com variações no número de exercícios utilizados por sessão, como, por exemplo, de 6 a 15; na quantidade de séries para cada exercício, em geral de 1 a 3 ; e no número de repetições, que pode oscilar entre 6 e 20. A intensidade dos exercícios resistidos pode ser ajustada de acordo com a intensidade relativa da força máxima e pode ser expressa em função da carga máxima possível para realizar uma repetição máxima (Teste de 1 repetição máxima ou 1RM). Carga de intensidade leve seria até 30\% de 1RM; intensidade média, entre 30 e 60 ou $70 \%$ de 1RM; e intensidade alta, acima de 60 ou $70 \%$ de 1RM. Outra possibilidade é a prescrição dos exercícios físicos resistidos de modo subjetivo, pela sensação de esforço (ver Tabela 2).

Um modo prático é o método de repetição variável, que tem como objetivo executar uma faixa de repetições (p. ex., de 10 a 15 repetições). Se o paciente não conseguir realizar corretamente o movimento na repetição mínima prescrita, significa que a carga aplicada está elevada. Por outro lado, se conseguir a repetição máxima prescrita de modo fácil, é porque a carga está leve. Assim, a carga será ajustada para que o treinamento ocorra dentro da faixa de repetições proposta. Esse método pode ser aplicado aos mais variados exercícios localizados e pode ser utilizado na progressão da prescrição, sendo que os limites da repetição podem ser modificados, dependendo dos objetivos almejados (força, hipertrofia ou resistência muscular).

Os exercícios de flexibilidade podem oferecer benefícios osteomioarticulares, na qualidade de vida relacionada à saúde e na prevenção de queda em idosos. Ao contribuírem para uma movimentação articular mais fácil e eficiente,

Tabela 2 - Classificações do exercício físico

\begin{tabular}{|c|c|c|}
\hline Denominação & & Característica \\
\hline \multirow{3}{*}{ Pela via metabólica predominante } & Anaeróbico alático & Grande intensidade e curtíssima duração \\
\hline & Anaeróbico lático & Grande intensidade e curta duração \\
\hline & Aeróbico & Baixa ou média intensidade e longa duração \\
\hline \multirow{2}{*}{ Pelo ritmo } & Fixo, constante ou contínuo & Sem alternância de ritmo ao longo do tempo \\
\hline & Variável, intermitente ou intervalado & Com alternância de ritmo ao longo do tempo \\
\hline \multirow{3}{*}{ Pela intensidade relativa* } & Baixa ou leve & Respiração tranquila, muito pouco ofegante $($ Borg < 4) \\
\hline & Média ou moderada & Respiração acelerada, ofegante, mas controlada. Consegue falar uma frase (Borg 4 a 7) \\
\hline & Alta ou pesada & Respiração muito acelerada, muito ofegante. Fala dificultada (Borg > 7) \\
\hline \multirow{2}{*}{ Pela mecânica muscular } & Estático & Não ocorre movimento, apenas tensão/recrutamento muscular. \\
\hline & Dinâmico & Ocorre movimento com a contração muscular realizada. \\
\hline
\end{tabular}

* Para a classificação, considerou-se a versão da escala de Borg, que varia entre 0 e 10. 


\section{Diretrizes}

Tabela 3 - Métodos de prescrição de intensidade moderada para os exercícios físicos aeróbicos

\begin{tabular}{|c|c|}
\hline Método & Descrição \\
\hline Sensação subjetiva de esforço (Borg) & $\begin{array}{l}\text { Exercícios com a autopercepção de esforço como moderado, médio ou pesado, } \\
\text { situando-se entre } 2 \text { e } 4 \text { na escala de Borg } 0-10 \text { ou } 10 \text { a } 13 \text { na escala 6-20 }\end{array}$ \\
\hline Teste da fala & $\begin{array}{l}\text { Execução dos exercícios em intensidade em que a respiração seja ofegante, porém } \\
\text { controlada, de modo que se consiga completar uma frase sem pausas }\end{array}$ \\
\hline Percentuais da FC pico & $\begin{array}{l}\text { Exercícios na intensidade entre } 70 \text { e } 85 \% \text { da FC pico* } \\
\qquad \text { FC alvo = FC pico x percentual }\end{array}$ \\
\hline FC de reserva (Karvonen) & $\begin{array}{l}\text { Exercícios na intensidade entre } 50 \text { a } 80 \% \text { da FC de reserva (FC pico }-F C \text { repouso })^{*} \\
\qquad F C \text { alvo }=F C \text { repouso }+(F C \text { pico }-F C \text { de repouso }) \times \text { percentual }\end{array}$ \\
\hline Limiares no teste cardiopulmonar & $\begin{array}{l}\text { Execução dos exercícios em intensidade entre os limiares ventilatórios } 1 \text { e } 2 \text { (limiar } \\
\text { anaeróbico e ponto de compensação respiratória) }\end{array}$ \\
\hline
\end{tabular}

FC: frequência cardíaca. * É preferencial a utilização da FC pico obtida em um teste de esforço máximo, visto que existem variações individuais que causam erros na predição da FC por idade, especialmente em pacientes em uso de medicações com efeito cronotrópico negativo.

reduzem a demanda por oxigênio em situações de movimento, favorecendo o desempenho do sistema cardiovascular. Nesses exercícios, procura-se alcançar a amplitude máxima do movimento, chegando até o ponto de leve desconforto, devendo a posição ser mantida estaticamente por 10 a 30 segundos.

Dependendo da faixa etária, das condições clínicas e dos objetivos do programa de exercício para um dado paciente, outros tipos de exercício podem ser incluídos na prescrição, como os de coordenação motora e de equilíbrio. Além disso, devem ser considerados os inúmeros benefícios decorrentes de formas mais lúdicas e socializantes de exercícios, como a dança e outras modalidades. ${ }^{85,86}$

A avaliação da aptidão física aeróbica e não aeróbica possibilita uma prescrição mais individualizada dos exercícios físicos, com o objetivo de se obterem os melhores resultados e, por meio da estratificação de risco e da busca de eventuais anormalidades, minimizar os riscos da prática. De modo geral, a avaliação inicial tem como base a anamnese, o exame físico e o ECG. Avaliações mais detalhadas deverão ser individualizadas, com realização de TCPE ou TE, avaliação antropométrica, de força/potência muscular e de flexibilidade. Na avaliação inicial, pode-se quantificar o déficit funcional frente ao desejável, bem como estabelecer metas a serem alcançadas. É importante enfatizar que os pacientes com baixa aptidão física inicial são os que mais se beneficiam da RCV, após adequada aderência ao programa de exercício supervisionado. ${ }^{87}$ É também possível obter subsídios clínicos e funcionais que possibilitem um adequado aconselhamento da atividade sexual, com base no modelo do KiTOMI, que foi proposto por autores brasileiros em 2016. ${ }^{88}$ Além disso, é fundamental para o paciente a reavaliação, com o intuito de estimular o comprometimento e mensurar a evolução e os benefícios obtidos.

Finalizando, vale ressaltar a fundamental importância do estabelecimento de um sistemático esquema de reavaliações, que, além de estimular o comprometimento dos pacientes, torne possível mensurar a evolução e os benefícios obtidos, produzindo relatórios que estimulem os ajustes do tratamento e que, portanto, devem ser sempre encaminhados aos médicos assistentes, os quais obviamente devem integrar ativamente o tratamento clínico pleno.

\subsection{Hipertensão Arterial Sistêmica}

A hipertensão arterial sistêmica (HAS) permanece como um dos maiores fatores de risco para o desenvolvimento de DAC, IC, DRC e acidente vascular cerebral (AVC) isquêmico ou hemorrágico, representando, social e economicamente, um enorme desafio à saúde pública mundial. ${ }^{89}$ Houve um aumento global do número de hipertensos de 594 milhões em 1975 para 1,13 bilhão em 2015, em grande parte creditado aos países subdesenvolvidos e em desenvolvimento. ${ }^{90}$ Considerando que a maioria dos casos está relacionada ao estilo de vida, com o sedentarismo ocupando lugar de destaque, fica clara a importância dos exercícios físicos ao lado de outras medidas comportamentais, além do uso de medicações, sempre que indicadas. ${ }^{72}$

\subsubsection{Benefícios Terapêuticos dos Exercícios Físicos}

A HAS apresenta fisiopatologia complexa e multifatorial, com modificações estruturais e fisiológicas, em particular, nos sistemas vascular (rarefação capilar, aumento da rigidez arterial e da razão parede/diâmetro das arteríolas), renal (diminuição da filtração glomerular, aumento da renina plasmática e da reabsorção de sódio e água) e neural (aumento da atividade simpática e de quimiorreceptores, diminuição da atividade parassimpática e da sensibilidade barorreflexa). ${ }^{91}$ A prática regular de exercícios físicos exerce efeito terapêutico na reestruturação fisiológica desses sistemas, com redução do estresse oxidativo e da inflamação, correção da disfunção barorreflexa, aumento do tônus vagal, diminuição da atividade simpática, reversão do remodelamento hipertrófico arteriolar em tecidos exercitados e redução da resistência vascular periférica, com consequente diminuição da PA e controle dos níveis pressóricos semelhante, ou mesmo superior, ao proporcionado pela farmacoterapia. ${ }^{92,93}$

No tecido vascular, a HAS caracteriza-se por desorganização das células musculares lisas, aumento dos depósitos de colágeno e diminuição da razão elastina/colágeno, além da formação de fibra elástica anormal e lâmina elástica interna com menor área fenestrada. ${ }^{94}$ Todas essas alterações estruturais da parede do vaso, que ocorrem tanto em território arterial como arteriolar, elevam a rigidez do sistema vascular, com consequente aumento da velocidade da onda 
de pulso do fluxo sanguíneo, da pressão de pulso (diferença entre a PA sistólica [PAS] e a diastólica [PAD]) e da pressão hidrostática no capilar. Soma-se a todo esse desequilíbrio estrutural a disfunção do endotélio, com o aumento de substâncias vasoconstritoras, de mediadores inflamatórios e de agentes oxidantes, em detrimento da produção de agentes vasodilatadores e antioxidantes. ${ }^{95,96}$

O exercício físico, por meio do aumento do estresse tangencial derivado da fricção do fluxo sanguíneo na superfície endotelial da parede do vaso (definido como força de cisalhamento e comumente descrito pelo termo "shear stress"), estimula positivamente o tecido endotelial, com aumento da produção de enzimas antioxidantes e agentes vasodilatadores, além de diminuição da ação dos radicais livres, das citocinas pró-inflamatórias, das moléculas de adesão e dos agentes vasoconstritores, restaurando, assim, o equilíbrio do funcionamento endotelial. ${ }^{97,98}$ Estudos experimentais ${ }^{94}$ em ratos espontaneamente hipertensos demonstram a reorganização de todas as estruturas vasculares da artéria aorta após a implementação de um período de exercício aeróbico. O treinamento aeróbico promove adaptações vasculares nas artérias de condutância (com diminuição da rigidez arterial e melhora da função endotelial), nas arteríolas (pela diminuição da razão parede/luz do vaso) e nos capilares, estimulando a angiogênese. ${ }^{99,100}$

Dessa maneira, a prática de exercícios físicos atua de modo multifatorial na HAS, sendo considerada intervenção-chave para mitigar o ônus da doença e suas comorbidades, ${ }^{101} \mathrm{com}$ efeito anti-hipertensivo semelhante ao das medicações, ${ }^{102}$ embora essa ação possa se superpor às dos fármacos e, eventualmente, exigir ajustes das doses medicamentosas.

Os exercícios físicos aeróbicos são os mais bem estudados e com maiores evidências de benefícios na redução pressórica em hipertensos, algo corroborado na meta-análise de Cornelissen et al., que mostrou redução média da PAS de $8,3 \mathrm{mmHg}$ e da diastólica de $5,2 \mathrm{mmHg}$, decorrente dos exercícios aeróbicos.

Os exercícios de resistência, que também exercem efeito anti-hipertensivo, ${ }^{103}$ agem na preservação ou no aumento de massa muscular, força e potência, fatores que diminuem a intensidade relativa para realização de tarefas do cotidiano, com consequente amortecimento da resposta pressórica, além de possivelmente promoverem uma melhora da sensibilidade barorreflexa. ${ }^{104}$

Além dos exercícios aeróbicos e resistidos dinâmicos, existem alguns estudos sobre exercícios isométricos (resistidos estáticos), que têm demonstrado efeitos expressivos na redução dos níveis tensionais. ${ }^{105-107} \mathrm{Em}$ uma meta-análise, foi demonstrado que o exercício isométrico de handgrip, realizado por 12 minutos, 3 a 5 vezes por semana, reduziu a PA em 5,2/3,9 mmHg. ${ }^{108}$ No entanto, há falta de estudos sobre a segurança e a eficácia dessas modalidades em longo prazo.

\subsubsection{Indicações de Exercícios Físicos na Hipertensão Arterial Sistêmica}

Maiores níveis de atividade física têm sido associados a uma diminuição no risco de desenvolvimento de HAS. Com o advento dos rastreadores eletrônicos de atividade e do monitoramento ambulatorial da $\mathrm{PA}$, tornou-se cada vez mais viável a realização de estudos que correlacionem a atividade física e a PA. ${ }^{109} \mathrm{~A}$ aptidão física, medida objetivamente por meio de testes de esforço graduados, atenua o aumento da pressão com a idade e impede o desenvolvimento de hipertensão. Em uma coorte de homens de 20 a 90 anos de idade, que foram seguidos por 3 a 28 anos, uma maior aptidão física diminuiu a taxa de aumento pressórico ao longo do tempo e atrasou o período até o início da HAS. ${ }^{110}$ Estudos epidemiológicos têm revelado associação inversa entre o nível de atividade física e a aptidão cardiorrespiratória, com a presença de hipertensão arterial. ${ }^{111,112}$

Os grandes ensaios clínicos randomizados e as meta-análises têm confirmado que o exercício físico regular pode reduzir os níveis pressóricos. ${ }^{102,112}$ Além disso, a prática constante de atividades físicas pode ser benéfica tanto na prevenção quanto no tratamento da hipertensão, reduzindo a morbimortalidade cardiovascular. Indivíduos ativos apresentam um risco até 30\% menor de desenvolver hipertensão que os sedentários ${ }^{111}$ e o aumento da atividade física diária reduz a pressão aterial de maneira significativa. ${ }^{113}$

A inatividade física tem sido um dos maiores problemas de saúde pública do mundo moderno, ${ }^{114}$ por ser o mais prevalente dos fatores de risco cardiovasculares e um dos principais fatores contribuintes para mortalidade no mundo. ${ }^{115}$ A sobrevida é menor em pessoas que passam a maior parte do tempo sentadas do que naquelas que passam pouco tempo desse modo. ${ }^{116}$ Há relação direta entre o período sentado ou o tempo de televisão com níveis elevados de PA, morbidade e mortalidade cardiovascular. ${ }^{117}$ Por esta razão, para a redução do tempo sentado, recomenda-se levantar-se por, pelo menos, 5 minutos a cada 30 minutos sentado, como medida válida de prevenção. A prática de exercícios físicos está indicada para todos os pacientes com HAS (Tabela 4). ${ }^{72,73,118}$

Além dos exercícios, o tratamento da hipertensão requer outras modificações do estilo de vida, como alimentação correta, controle do peso e remoção de fatores de risco como o tabagismo e o excesso de consumo alcoólico.

Além do efeito direto dos exercícios na HAS, outro componente importante da RCV se relaciona ao manejo da terapia farmacológica, a qual pode ser otimizada no ambiente da reabilitação, por meio de educação sobre a doença, aconselhamento quanto à necessidade de tratamento e informações sobre os efeitos colaterais e importância da adesão. ${ }^{119}$

\subsubsection{Avaliação Pré-participação}

Obviamente, cabe ao médico assistente estabelecer o diagnóstico da HAS, pesquisar outros fatores de risco cardiovasculares e rastrear lesões em órgãos-alvo e outras doenças associadas, de modo a definir a estratégia terapêutica, que pode ser farmacológica e/ou composta de uma ou mais modificações comportamentais. ${ }^{72}$

$\mathrm{Na}$ avaliação para a prescrição de exercícios físicos é relevante a realização de um TCPE ou TE, especialmente se houver suspeita de cardiopatia, lesões em órgão-alvo ou presença de três ou mais fatores de risco. ${ }^{72}$ Quando o TCPE ou TE for utilizado para prescrição de exercícios físicos, o ideal 
Tabela 4 - Indicação de exercícios físicos na hipertensão arterial sistêmica

\begin{tabular}{lcc}
\hline Indicação & Recomendação & Nível de evidência \\
\hline Exercícios físicos aeróbicos na prevenção do desenvolvimento de HAS ${ }^{110-112}$ & I & A \\
Exercícios físicos aeróbicos no tratamento da HAS & I,102,103,112 & A \\
Exercícios físicos de resistência muscular dinâmicos no tratamento da HAS & B & Ila \\
Exercícios físicos isométricos no tratamento da HAS ${ }^{105-108}$ & B \\
\hline
\end{tabular}

HAS: hipertensão arterial sistêmica.

é que seja executado na vigência das medicações habituais, principalmente das que inibam a resposta cronotrópica, a fim de mimetizar a condição que estará presente durante as sessões de treinamento físico, possibilitando a utilização da FC pico do TE ou os limiares ventilatórios do TCPE para a determinação da zona-alvo de treinamento com base na FC.

\subsubsection{Particularidades na Prescrição e no Acompanhamento dos Exercícios Físicos}

A recomendação de exercício para pacientes hipertensos, de maneira semelhante ao proposto para a população em geral, é de, pelo menos, 150 minutos por semana (5 sessões de 30 minutos) de atividade aeróbia de moderada a alta intensidade, sendo aconselhável associar duas a três sessões de exercícios resistidos por semana. Na ausência de contraindicações, pode ocorrer aumento gradativo, visando a meta de $300 \mathrm{~min} / \mathrm{semana}$ de exercícios aeróbios de intensidade moderada ou $150 \mathrm{~min} / \mathrm{semana}$ de exercícios aeróbios de alta intensidade, para obtenção de maiores benefícios.

Durante o treinamento, é importante que a PA seja avaliada em repouso e em esforço. Para pacientes com valores em repouso superiores a 160/100 mmHg ou com lesão de órgãos-alvo (hipertrofia ventricular esquerda, retinopatia, nefropatia e outras), é recomendado o ajuste dos fármacos anti-hipertensivos para melhor controle pressórico antes de iniciar ou retornar às sessões de exercício, ${ }^{37}$ ou a redução da intensidade de treinamento até a obtenção de melhor controle pressórico. Em programas de RCV supervisionados, flexibilizações dessas recomendações podem ser realizadas individualmente, de acordo com a avaliação do médico da reabilitação e as respostas observadas no teste de esforço e nas sessões de exercícios. Durante o exercício, é recomendado que a PA se mantenha inferior a 220/105 mmHg. Se estiver superior a esse nível, deve-se considerar a interrupção da sessão ou a redução da intensidade de cargas, considerando o ajuste das medicações. ${ }^{37}$

Após a sessão de exercício, a PA deve ser verificada e é comum a identificação de valor inferior ao observado antes do início das atividades. Em hipertensos, o efeito anti-hipertensivo agudo de uma sessão tende a ser maior com níveis mais intensos de exercícios aeróbios. ${ }^{120}$ Esse efeito agudo do treinamento físico pode causar hipotensão sintomática após o término, que geralmente melhora com repouso e hidratação. Pacientes em uso de alfabloqueadores, betabloqueadores, bloqueadores de canais de cálcio e vasodilatadores podem ter maior risco de hipotensão pós-exercício, necessitando de atenção especial no desaquecimento. A recorrência dessa situação, que costuma decorrer do resultado da assimilação do treinamento que se soma aos efeitos anti-hipertensivos dos fármacos, exige considerar a necessidade de ajustes das doses ou mesmo suspensão de medicamentos.

Há poucos dados quanto ao efeito do exercício em pacientes com hipertensão resistente, que se caracteriza pela PA acima da meta apesar do uso de três ou mais medicações anti-hipertensivas. Em relação a esses pacientes, que requerem maior monitoramento, um ensaio clínico randomizado unicêntrico mostrou que exercício em água aquecida (30 a $\left.32^{\circ} \mathrm{C}\right)$ resultou em pronunciada redução da $\mathrm{PA}(36 / 12 \mathrm{mmHg})$ após 3 meses. ${ }^{121}$ Embora tais efeitos precisem ser reproduzidos em mais estudos, exercício em água aquecida parece ser apropriado para pacientes com hipertensão arterial resistente.

\subsection{Coronariopatia Estável após Evento Agudo ou Revascularizações}

As DCV, lideradas pela DAC, são responsáveis pela maior parte das mortes da população adulta. ${ }^{122-124}$ Os mecanismos subjacentes da DAC estável incluem obstrução aterosclerótica dos vasos epicárdicos, doença microvascular e espasmo coronário, isolados ou em associação. ${ }^{5}$ Clinicamente a manifestação mais comum da DAC estável é a angina do peito, que se caracteriza por episódios reversíveis de dor torácica por isquemia miocárdica, decorrentes do desequilíbrio entre oferta e consumo de oxigênio pelo miocárdio, em geral desencadeados pelo esforço físico ou estresse emocional, que cessam com o repouso ou uso de nitrato de ação rápida. ${ }^{5}$

A DAC estável tem bom prognóstico, com mortalidade anual estimada em 1,5\% e incidência de infarto não fatal de $1,4 \%,{ }^{125}$ sendo fundamental o tratamento clínico pleno, com otimização do tratamento farmacológico e prática de exercícios físicos regulares, além de outras modificações comportamentais relacionadas a tabagismo, dieta e composição corporal. Revascularizações eletivas também podem ser indicadas nos pacientes com DAC estável, a depender da sintomatologia e do risco cardiovascular. ${ }^{5}$ Porém, vale ressaltar que, quando o quadro é estável, mesmo nos pacientes com angina, o tratamento exclusivamente clínico não tem se mostrado inferior ao tratamento com adição de abordagem intervencionista. ${ }^{70,126,127}$ A ocorrência de eventos agudos de instabilização da doença, com quadros de IAM ou angina instável, está relacionada com elevado aumento do risco cardiovascular, frequentemente exigindo ajustes da terapia farmacológica e revascularização cirúrgica ou percutânea de urgência. ${ }^{128-131}$ 


\subsubsection{Benefícios Terapêuticos dos Exercícios Físicos}

Estão cientificamente demonstrados os efeitos benéficos do exercício físico regular realizado em curto e longo prazos nos portadores de DAC estável. Em um período inicial de reabilitação cardiovascular, de 8 a 12 semanas, destacam-se o aumento do limiar isquêmico, ${ }^{132-136}$ a melhora da capacidade funcional cardiorrespiratória ${ }^{132,134,136}$ e a melhora perfusional cintilográfica. ${ }^{137-140}$ Os benefícios adquiridos persistem com a manutenção da prática regular de exercícios físicos, ${ }_{103,141-144}$ que contribui para a melhora da qualidade de vida $^{1,146}$ e redução das taxas de mortalidade cardiovascular e hospitalização. ${ }^{1,144,146-148}$

Em pacientes com DAC estável, diferentes mecanismos explicam o aumento do limiar isquêmico, permitindo gradativamente cargas superiores de atividade física. A redução do duplo produto para cargas submáximas de trabalho está associada, dentre outros mecanismos, à melhora da modulação autonômica cardíaca. ${ }^{144}$ Destaca-se ainda um aumento da perfusão miocárdica decorrente da melhora da resposta vasodilatadora dependente do endotélio ${ }^{149-151}$ e do aumento do recrutamento de vasos colaterais durante o exercício, ${ }^{134,144,152}$ algo que reflete na atenuação da depressão do segmento ST durante o exercício. ${ }^{35,132,137}$ Ressalta-se, ainda, que o treinamento físico associado à dieta pobre em gorduras pode influenciar na progressão da placa aterosclerótica. ${ }^{152,153}$

A RCV é uma terapia adjuvante eficaz no tratamento de pacientes após evento coronariano agudo, CRVM e ICP. Revisão sistemática e meta-análise ${ }^{1}$ de 63 estudos envolvendo 14.486 pacientes com idade entre 47 e 71 anos revelaram que a RCV reduziu a mortalidade cardiovascular em $26 \%$ e a hospitalização global em 18\%, com melhora adicional na qualidade de vida nessa população, devendo ser encorajada sempre que possível.

A melhora da capacidade cardiorrespiratória é um dos fatores responsáveis pelos achados na redução da mortalidade total. Em coorte realizada com 5.641 pacientes participantes de RCV no Canadá, verificou-se que cada 1 MET de aumento na capacidade cardiorrespiratória durante a RCV reduziu a mortalidade total em 25\%. ${ }^{154}$ Outros estudos similares reportaram redução da mortalidade cardíaca ou total entre 8 e 34\% para cada MET de melhora na capacidade cardiorrespiratória. ${ }^{155,156}$

Além disso, a RCV oferece efeito adicional na redução de eventos cardiovasculares após ICP, conforme evidenciado pelo estudo ETICA (Exercise Training Intervention After
Coronary Angioplasty), em que houve aumento de $26 \%$ no $\mathrm{VO}_{2}$ pico, melhora de $27 \%$ na qualidade de vida e redução de $20 \%$ nos eventos cardíacos, incluindo diminuição de IAM e menor número de hospitalizações em pacientes que realizaram RCV após angioplastia, quando comparados aos que permaneceram sedentários. ${ }^{157}$

\subsubsection{Quando Indicar Reabilitação}

A RCV está indicada em todos os casos de DAC (Tabela 5), sendo considerada útil e efetiva, tanto quando é centrada somente no exercício físico como quando é acompanhada de conteúdo educacional, manejo de fatores de risco e aconselhamento psicológico. ${ }^{146}$

Apesar de tratamentos intervencionistas cada vez mais precoces e diminuição no tempo de permanência hospitalar após síndrome coronariana aguda, não é incomum o paciente iniciar a reabilitação apenas após seu retorno ambulatorial com médico assistente, o que pode significar 15 dias ou mais após o evento. O início precoce é possível e pode interferir direta e positivamente na aderência e nos benefícios clínicos alcançados após o evento agudo.

Uma das maiores preocupações do treinamento físico precoce refere-se ao seu efeito no processo de remodelamento ventricular. Enquanto alguns autores reportam efeitos negativos, ${ }^{163}$ outros relatam efeitos positivos ${ }^{158,164}$ ou mesmo neutros ${ }^{139}$ sobre esse processo. Uma revisão sistemática e meta-análise ${ }^{159}$ realizada para responder a essa questão identificou que as mudanças observadas na função e no diâmetro ventriculares, bem como a capacidade funcional, foram diretamente relacionadas ao tempo de início do treinamento. As maiores mudanças no remodelamento ventricular e na capacidade funcional foram obtidas quando os programas eram iniciados na fase aguda após o evento (após 6 horas a 7 dias), com diminuição desses efeitos entre 7 e 28 dias e superior a 29 dias, quando progressivamente se perdia o efeito positivo sobre o remodelamento ventricular. É importante ressaltar que não houve diferença em relação a eventos entre as fases de início do treinamento e que a amostra estudada foi prioritariamente de homens jovens, o que reforça a necessidade de mais estudos, principalmente em outras populações, como a de idosos e mulheres. Para cada 1 semana de atraso no início dos exercícios após o infarto, poderá ser necessário 1 mês adicional de treinamento para obtenção de benefícios similares no volume sistólico final e na fração de ejeção do ventrículo esquerdo (FEVE). ${ }^{160}$

Tabela 5 - Indicação de reabilitação cardiovascular na doença arterial coronariana

\begin{tabular}{|c|c|c|}
\hline Indicação & Recomendação & Nível de evidência \\
\hline RCV para redução da isquemia miocárdica ${ }^{132-140,158}$ & 1 & A \\
\hline RCV para aumento da capacidade física ${ }^{132,134,140}$ & I & $A$ \\
\hline RCV para redução de mortalidade $1,154,155$ & I & A \\
\hline RCV após evento coronariano ou revascularização 140,157 & I & A \\
\hline RCV precoce (uma semana após evento agudo) ${ }^{159,160}$ & Ila & A \\
\hline RCV em pacientes com angina refratária ${ }^{161,162}$ & $\mathrm{Ilb}$ & C \\
\hline
\end{tabular}

RVC: reabilitação cardiovascular. 
Embora referendada amplamente pela literatura médica por seus efeitos benéficos e custo-efetividade, somente uma minoria dos pacientes elegíveis participa de programas de RCV, algo explicável por múltiplas barreiras, como inexistência de programas, dificuldade de acesso aos serviços, reduzido número de encaminhamentos, mobilidade urbana de má qualidade, entre outros, afetando principalmente mulheres, idosos e minorias étnicas. ${ }^{165-168}$ Sendo assim, mudanças políticas, sociais, estruturais e na cultura médica são necessárias para modificar esse cenário.

\subsubsection{Avaliação Pré-participação e Prescrição de Exercícios}

Tanto nos pacientes com DAC estável como naqueles após evento coronário e/ou revascularizações, é fundamental a estratificação de risco para a RCV, por meio de avaliação clínica focada no conhecimento detalhado da DCV e nos tratamentos realizados, sejam medicamentosos ou intervencionistas. Questões relacionadas com existência de sintomas, função ventricular, capacidade funcional, presença de arritmias e possibilidade de isquemia residual auxiliam na estratificação e devem fazer parte da avaliação inicial. O ideal é que essa avaliação médica seja realizada por profissional integrado à equipe da RCV (médico da reabilitação).

$\mathrm{O}$ perfil de um paciente encaminhado à RCV pode ser bastante variado, desde o que é submetido a tratamento de maneira eletiva até aquele com síndrome coronariana aguda complicada e internação prolongada. Uma avaliação mais ampla, incluindo questões nutricionais, psicológicas e osteomusculares, deve fazer parte da anamnese, pois esses fatores podem impactar diretamente no processo da RCV. Sempre devem ser realizadas cuidadosas avaliações, seja do local de punção arterial, principalmente no acesso femoral, nos pacientes submetidos à ICP, assim como das feridas cirúrgicas, em especial quanto à estabilidade esternal e eventuais infecções, nos pacientes submetidos à CRVM. A presença de situação que implique necessidade de cuidados especiais exige as pertinentes orientações à equipe responsável pelo treinamento físico dos pacientes.

A avaliação pré-participação para a RCV, por meio de provas funcionais, objetiva o melhor conhecimento da capacidade funcional, a avaliação de isquemia residual e a pesquisa de arritmias induzidas pelo esforço. A identificação de isquemia miocárdica ao esforço é realizada por meio da ocorrência de sintomas como angina de peito e/ou por alterações eletrocardiográficas. O limiar isquêmico identificado no TE pelo início dessas alterações clínicas e/ou eletrocardiográficas, pode eventualmente ser caracterizado segundo a carga de trabalho e FC, a partir dos quais a isquemia se manifesta, algo que poderia ser utilizado na prescrição de exercício.

O TE, para fins de prescrição, deverá será realizado sob o uso das medicações habituais, principalmente as que causam interferência na FC, para que haja reprodução na avaliação da condição que estará presente durante as sessões de treinamento. Por exemplo, em situações de pacientes que alteram a dose de betabloqueador durante a reabilitação, o ideal seria realizar um novo teste para ajuste da prescrição. Em caso de impossibilidade dessa conduta, o uso da percepção subjetiva de esforço poderá auxiliar na prescrição até a realização de novo exame.
Em alguns casos, os pacientes ingressantes na RCV podem estar com alguma limitação clínica para realização de um teste funcional máximo. Nestes, pode-se realizar um teste inicial submáximo para guiar a prescrição, com posterior teste máximo após a melhora clínica e/ou otimização do tratamento farmacológico. Considerando a possibilidade de grandes erros, devido à intensa variação individual da resposta cronotrópica, não devem ser usadas fórmulas que consideram a idade para definição da FC pico, sendo este erro ainda maior nos pacientes em uso de betabloqueadores.

Quando a reabilitação for iniciada sem a execução de um teste funcional, a prescrição poderá basear-se na escala de percepção subjetiva de esforço (escala BORG entre 11-15, na escala de 6-20) e com limitação da FC de treinamento de modo arbitrário, ou seja, a utilização da FC de repouso +20 bpm para pacientes que tiveram síndrome coronariana aguda, ou FC de repouso + 30 bpm para aqueles após cirurgia ou tratamento intervencionista eletivo. ${ }^{131} \mathrm{~A}$ intensidade também pode ser determinada pela ventilação pulmonar, sendo a atividade considerada de moderada intensidade quando o indivíduo permanece apenas discretamente ofegante, conseguindo falar frases completas sem interrupções (ver Tabela 3).

Quando o TE for realizado, a intensidade dos exercícios prescritos poderá situar-se entre 40 e $80 \%$ da FC de reserva [método de Karvonen: (FC pico - FC de repouso) x percentual de intensidade + FC de repouso]. Nesses casos, habitualmente se inicia com a FC no limite inferior da prescrição, sendo realizadas progressões, conforme a evolução clínica e melhora da capacidade funcional. A maioria dos pacientes terá intensidade prescrita entre 50 e $70 \%$ da FC de reserva. Os mais limitados ou com disfunção ventricular importante poderão trabalhar em intensidades menores, entre 40 e $60 \%$, e aqueles previamente ativos e com melhor capacidade funcional, entre 50 e $80 \%$. Os percentuais da FC pico também podem ser utilizados, sendo que intensidades moderadas correspondem de 70 a $85 \%$ da FC pico (ver Tabela 3).

O TCPE, por meio da análise da resposta do pulso de oxigênio, contribui para o aumento da sensibilidade e especificidade para o diagnóstico da isquemia miocárdica. ${ }^{169}$ Na presença de platô precoce do pulso de oxigênio ou, principalmente, queda dessa variável durante o esforço, a prescrição da intensidade do exercício pode ser limitada às cargas abaixo dessa ocorrência. Desse modo, o TCPE é considerado o padrão-ouro na avaliação para a prescrição dos exercícios e deve ser utilizado sempre que estiver disponível. ${ }^{169-171}$ Nesses casos, a recomendação de intensidades moderadas poderá ser realizada entre os limiares ventilatórios (limiar anaeróbico e ponto de compensação respiratória), com evolução da intensidade de maneira progressiva.

Em relação ao volume dos exercícios, recomenda-se, no mínimo, 150 minutos por semana, que poderá ser distribuído em 3 a 5 sessões. De acordo com a tolerância, adaptações ao treinamento e preferências individuais, além das considerações sobre o quadro clínico, este volume poderá aumentar para 300 minutos ou mais por semana.

Em relação ao treinamento resistido, o método considerado padrão-ouro para a prescrição da intensidade seria o teste de uma repetição máxima. Entretanto, na prática, muitos 
programas de reabilitação não o utilizam pela limitação de tempo para aplicá-lo, ou mesmo por razões clínicas, como em pacientes submetidos a CRVM, que podem ter limitações não apenas pela esternotomia, mas também por lesões da safenectomia. Nesses casos, a percepção subjetiva de esforço é um método prático e útil.

Em pacientes com esternotomia, trabalhos com MMSS devem ter cargas restritas durante 5 a 8 semanas e limitadas a baixas intensidades. Exercícios com amplitude de movimentos com os braços poderão ser permitidos após essa fase, se não existir instabilidade de esterno, embora novos estudos estejam avaliando a segurança de prescrição mais precoce do exercício após a CRVM. ${ }^{172,173}$

Os pacientes devem sempre ser orientados quanto à maneira correta de execução do movimento e à respiração, evitando a manobra de Valsalva. O intervalo entre as séries dos exercícios resistidos pode ser entre 45 segundos e 1 minuto, a depender das cargas aplicadas e da tolerância do paciente.

\subsubsection{Particularidades na Prescrição e Acompanhamento dos Exercícios Físicos}

\subsubsection{Angina Refratária}

Pacientes com angina refratária são caracterizados por angina limitante com evolução superior a 3 meses, em tratamento clínico otimizado, com documentação de isquemia miocárdica e não considerados elegíveis para intervenção coronariana percutânea e/ou cirúrgica. ${ }^{174,175}$ Tais pacientes geralmente não são referenciados aos programas de RCV, devido ao temor de eventos adversos durante o treinamento físico, embora a reabilitação já tenha sido considerada como uma possibilidade terapêutica exequível e segura para esses pacientes. ${ }^{175}$

O objetivo das intervenções terapêuticas nesse cenário contribui para a melhora da qualidade de vida, facilitando a realização de atividades da vida diária. ${ }^{176-178}$ Há um único estudo controlado envolvendo RCV em pacientes com angina refratária. Ele avaliou 42 indivíduos, randomizados para o programa de exercícios de RCV ou manutenção do tratamento clínico habitual, durante 8 semanas. Os pacientes do grupo de exercício receberam a prescrição de FC de treino entre 60 e 75\% da FC de reserva (para aqueles com função ventricular preservada) e entre 40 e $60 \%$ da FC de reserva quando a FEVE era inferior a $40 \%$. Os pacientes do grupo de reabilitação aumentaram em 50 m a distância total no teste de caminhada (avaliado pelo Shuttle Walk test), sem mudança na intensidade ou frequência da angina e sem eventos adversos em ambos os grupos. ${ }^{161}$

Um estudo brasileiro randomizado ainda em andamento ${ }^{162}$ está avaliando a segurança e eficácia de um programa de exercícios realizado durante um período de 12 semanas, supervisionado em ambiente hospitalar e com monitoramento eletrocardiográfico contínuo. A prescrição está sendo individualizada e pautada nos parâmetros do TCPE e no limiar de isquemia e/ou angina. Até o momento, 42 pacientes foram incluídos, e não houve documentação de eventos cardiovasculares e hospitalizações relacionadas aos exercícios. A troponina T ultrassensível, preditor conhecido de pior prognóstico, ${ }^{179}$ não apresentou oscilação no seu nível sérico em 32 pacientes submetidos a uma sessão aguda de exercício aeróbico (no limiar de isquemia) de 40 min de duração, no momento da inclusão no estudo (dados não publicados).

Nos pacientes com angina refratária e baixo limiar isquêmico, a utilização de nitratos de ação rápida antes do início da sessão de treinamento físico pode contribuir para um treino mais duradouro e até maiores intensidades de exercícios. ${ }^{180}$

\subsubsection{Treinamento com Indução de Isquemia Miocárdica}

Tradicionalmente, existe a recomendação de que os exercícios físicos nos pacientes com DAC sejam realizados abaixo do limiar isquêmico clínico e eletrocardiográfico. Porém, isso pode ser difícil de controlar. Estudos prévios já demonstraram que os exercícios físicos, prescritos conforme recomendações da literatura, podem desencadear defeitos de perfusão cintilográficos, que não são evidenciados por meio de anormalidades no ECG e angina, ${ }^{181,182}$ pois as alterações contráteis e os defeitos perfusionais precedem as alterações clínicas e eletrocardiográficas isquêmicas. ${ }^{183,184}$

O significado funcional da indução de isquemia cintilográfica ainda é incerto, mas estudos com realização de treinamentos acima do limiar isquêmico já foram realizados. Em um estudo com realização de uma única sessão de treinamento com duração de 20 min acima do limiar isquêmico, não foram identificados indícios de dano miocárdico agudo. ${ }^{185}$ Outros autores demonstraram em pequena série de pacientes que, após seis semanas de treinamento em pacientes com DAC, estímulos isquêmicos repetitivos também não resultaram em danos, disfunções miocárdicas e arritmias significativas. ${ }^{186,187}$

Portanto, existem evidências que sugerem a possibilidade da aplicação de treinos intervalados em pacientes com DAC estável, modalidade que tem se revelado segura e efetiva em melhorar o condicionamento físico, a função endotelial e a função ventricular esquerda, acima dos resultados obtidos no treinamento moderado contínuo. ${ }^{187,188}$ Adicionalmente, cabe enfatizar as evidências da superioridade da combinação de treinos aeróbicos e resistidos em relação a treinos aeróbicos isolados nos pacientes com DAC. ${ }^{189}$

\subsubsection{Ajustes de Fármacos Diante da Assimilação do Treinamento Físico}

Os pacientes portadores de DAC estável geralmente utilizam medicamentos para alívio da sintomatologia, redução de isquemia, melhora da função endotelial, estabilização da placa aterosclerótica, controle dos fatores de risco e adequação do padrão hemodinâmico. Por exemplo, níveis elevados de PAS e/ou FC (aumento do duplo produto), aumentando o consumo de oxigênio miocárdico, obviamente contribuem para piorar a tolerância ao esforço e situação clínica.

Nos programas de RCV, particular atenção deve ser dada à melhora do limiar anginoso antes do início do treinamento, já que possibilita maior tolerância à progressão da intensidade de exercícios e, com isso, a obtenção dos efeitos benéficos almejados. Sendo assim, a otimização do tratamento farmacológico é fundamental para uma RCV segura e eficaz. 
O paciente submetido à RCV pode apresentar uma série de adaptações fisiológicas relacionadas ao exercício, como, por exemplo, modulação favorável do sistema nervoso autônomo (maior tônus vagal), com maior variabilidade de $\mathrm{FC}$, redução da $\mathrm{FC}$ basal, redução do duplo produto de repouso e melhora da função endotelial, ${ }^{190}$ o que pode significar menor necessidade de fármacos usados no tratamento das DCV, sendo papel do médico de reabilitação discutir com o médico assistente sobre a eventual necessidade de ajustes farmacológicos.

\subsection{Insuficiência Cardíaca}

A IC crônica é uma síndrome complexa que compromete múltiplos sistemas, ocasionando como principais sintomas a dispneia e intolerância progressiva ao esforço físico. Apesar dos recentes avanços na terapêutica farmacológica, com redução da elevada morbimortalidade, os sintomas tendem a persistir, comprometendo a qualidade de vida dos pacientes. Existem evidências consistentes de que a redução do nível de atividade física na IC desencadeia um círculo vicioso, que contribui para aumentar os sintomas e a intolerância ao exercício, secundários à redução da capacidade funcional, produzindo efeitos psicológicos negativos, ${ }^{191}$ deterioração da vasorreatividade periférica com disfunção endotelial ${ }^{192} \mathrm{e}$ inflamação crônica. ${ }^{193}$ Nesse contexto, o exercício físico se estabeleceu como estratégia terapêutica segura, que atenua os efeitos do descondicionamento físico progressivo decorrente da evolução natural da doença. ${ }^{194}$

Estudos randomizados pequenos, revisões sistemáticas e meta-análises têm consistentemente demonstrado que o treinamento físico regular é seguro, aumenta a tolerância aos exercícios, melhora a qualidade de vida e reduz hospitalizações por IC. ${ }^{195-197}$ No entanto, um único e grande estudo randomizado multicêntrico, o HF-ACTION, ${ }^{198}$ revelou apenas uma modesta, mas não significativa, redução nos desfechos primários de morte e hospitalizações por todas as causas, embora tenha demonstrado benefícios importantes na qualidade de vida e redução da taxa de hospitalizações por IC. Como crítica à pesquisa, há que se considerar que a baixa adesão aos exercícios provavelmente prejudicou a eficácia da intervenção, hipótese que foi confirmada posteriormente em outro estudo, que demonstrou ser a adesão aos exercícios fator determinante para a obtenção de benefícios a médio prazo. ${ }^{199}$
Em uma revisão sistemática ${ }^{2}$ sobre treinamento físico em pacientes com IC, que analisou 33 estudos randomizados com inclusão de 4.740 pacientes com predomínio FEVE reduzida, houve tendência à redução da mortalidade total com os exercícios físicos após um ano de seguimento. Comparado ao controle, o grupo de treinamento físico teve menor taxa de hospitalização por IC e melhora da qualidade de vida. Quanto aos benefícios nas mulheres com IC, os estudos disponíveis sugerem que são positivos e equivalentes aos observados nos homens. ${ }^{200}$

Para pacientes com sintomas avançados (classe IV da NYHA - New York Heart Association), ainda não há dados suficientes para indicar programas de exercício, pois apenas um estudo randomizado brasileiro testou um programa de exercícios diários em cicloergômetro com ventilação não invasiva. Foram avaliados pacientes internados com IC descompensada, sendo observados benefícios funcionais e redução do tempo de internação. ${ }^{201}$ Portanto, para um grau de recomendação mais forte, há necessidade de mais estudos que confirmem os resultados iniciais.

Na IC com FEVE preservada há evidências recentes provenientes de estudos randomizados pequenos e revisão sistemática que mostraram benefícios no $\mathrm{VO}_{2}$ pico medido pelo TCPE, ${ }^{202,203}$ na qualidade de vida ${ }^{203,204}$ e na função diastólica avaliada pelo ecocardiograma. ${ }^{205,206}$

Diante dessas evidências, a RCV com exercícios é recomendada na IC (Tabela 6), quer a FEVE esteja preservada ou reduzida. Assim, políticas públicas devem ser adotadas para que maior número de pacientes elegíveis se beneficie do tratamento em programas estruturados de RCV. ${ }^{207}$

Os exercícios físicos, apenas não devem ser prescritos para pacientes com IC clinicamente instáveis, com quadro de miocardite aguda ou na ocorrência de processos infecciosos agudos sistêmicos (Classe IIIC).

\subsubsection{Prescrição dos Exercícios Físicos e Avaliação Pré-participação}

Internacionalmente, os programas de RCV são implementados com vários formatos, utilizando-se modalidades isoladas ou associadas. Os exercícios aplicados podem ser aeróbicos (moderada e/ou alta intensidade), de resistência muscular localizada e treinamento de musculatura respiratória (Figura 2).

Tabela 6 - Indicação de reabilitação cardiovascular na insuficiência cardíaca

\begin{tabular}{lcc}
\hline Indicação & Recomendação & Nível de evidência \\
\hline $\begin{array}{l}\text { Exercícios aeróbicos regulares em pacientes com IC para aumentar a } \\
\text { capacidade funcional, reduzir sintomas e melhorar qualidade de vida } 2,195-199,205\end{array}$ & I & A \\
$\begin{array}{l}\text { Exercícios aeróbicos regulares em pacientes com FEVE reduzida para diminuir } \\
\text { hospitalizações por IC }\end{array}$ & A 198 \\
$\begin{array}{l}\text { Exercícios aeróbicos em pacientes com FEVE preservada para aumentar } \\
\text { capacidade funcional e melhorar a função diastólica }{ }^{203,205,206}\end{array}$ & Ila \\
$\begin{array}{l}\text { Exercícios aeróbicos de baixa intensidade na fase hospitalar da IC com } \\
\text { ventilação não invasiva }{ }^{201}\end{array}$ & Ilb \\
\hline
\end{tabular}

IC: insuficiência cardiaca; FEVE: fração de ejeção do ventrículo esquerdo. 


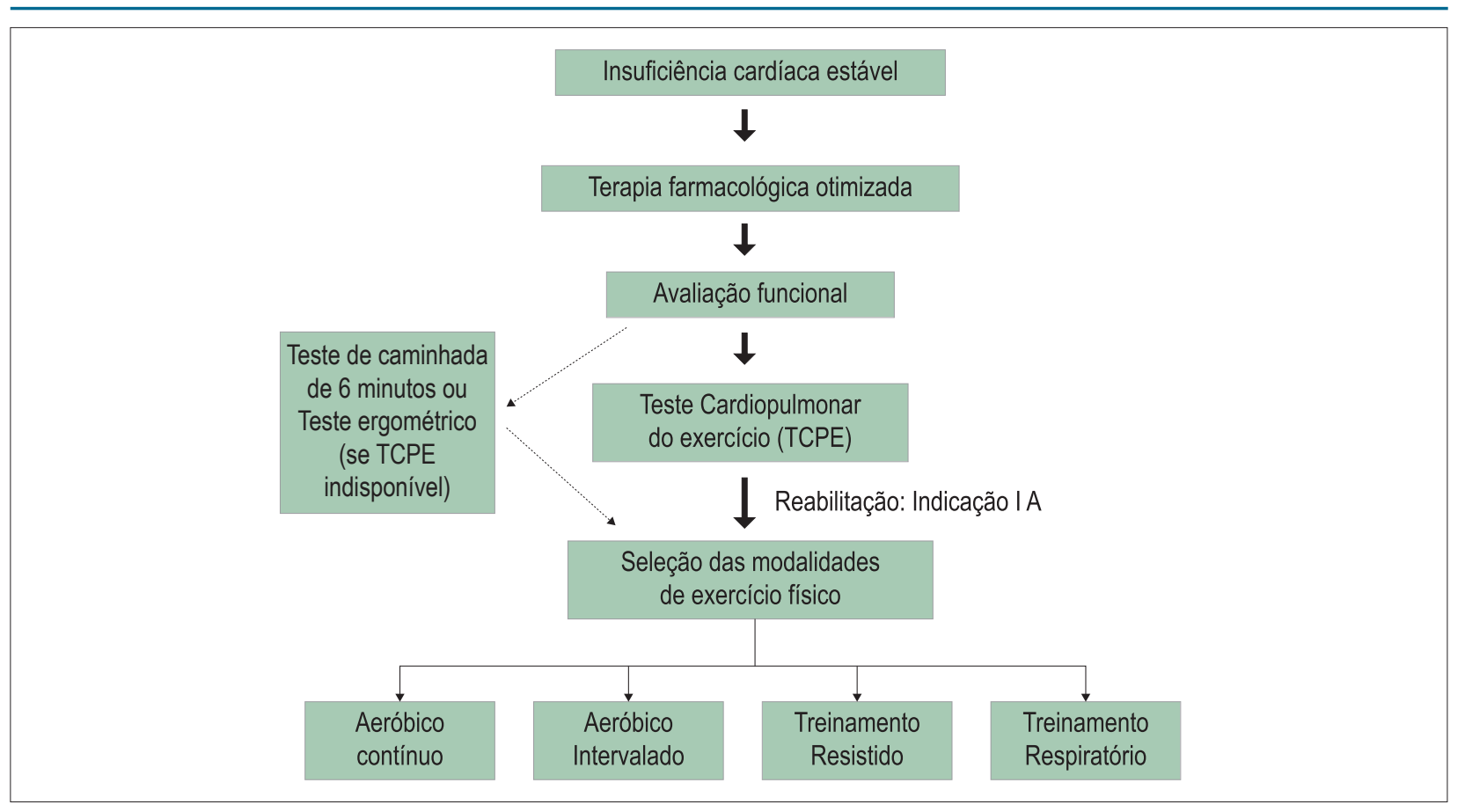

Figura 2 - Fluxograma da reabilitação cardiovascular no paciente com insuficiência cardíaca.

Antes de iniciar o programa de treinamento, é fundamental que o paciente esteja com o tratamento farmacológico otimizado e clinicamente estável; o ideal é que realize uma avaliação funcional, preferencialmente com TCPE ou TE. Na indisponibilidade das provas funcionais citadas, o teste de caminhada de 6 minutos pode servir de parâmetro de acompanhamento dos ganhos funcionais. ${ }^{208}$ Os testes funcionais devem ser realizados em uso das medicações prescritas para mimetizar a condição que estará presente durante o treinamento.

Os treinamentos aeróbicos recomendados podem ser contínuos de moderada intensidade (TCMI), que correspondem à zona de FC delimitada pelos limiares ventilatórios do TCPE, ou, no caso do $\mathrm{TE}$, à zona situada entre 60 e $80 \%$ da FC pico ou 50 e $70 \%$ da FC de reserva. Pacientes mais graves e com maior limitação funcional podem iniciar no limite inferior da prescrição. Progressões de intensidade até o limite superior podem ser realizadas com a evolução do treinamento.

Recentemente, tem aumentado a utilização de exercícios aeróbicos de alta intensidade realizados de modo intervalado, denominado de treinamento intervalado de alta intensidade (TIAI). Ele alterna períodos mais intensos com momentos de recuperação passiva ou ativa, o que possibilita maior duração total de exercícios na alta intensidade e, consequentemente, pode produzir maior estímulo para adaptações fisiológicas centrais e periféricas.

Em pacientes com IC e FEVE reduzida, Wisløff et al. ${ }^{209}$ demonstraram que o TIAI foi superior ao TCMI em promover a melhora na capacidade funcional e em diferentes parâmetros cardiovasculares. Posteriormente, outros ensaios clínicos foram realizados e meta-analisados. No que tange ao efeito do TIAI sobre a capacidade funcional, a superioridade do método em relação ao TCMI foi confirmada em uma meta-análise. ${ }^{210}$ Entretanto, o maior estudo multicêntrico publicado, o Smartex-HF, 211 comparou as modalidades de exercícios contínuos de moderada intensidade com os intervalados de alta intensidade. A conclusão foi que os benefícios são semelhantes, não havendo superioridade de modalidade em nenhum aspecto. Portanto, a escolha do protocolo vai depender de experiência da equipe, condições clínicas, capacidade física e preferências do paciente.

Além disso, o modo de utilizar o TIAI pode variar bastante, com vários protocolos descritos. ${ }^{212}$ Um deles é composto por 4 minutos de exercícios de alta intensidade (90 a 95\% da FC máxima), alternados com 3 minutos de leve intensidade (70\% da FC máxima). ${ }^{209}$ Protocolos com duração da carga intensa bem menores, com 30 ou 90 s, já foram descritos, e a tolerância a diferentes modelos de TIAI pode variar de acordo com a escolha e a capacidade física do paciente. ${ }^{213}$ Portanto, a utilização e o modo de execução vai depender das características clínicas e escolhas do paciente, bem como da experiência e das preferências da equipe de RCV.

Além do treinamento aeróbico, a adição de exercícios de resistência muscular localizada tem sido sugerida para obtenção de benefícios adicionais. ${ }^{214}$ Eles podem ser prescritos como percentuais da contração voluntária máxima ou de acordo com a percepção subjetiva ao esforço. As cargas e repetições recomendadas podem variar de acordo com as limitações funcionais do paciente e devem ser individualizadas, com progressão de acordo com evolução na RCV.

Os exercícios respiratórios têm sido indicados para programas de treinamento de pacientes com fraqueza da musculatura respiratória. ${ }^{215} \mathrm{~A}$ meta-análise de Smart et 
al., ${ }^{216}$ que avaliou 11 estudos com 287 participantes com IC, sendo 148 submetidos ao treinamento da musculatura inspiratória (TMI) comparados com 139 controles sedentários, mostrou significativos ganhos devidamente documentados: a) no TCPE, pelo aumento de consumo de oxigênio miocárdico no pico do esforço $\left(\mathrm{VO}_{2}\right.$ pico) e melhora da eficiência ventilatória observada na relação da ventilação pulmonar com a produção de dióxido de carbono (VE/VCO slope); b) na espirometria, pelo aumento da pressão inspiratória máxima; c) no teste de caminhada de 6-minutos, pela maior distância percorrida; d) melhora da qualidade de vida. Portanto, o TMI proporcionou ganhos da aptidão cardiorrespiratória e na qualidade de vida de similar magnitude aos obtidos com o treinamento convencional, devendo ser considerado alternativa válida para os pacientes com IC gravemente descondicionados fisicamente e muito debilitados, em uma transição para os exercícios físicos convencionais.

\subsubsection{Considerações Finais}

É fundamental que pacientes com IC realizem exercícios físicos, idealmente com prescrição individualizada, no contexto de um programa de RCV, levando-se em consideração a combinação de treinamentos aeróbicos de moderada e/ ou alta intensidade, exercícios de resistência muscular localizada e treinamento da musculatura respiratória (treinamento ventilatório). Para isso, devem ser levadas em consideração, além do quadro clínico e limitações funcionais a ele relacionadas, preferências do paciente e a experiência da equipe. Por fim, é relevante ressaltar a existência de alternativas válidas mesmo para os pacientes muito debilitados e gravemente descondicionados..$^{214,217}$

\subsection{Transplante Cardíaco}

O transplante cardíaco ( $\mathrm{TxC}$ ) é o tratamento de escolha para pacientes com IC refratária, que permanecem com sintomas graves mesmo em uso de todo o arsenal farmacológico disponível e na realização de procedimentos cirúrgicos indicados.

Nos últimos anos ocorreram avanços significativos no TxC, com surgimento de novas técnicas cirúrgicas e desenvolvimento de substâncias imunossupressoras mais eficientes. No Brasil, houve um crescimento substancial na quantidade de procedimentos, o que estava estagnado desde 2015, com taxa de 1,7 TxC por milhão da população (pmp). Em 2019 houve um crescimento de $17,6 \%$, chegando a 2 TxC pmp, muito próximo da meta estabelecida para o ano (2,1 pmp). Em 2018 foram realizados 357 procedimentos, e até março de 2019, 104 corações já foram transplantados no Brasil.. 218

$\mathrm{O}$ TxC tem como objetivo promover a melhora na qualidade de vida, assim como aumento da sobrevida. ${ }^{219,220}$ Os receptores são capazes de retornar ao trabalho e ter uma vida normal, com mínimos sintomas ou mesmo assintomáticos. ${ }^{221} \mathrm{~A}$ taxa de sobrevida no 10 ano é estimada em $90 \%$ e em 5 anos em cerca de $70 \%$. $^{222}$

Embora o TxC melhore significativamente a capacidade funcional dos pacientes, o $\mathrm{VO}_{2}$ pico ainda se encontra reduzido quando comparado ao de indivíduos saudáveis, pareados por idade. ${ }^{223,224}$ Dentre outros fatores, isso pode ser explicado por: 1) imediatamente no período pós-transplante, o aloenxerto apresenta ausência de inervação simpática e parassimpática (denervação autonômica), provocando aumento da FC de repouso, o que atenua a sua elevação natural como resposta ao exercício e prejudica a recuperação após o esforço 224,225 ; 2) ocorrência de disfunção muscular esquelética (às vezes chegando à caquexia), na qual a terapia imunossupressora, associada à IC prévia, exerce papel de destaque ${ }^{226}$; 3) comprometimento da função vascular e diastólica. ${ }^{227} \mathrm{Em}$ pacientes com TxC, na fase aguda do exercício, o aumento do débito cardíaco depende fundamentalmente do mecanismo de Frank-Starling, do aumento do retorno venoso, do inotropismo, do cronotropismo e da redução da pós-carga. ${ }^{228,229}$ Além disso, ocorre aumento das concentrações de catecolaminas circulantes, ${ }^{227}$ que reduzem lentamente após o término do exercício, justificando uma lenta recuperação da FC. ${ }^{230}$

A imunossupressão pode predispor a maior risco de outras complicações, ${ }^{231}$ e os pacientes transplantados podem evoluir com desenvolvimento de HAS, diabetes melito e coronariopatia. ${ }^{232}$ Por sua vez, o treinamento físico é conhecido como terapêutica de excelência para o manejo dessas doenças crônicas, ${ }^{93,233}$ sendo eficaz na otimização do controle autonômico. ${ }^{230,234}$

O treinamento físico após o TxC contribui para o aumento do $\mathrm{VO}_{2}$ pico e a melhora do controle hemodinâmico, da força muscular e da densidade mineral óssea, ${ }^{233-236}$ contribuindo para melhorar o prognóstico. ${ }^{19}$ Embora existam inúmeras possibilidades de prescrição de treinamento, o principal método preconizado permanece sendo o exercício aeróbico, que pode ser realizado de maneira contínua ou intervalada, ${ }^{170}$ sempre que possível devem ser realizados também exercícios resistidos. ${ }^{6}$

\subsubsection{Benefícios dos Exercícios Físicos}

No estudo pioneiro de Richard et al., ${ }^{237}$ os pesquisadores observaram que, após um período de 46 meses pós TxC, pacientes que realizaram treinamento aeróbico, apresentaram capacidade funcional e função cronotrópica semelhantes às verificadas em indivíduos saudáveis. ${ }^{234,238-240}$

Uma meta-análise da Cochrane, que reuniu nove ensaios clínicos randomizados, totalizando 284 pacientes, comparou o efeito do treinamento físico aos cuidados usuais em pacientes pós $\mathrm{TxC}_{1}{ }^{234}$ evidenciando aumento médio do $\mathrm{VO}_{2}$ pico de $2,5 \mathrm{ml} \cdot \mathrm{kg}^{-1} \cdot \mathrm{min}^{-1}$ nos que realizaram treinamento, em relação aos alocados para cuidados usuais. Rosembaun et al. ${ }^{241}$ estudaram a relação entre a participação precoce em um programa de RCV de pacientes após TxC e verificaram que o número de sessões realizadas nos primeiros 90 dias esteve relacionado diretamente com melhor sobrevida em 10 anos.

Haykowsky et al. ${ }^{242}$ descreveram melhoras significativas no $\mathrm{VO}_{2}$ pico de pacientes após $\mathrm{TxC}$, com aumento médio de 3,1 $\mathrm{ml} \cdot \mathrm{kg}^{-1} \cdot \mathrm{min}^{-1}$ após 12 semanas de treinamento combinado (resistido e aeróbico). Kobashigawa et al. ${ }^{243}$ estudaram 27 pacientes após TxC, os quais foram submetidos a uma combinação de treinamento aeróbico, resistido e de flexibilidade durante 6 meses versus grupo-controle. A duração e a intensidade das sessões de exercícios aeróbicos 
tiveram como meta, no mínimo, 30 min de exercício contínuo de intensidade moderada em bicicleta estacionária. O grupo intervenção apresentou aumento médio de $4,4 \mathrm{ml}^{-1} \cdot \mathrm{kg}^{-1} \cdot \mathrm{min}$ no $\mathrm{VO}_{2}$ pico, versus $1,9 \mathrm{ml} . \mathrm{kg}^{-1} \cdot \mathrm{min}^{-1}$ no grupo-controle. Esses dados fornecem informações valiosas da importância de ambos os tipos de treinamento após TxC.

Em relação ao treinamento de alta intensidade em pacientes após TxC, os resultados são motivadores, mas ainda há um pequeno número de estudos. Em um estudo crossover, Dall et al. ${ }^{244}$ verificaram efeito superior do TIAI em relação ao $\mathrm{TCMI}$ no $\mathrm{VO}_{2}$ pico, com ganho adicional de 2,3 $\mathrm{ml} \mathrm{kg}^{-1} \cdot \mathrm{min}^{-1}$ e melhora superior na qualidade de vida. Em meta-análise que reuniu três ensaios clínicos randomizados que compararam o TIAI (blocos intensos: 80 a 100\% do $\mathrm{VO}_{2}$ pico ou 85 a 95\% da FC pico) aos cuidados usuais, os pacientes que realizaram $\mathrm{TIAI}$ apresentaram aumento adicional no $\mathrm{VO}_{2}$ pico de $4,45 \mathrm{ml} \cdot \mathrm{kg}^{-1} \cdot \mathrm{min}^{-1}$ após o período de intervenção, que variou de 8 a 12 semanas, com três a cinco sessões semanais. ${ }^{233}$

Nytrøen et al. ${ }^{224}$ avaliaram os efeitos de um programa de TIAI após TxC em 43 pacientes. Foram observados os efeitos na progressão da vasculopatia do enxerto, avaliada por ultrassom intracoronário, constatando menor progressão de placas de ateroma no grupo TIAI. Porém, mais estudos ainda são necessários para esclarecer melhor os benefícios dessa modalidade de treinamento. ${ }^{245}$

Sabe-se que alguns dos efeitos adversos comuns ao uso de glicocorticoides após o TxC são atrofia e fraqueza musculares. Em 1998, Braith et al. ${ }^{235}$ estudaram, pela primeira vez, o efeito do treinamento resistido na miopatia induzida por glicocorticoide em receptores de TxC. Um grupo realizou treinamento e foi comparado com um grupo-controle. Após 6 meses, apesar de ambos terem apresentado aumento na força muscular do quadríceps e dos extensores lombares, houve um aumento até 6 vezes maior no grupo treinado.

O treinamento resistido também parece ter importante efeito terapêutico para melhoria do metabolismo ósseo. Após o TxC, os pacientes não raramente apresentam perda óssea significativa na cabeça do fêmur e perda óssea mineral total. Em pacientes arrolados para treinamento resistido, após 2 meses da realização do $\mathrm{TxC}$, o treinamento de força se mostrou capaz de restaurar a densidade mineral óssea a níveis pré-transplante. ${ }^{236}$

\subsubsection{Avaliação Pré-participação e Particularidades}

Os pacientes após TxC devem realizar anamnese, exame físico, ECG de repouso de 12 derivações, ecocardiograma com Doppler colorido ou outros exames a critério dos profissionais envolvidos. O ideal é a realização de um teste funcional em exercício, preferencialmente o TCPE realizado por médico experiente com o método. O TCPE considerado o padrão-ouro para avaliação da capacidade funcional, permite a determinação das respostas cardiopulmonar e metabólicas ao esforço físico, por meio de diversas variáveis que são de grande utilidade para a avaliação clínica e prescrição otimizada dos exercícios físicos. ${ }^{246}$ Os fisioterapeutas e profissionais de educação física devem atuar na prescrição, aplicação, supervisão e orientação dos exercícios, mas seguindo os limites de segurança recomendados pelos médicos responsáveis pela avaliação pré-participação. ${ }^{6,247}$
A impossibilidade da realização do TCPE não deve ser um impedimento para prática dos exercícios; na ausência dele, sugere-se um TE convencional. ${ }^{170}$ Quando nem mesmo este estiver disponível, o teste de caminhada de 6 minutos poderá auxiliar na avaliação clínica e prescrição de exercício, sendo parâmetro válido de comparação da capacidade funcional no decorrer do treinamento. ${ }^{248,249}$

\subsubsection{Prescrição do Treinamento Físico}

O treinamento aeróbico, ressaltando que o TCMI tem sido o método usado na maioria dos estudos, tem sido o mais preconizado, devendo ser complementado pelo treinamento resistido a partir da 6 6 ${ }^{\underline{a}}$ semana após TxC. Mas, diferentes metodologias de treinamento vêm sendo estudadas de maneira isolada ou combinada e têm se mostrado eficazes na promoção da saúde cardiovascular nos indivíduos em RCV, abrindo um leque de possibilidades a serem consideradas. ${ }^{6,170}$

De acordo com a condição clínica do paciente, a intensidade do exercício aeróbico pode aumentar gradualmente de moderada a alta ao longo do treinamento, pois a intensidade está diretamente associada à magnitude das desejáveis adaptações cardiovasculares. ${ }^{250}$ Nesse sentido, programas que incluíram o treinamento intervalado, até mesmo de alta intensidade, mostraram bons resultados. ${ }^{233}$ Porém, para uma otimizada e segura prescrição, deve haver adequada individualização de cada componente da sessão de treinamento. ${ }^{170}$

A determinação de zonas-alvo de treinamento é recomendável, visando otimização da prescrição do exercício. ${ }^{170}$ Entretanto, tendo em vista a resposta cronotrópica ainda comprometida, ${ }^{251}$ a prescrição com base nos percentuais da FC máxima ou nas FC dos limiares não é possível nas primeiras sessões de treinamento, podendo ser úteis quando ocorre melhora na resposta autonômica. ${ }^{224}$ Por esse motivo, a contínua avaliação do comportamento da FC durante o exercício e na recuperação se torna de suma importância. Quando um TCPE for disponível, a prescrição do exercício aeróbico poderá ser pautada nas cargas atingidas nos limiares ventilatórios ou nos percentuais estabelecidos do $\mathrm{VO}_{2}$ pico. Outra estratégia simples e viável é a avaliação da percepção subjetiva do esforço, por meio da escala BORG, 4,170,252 devendo haver empenho da equipe multiprofissional em educar o paciente em relação à percepção de esforço e às manifestações de sintomas. ${ }^{4,6}$

Além da avaliação e prescrição dos exercícios aeróbicos, é fundamental a realização de exercícios resistidos. Tradicionalmente têm sido utilizados, para a avaliação e prescrição destes exercícios, os testes de carga de uma repetição máxima, cuja aplicação, entretanto, é questionável, principalmente após o TxC recente, pois sua segurança carece de investigações clínicas nos transplantados. Uma alternativa seria o teste de sentar e levantar da cadeira em 30 segundos, ${ }^{253}$ que foi validado em idosos ativos e se mostrou razoavelmente confiável em fornecer informações sobre a força de MMII, sendo bastante utilizado em centros de reabilitação e em estudos científicos de diferentes condições clínicas. ${ }^{254-256}$

Uma possibilidade de grande aplicabilidade é a prescrição dos exercícios físicos resistidos de modo subjetivo, segundo a percepção de esforço considerado moderado, associado ao método de repetição variável, com o objetivo de executar uma 
faixa de repetições (por exemplo, de 10 a 15 repetições). Se o paciente não conseguir executar o mínimo, a carga aplicada está elevada; se executar o máximo de modo fácil, a carga está leve. Desse modo, a carga pode ser ajustada para que o treinamento seja realizado dentro da faixa de repetições proposta.

Durante o treinamento, especial atenção deve ser dada às complicações como as infecções relacionadas ao procedimento do transplante. Em levantamento realizado nos Estados Unidos, foi evidenciado que $36 \%$ dos receptores são hospitalizados ao longo do primeiro ano, e $61 \%$, dentro de um período de 4 anos após $\mathrm{TxC}_{1}^{257,258}$ o que deixa evidente a importância da supervisão dos pacientes ao longo do treinamento, com eventual necessidade de que as sessões sejam temporariamente interrompidas. Tendo em vista o exposto, alguns autores sugerem que os pacientes não devam realizar exercício físico durante o período de administração de terapia com pulsos de esteroides e nos dias de biópsia miocárdica. ${ }^{170}$

\subsubsection{Reabilitação Cardiovascular Domiciliar}

Estudos têm demonstrado que os programas de RCVD são seguros e efetivos, ${ }^{1}$ sendo recomendáveis como uma alternativa para a RCV tradicional em pacientes de menor risco. ${ }^{71}$

Wu et al. ${ }^{259}$ conduziram um estudo prospectivo e randomizado para avaliar o efeito de um programa de exercícios domiciliares durante 2 meses em 37 pacientes após TxC. O grupo controle manteve o estilo de vida habitual durante o período de estudo. Os indivíduos do grupo intervenção realizaram um programa de exercícios no mínimo três vezes na semana, que englobou 5 min de aquecimento, atividades de fortalecimento de MMSS e MMII, 15 a 20 min de exercício aeróbico em intensidade de 60 a $70 \%$ do $\mathrm{VO}_{2}$ pico, além de 5 min de desaquecimento. Para garantir a execução domiciliar correta, inicialmente foi realizado um período supervisionado para orientação e prescrição. Ao final de 2 meses, os pacientes melhoraram força e resistência muscular, índice de fadiga e qualidade de vida no domínio físico. Por meio do TCPE, foi observado aumento da carga de trabalho, mas sem modificação do $\mathrm{VO}_{2}$ pico, provavelmente pelo curto período de seguimento ou pela metodologia da prescrição do treinamento, que foi de menor intensidade. Outro estudo, ${ }^{260}$ com protocolo de treinamento aeróbico equivalente, porém maior duração, cinco vezes por semana durante 6 meses, documentou melhora no $\mathrm{VO}_{2}$ pico, na carga de trabalho e na PA de indivíduos após TxC. Além disso, ocorreram sinais de reinervação simpática cardíaca e restauração da sensibilidade à modulação autonômica nas artérias, sendo que nenhuma alteração foi observada no grupo controle.

Mesmo com período superior a 5 anos após o TxC, a RCVD melhora a capacidade funcional, conforme demonstra um estudo em que 21 pacientes foram instruídos a realizar um programa de treinamento físico domiciliar por 1 ano em bicicleta ergométrica, enquanto nove pacientes serviram como controle. Para garantir o adequado controle, os pacientes receberam um cartão inteligente, programado para um aquecimento de $6 \mathrm{~min}$ e uma carga de trabalho constante durante $20 \mathrm{~min}$, com ajuste de carga de acordo com a prescrição e o monitoramento da FC. Ao final de 12 meses, houve modesta melhora no $\mathrm{VO}_{2}$ pico. ${ }^{261}$
Karapolat et al. ${ }^{262}$ em estudo publicado em 2008, compararam os efeitos de programa domiciliar e presencial sobre a capacidade de exercício e variáveis cronotrópicas em 28 pacientes após TxC. Foram observadas melhoras significativas no $\mathrm{VO}_{2}$ pico e na FC de reserva apenas no grupo da RCV tradicional. Porém, novos estudos, com inclusão de um maior número de pacientes, são necessários para melhor elucidação desta superioridade da RCV presencial observada neste estudo.

\subsubsection{Recomendações}

Com base nas diversas evidências expostas, o efeito benéfico do treinamento físico em indivíduos após TxC é inequívoco e essa terapia se mostra segura e exequível, podendo ser realizada no ambiente hospitalar ou domiciliar (Tabela 7). No entanto, embora ambas as estratégias sejam eficazes em promover aumento na capacidade funcional, existem indícios de que a magnitude do efeito seja maior quando o treinamento é realizado em ambientes supervisionados.

A RCV deve ser iniciada entre 6 e 8 semanas após o $\mathrm{TxC}$, sendo o direcionamento realizado na alta hospitalar. Em casos selecionados e após criteriosa avaliação da equipe, o início pode ser mais precoce. Assim como em qualquer situação na qual o paciente seja submetido a esternotomia, um cuidado especial em relação a não realizar exercícios que sobrecarreguem a musculatura torácica e levem à tração do esterno deve ser salientado, principalmente nos primeiros 90 dias após o procedimento cirúrgico.

A prescrição ideal inclui exercícios para promoção das diferentes valências físicas, sempre enfatizando o que é preconizado para cada condição. No cenário após Txc, assim como em outras indicações de RCV, o exercício aeróbico é a parte principal das sessões de treinamento, devendo ser complementado pelos resistidos e de flexibilidade, dentro de um programa individualizado e periodizado. As sessões devem sempre iniciar com um período de aquecimento, assim como encerrar com um desaquecimento controlado. Tal estratégia visa, além do aquecimento muscular, um período para ajuste da FC e da PA, que estão alteradas nesses pacientes pela denervação do coração, especialmente no início do programa de treinamento após o procedimento.

O exercício aeróbico pode ser realizado em forma de caminhada ou ciclismo, tanto indoor, utilizando recursos como esteiras e/ou bicicletas ergométricas, ou quanto outdoor. Recomenda-se frequência semanal de três a cinco sessões, com duração de 20 a 40 minutos. A frequência e duração das sessões serão ajustadas conforme condições prévias do paciente e devem progredir ao longo do treinamento. O controle da intensidade é fundamental e, devido ao maior número de evidências, preconiza-se o TCMI (Entre o 1ํe o 2 ㅇ limiar ventilatório), com uma percepção de esforço referida entre 11 e 13 na Escala Borg modificada. O treinamento intervalado pode ser adotado, em casos selecionados, com objetivo de variação na forma do treino e busca de um ganho funcional potencialmente maior.

Os exercícios resistidos têm papel fundamental, principalmente na fase inicial após TxC. Muitos apresentaram IC de longa duração, estiveram internados por longos períodos e passaram pelo estresse cirúrgico. No início do treinamento, 
Tabela 7 - Indicação de reabilitação cardiovascular no transplante cardíaco

\begin{tabular}{|c|c|c|}
\hline Indicação & Recomendação & Nível de evidência \\
\hline $\begin{array}{l}\text { RCV com exercícios aeróbicos moderados são recomendados para } \\
\text { pacientes após } \operatorname{TxC}^{234,239,241,243}\end{array}$ & I & $A$ \\
\hline $\begin{array}{l}\text { RCV com exercício aeróbico de alta intensidade é recomendada para } \\
\text { pacientes após } T x C^{233,238,244}\end{array}$ & Ila & $B$ \\
\hline $\begin{array}{l}\text { RCV com exercícios físicos resistidos é recomendada para pacientes } \\
\text { após } \mathrm{TxC}^{235,236}\end{array}$ & I & $B$ \\
\hline
\end{tabular}

RCV: reabilitação cardiovascular; TxC: Transplante cardíaco.

atividades sem carga externa, ou seja, apenas com peso corporal, podem ser consideradas como estímulo suficiente para esses pacientes. Em seguida, bandas elásticas, halteres, caneleiras e aparelhos de musculação podem ser incluídos no programa de treinamento. Maior cuidado deve ser dado aos exercícios de MMSS, devido à toracotomia, levando em consideração que, com o uso de corticosteroides, o período de cicatrização pode ser maior.

Outras informações e exemplos de protocolos de treinamento nesses pacientes podem ser obtidos em outras publicações. ${ }^{263-265}$

\subsection{Miocardiopatias}

Nesta seção, serão abordadas a miocardiopatia hipertrófica $(\mathrm{MCH})$, a miocardite e outras miocardiopatias, cujas indicações de RCV estão listadas na Tabela 8.

\subsubsection{Miocardiopatia Hipertrófica}

A $\mathrm{MCH}$ é uma doença caracterizada por hipertrofia do ventrículo esquerdo, geralmente com câmaras ventriculares não dilatadas, na ausência de outra doença cardíaca ou sistêmica capaz de produzir a magnitude da hipertrofia evidenciada, ${ }_{1}^{271}$ sendo a doença cardíaca herdada mais comum na população e causada por uma gama de mutações de genes responsáveis pelas proteínas do sarcômero cardíaco. ${ }^{268}$ A principal característica é uma expressão clínica heterogênea, com alterações fisiopatológicas peculiares e uma história natural variável. Até 10\% dos casos são causados por outras doenças genéticas, incluindo metabólicas e neuromusculares hereditárias, anormalidades cromossômicas e síndromes genéticas. ${ }^{272}$ Alguns pacientes apresentam outros distúrbios que podem mimetizar formas da doença, como, por exemplo, amiloidose. ${ }^{273}$

A prevalência populacional é estimada em torno de $0,2 \%$ ou 1:500. ${ }^{268}$ No entanto, essa estimativa parece ser distinta na prática clínica, o que permite inferir que uma parcela dos indivíduos afetados são assintomáticos. Diversos padrões de hipertrofia assimétrica do ventrículo esquerdo são comuns à $\mathrm{MCH}$, e pode haver fenótipos diversos em familiares de primeiro grau. Tipicamente, uma ou mais regiões do ventrículo esquerdo têm espessura parietal aumentada quando comparadas com outras, e podem ocorrer transições e variações de espessura em áreas adjacentes ou áreas não contíguas. Contudo, apesar da hipertrofia septal assimétrica ser a mais comumente debatida, não existe um padrão clássico de $\mathrm{MCH}$ e, virtualmente, todos os padrões possíveis de hipertrofia ventricular esquerda podem ocorrer. Mesmo a ausência de hipertrofia pode ser encontrada em indivíduos geneticamente acometidos (fenótipo negativo).

Diferentes estudos de coorte retrospectivos e observacionais, de populações multicêntricas, esclareceram a história natural e o curso clínico dessa cardiopatia. Alguns mais recentes têm mostrado mortalidade anual em torno de $1 \%$, valor muito menor do que em pesquisas mais antigas. ${ }^{274}$ Notavelmente, apenas em um pequeno subgrupo de pacientes com $\mathrm{MCH}$ ocorre morte prematura e complicações significativas relacionadas à doença, as quais podem ocorrer por obstrução da via de saída do ventrículo esquerdo, IC com disfunção diastólica e/ou sistólica e morte súbita (MS) ou arritmias cardíacas (fibrilação atrial e taquicardia ou fibrilação ventricular). ${ }^{275} \mathrm{~A}$ MS na $\mathrm{MCH}$ pode acontecer em qualquer faixa etária, embora seja mais comum em adolescentes e adultos jovens; por isso, a identificação de indivíduos sob maior risco é muito importante na avaliação pré-participação esportiva. ${ }^{276}$

Em muitos casos, a MS pode ser a primeira manifestação da doença nesses indivíduos, ocorrendo mais comumente naqueles sem sintomas de alerta, os quais não haviam sido diagnosticados previamente ao evento. Entretanto, a maioria dos pacientes com $\mathrm{MCH}$ apresenta uma expectativa de vida normal ou quase normal, com mortalidade relacionada a outras doenças, algumas, inclusive, de etiologia não cardiovascular. ${ }^{277-279}$ Portanto, incentivar um estilo de vida saudável para pacientes com $\mathrm{MCH}$ é essencial para reduzir o risco global de doença.

\subsubsection{Benefícios Terapêuticos do Exercício Físico}

O nível de aptidão cardiorrespiratória está associado ao risco de mortalidade cardiovascular e por todas as causas na população em geral. ${ }^{19} \mathrm{Em}$ paciente com $\mathrm{MCH}$, forma obstrutiva e minimamente sintomática, também já foi observada associação de mortalidade com a aptidão aeróbica. ${ }^{280,281}$ Pacientes com $\mathrm{VO}_{2}$ pico abaixo de $18 \mathrm{ml} . \mathrm{kg}^{-1} \cdot \mathrm{min}^{-1}$ no TCPE apresentaram maior mortalidade e sintomatologia mais exuberante em comparação aos que obtiveram valores iguais ou superiores. A presença de $\mathrm{VO}_{2}$ pico inferior a $60 \%$ do previsto significou pior sobrevida em 4 anos, em torno de $60 \%{ }^{280}$

O aumento da fibrose miocárdica e o desarranjo miofibrilar podem estar por trás do risco aumentado de $\mathrm{MS}$ na $\mathrm{MCH}$, pois essa alteração atua como substrato para arritmias fatais. ${ }^{271}$ Evidências sugerem que o treinamento físico intenso poderia acelerar tais alterações, mas esse ainda é um tema controverso. Entretanto, sabe-se que o aumento da fibrose miocárdica está associado a menor $\mathrm{VO}_{2}$ pico nessa população. ${ }^{282}$ 


\section{Diretrizes}

Tabela 8 - Indicação de exercícios físicos nas miocardiopatias

\begin{tabular}{|c|c|c|}
\hline Indicação & Recomendação & Nível de evidência \\
\hline Exercícios aeróbicos moderados, para pacientes selecionados, com MCH ${ }^{266,267}$ & Ila & B \\
\hline Exercício físico vigoroso ou competitivo para pacientes com $\mathrm{MCH}^{268,269}$ & III & C \\
\hline $\begin{array}{l}\text { Exercícios aeróbicos moderados, para pacientes selecionados, após } 3 \text { a } \\
6 \text { meses do quadro agudo de miocardite }\end{array}$ & $\mathrm{llb}$ & C \\
\hline $\begin{array}{l}\text { Exercícios aeróbicos leves a moderados para pacientes selecionados } \\
\text { com CAVD }{ }^{270}\end{array}$ & Ilb & B \\
\hline $\begin{array}{l}\text { Exercícios físicos de alta intensidade ou competitivos para pacientes } \\
\text { com CAVD } 268,269\end{array}$ & III & C \\
\hline
\end{tabular}

MCH: miocardiopatia hipertrófica; CAVD: cardiomiopatia arritmogênica do ventrículo direito.

Sendo assim, avaliar a aptidão aeróbica, preferencialmente pelo TCPE, é importante nos pacientes com MCH. ${ }^{281}$ Quando existe redução do $\mathrm{VO}_{2}$ pico, a prática de exercícios físicos pode contribuir para aumentar a capacidade funcional.

Até o momento, apenas um ensaio clínico randomizado controlado examinou o efeito do treinamento físico em pacientes com MCH (RESET-MCH). Esse estudo, que contemplou 136 pacientes, demonstrou aumento no $\mathrm{VO}_{2}$ pico após treinamento de moderada intensidade depois de 16 semanas de intervenção $\left(+1,35 \mathrm{ml} \cdot \mathrm{kg}^{-1} \cdot \mathrm{min}^{-1}\right.$ ou $<0,5$ MET). ${ }^{266}$ Outro estudo prospectivo não randomizado incluiu 20 pacientes com $\mathrm{MCH}$ e mostrou aumento significativo na duração do TE, assim como na capacidade funcional estimada $(+2,5 \mathrm{MET}){ }^{267}$ Nesse estudo, os pacientes completaram um programa de RCV com sessões de 60 min de exercício moderado a vigoroso, realizados em esteira ou cicloergômetro, 2 vezes por semana. A intensidade do exercício progrediu de 50 para $85 \%$ da FC de reserva, o que resultou em aumento gradual do condicionamento e pode ter minimizado o risco de eventos adversos, como arritmias induzidas pelo exercício. Em nenhum desses estudos com treinamento houve ocorrência de eventos adversos sérios, como morte, MS cardíaca abortada, terapia do cardioversor desfibrilador implantável (CDI) ou taquicardia ventricular sustentada. 266,267

\subsubsection{Quando indicar exercícios físicos}

A intensidade de exercício liberado para pacientes com $\mathrm{MCH}$ representa um grande desafio. Se por um lado, o exercício físico intenso pode ser deletério, com aumento do risco de arritmias potencialmente fatais; por outro, a restrição excessiva de atividade física conduz ao descondicionamento e pode ter efeitos negativos na saúde e na qualidade de vida do paciente, podendo até aumentar o risco cardiovascular, visto que existe associação entre aptidão física e mortalidade. . $^{280,281}$

A American Heart Association, em seu posicionamento oficial para o tratamento da $\mathrm{MCH}$, desencoraja os pacientes com a doença a se envolverem em esportes competitivos de intensidade moderada a vigorosa (ver Tabela 8). A limitação serviria para minimizar as mudanças súbitas na $\mathrm{PA}$ e no aumento do débito cardíaco, de modo a, supostamente, proteger dos efeitos negativos do exercício em um coração patologicamente hipertrofiado. ${ }^{283}$
O exercício como gatilho para arritmias em curto prazo e remodelamento adverso em longo prazo são os efeitos mais temidos na $\mathrm{MCH}$. O receio da MS cardíaca durante o esporte estende-se a atividades atléticas não competitivas, embora exista uma clara falta de evidência sobre a segurança do exercício neste perfil de pacientes. No entanto, deve ser ressaltado que esse risco dos exercícios é teórico e as recomendações para as limitações da atividade física têm sido advogadas com cautela, pela opinião de especialistas e não por evidências mais robustas. ${ }^{284}$

Desse modo, os pacientes com $\mathrm{MCH}$ recebem pouca ou nenhuma orientação em relação à melhor dose ou quantidade de atividade física para manutenção da saúde geral e do bem-estar, sendo que maior foco é dado nas restrições às atividades físicas. Como resultado, mais de 50\% dos pacientes com $\mathrm{MCH}$ não alcançam o mínimo de atividade física recomendada, devido à crença de que são incapazes de exercê-la e/ou de que a atividade física pode piorar a doença.

Sendo assim, o equilíbrio parece ser o mais adequado e os extremos devem ser evitados (nem exercício vigoroso competitivo, nem sedentarismo), pois ambos poderiam aumentar o risco cardiovascular.

Em virtude das novas evidências, pode-se considerar haver efeito positivo dos exercícios físicos moderados em pacientes selecionados com $\mathrm{MCH}$, com a avaliação de risco e a prescrição realizadas individualmente. Ressalta-se que as evidências sugerem benefícios para o treinamento moderado contínuo, sendo que outras modalidades ainda devem ser mais estudadas.

Entretanto, a presença das seguintes características poderiam ser consideradas contraindicações maiores à prática de exercício: história de MS abortada e ausência de CDI; história de síncope aos esforços; ocorrência de taquicardia ventricular induzida pelo exercício; aumento do gradiente com o exercício (superior a $50 \mathrm{mmHg}$ ) e resposta pressórica anormal ao esforço.

\subsubsection{Avaliação Pré-participação}

A definição da liberação para iniciar os exercícios deve ser realizada pela avaliação médica pré-participação, realizando-se anamnese, exame físico e ECG de 12 derivações. 
Uma grande parcela dos indivíduos com $\mathrm{MCH}$ é assintomática ou oligossintomática e a suspeita clínica é dada por alterações no ECG de repouso, o qual é anormal em até $95 \%$ dos pacientes com a doença. ${ }^{285}$ As alterações eletrocardiográficas podem preceder doença estruturalmente detectada por alguns anos, o que torna a realização do ECG de suma importância nesse cenário. ${ }^{269}$ Somente uma minoria dos pacientes com $\mathrm{MCH}$ apresentam ECG normal, em geral aqueles sem outra manifestação fenotípica da doença (genótipo positivo/fenótipo negativo).

O ecocardiograma segue como o exame mais empregado para o diagnóstico de $\mathrm{MCH}$, restando a ressonância magnética nuclear (RMN) como alternativa para os casos em que o primeiro não for conclusivo, ou para avaliar situações de hipertrofia mais localizada (formas apicais, por exemplo). Em atletas jovens, a diferenciação entre a hipertrofia fisiológica do coração de atleta e a hipertrofia patológica da $\mathrm{MCH}$ é um desafio. Isso porque, tal como acontece com indivíduos sedentários com $\mathrm{MCH}$, a maioria dos atletas com a doença mostra um padrão assimétrico de hipertrofia do ventrículo esquerdo. Em contraste, aqueles com hipertrofia fisiológica do ventrículo esquerdo mostram distribuição mais homogênea e simétrica da espessura da parede, com apenas pequenas diferenças entre os segmentos contíguos e um padrão simétrico de hipertrofia do ventrículo esquerdo. ${ }^{286}$

O teste de exercício, previamente ao início da RCV, está sempre recomendado nesses pacientes, seja para avaliação da capacidade funcional ou para detecção de respostas anormais da PA e sinais de aumento da obstrução dinâmica da via de saída com o esforço. Para melhor detecção de obstrução da via de saída durante o exercício, a associação de exame de imagem (ecocardiograma) com teste de esforço é a melhor modalidade disponível e deve ser encorajada sempre que possível. Pacientes com ausência de obstrução no repouso podem apresentar gradientes significativos no esforço, sendo reclassificados em relação ao prognóstico. ${ }^{287}$

Quando estiver disponível, sugere-se a realização do TCPE para uma melhor avaliação em esforço, com medida direta do $\mathrm{VO}_{2}$ pico, em virtude do seu documentado valor prognóstico. ${ }^{280,281}$ Além disso, a obtenção dos limiares ventilatórios contribui para uma prescrição mais individualizada.

\subsubsection{Particularidades na Prescrição e no Acompanhamento dos Exercícios Físicos}

Algumas particularidades dos exercícios em pacientes com $\mathrm{MCH}$ devem ser destacadas:

- Atividades do tipo "explosão" (p. ex., basquete, futebol e tênis), em que há potencial para rápida aceleração e desaceleração, devem ser evitadas;

- Atividades com consumo de energia estável e constante (p. ex., corrida leve ou natação) são preferidas;

- Exercício em condições ambientais adversas, incluindo calor ou frio extremos, deve ser evitado, pois há um aumento do risco de exacerbação das alterações fisiológicas induzidas pelo exercício;

- Programas de treinamento que visem competitividade, ou obtenção de níveis mais altos de condicionamento físico e excelência, devem ser evitados, pois normalmente motivam os pacientes a se esforçarem além dos limites.

- Exercícios estáticos (isométricos) intensos, como levantamento de peso, devem ser evitados, pois há risco aumentado de provocar obstrução da via de saída do ventrículo esquerdo, devido à intensa manobra de Valsalva;

- Treinamento resistido com baixa carga e maior número de repetições foi considerado seguro para pacientes com DCV, embora não haja evidência sólida do seu uso na $\mathrm{MCH}$.

Em relação ao uso de medicações, algumas observações são importantes. O uso de betabloqueadores e antagonistas do cálcio pode estar indicado no tratamento da $\mathrm{MCH}$. Como essas medicações atenuam a resposta da FC, é possível ocorrer uma resposta cronotrópica muito reduzida ao esforço, o que pode ocasionar aumento da intolerância ao exercício e indicar necessidade de ajuste da medicação. O uso de diuréticos em excesso pode ser deletério por aumentar o gradiente da via de saída. Sendo assim, devem ser utilizados com cautela. Do mesmo modo que os diuréticos, a desidratação pelo exercício pode elevar o gradiente. Assim, é importante atenção a uma adequada hidratação durante o treinamento.

\subsubsection{Miocardite}

A patogênese da miocardite consiste em três fases: lesão aguda, geralmente de etiologia viral; resposta imune do hospedeiro; e recuperação, ou transição para fibrose e miocardiopatia dilatada, sendo que, clinicamente, não existe uma distinção clara entre essas fases. A lesão inicial pode causar dano agudo ao miocárdio, com comprometimento contrátil mediado por citocinas produzidas pelo processo inflamatório local. Esse quadro inflamatório agudo pode evoluir, na fase tardia, para fibrose extensa, o que pode causar dilatação e disfunção ventricular.

A miocardite aguda é suspeitada quando existe a presença dos seguintes critérios: ${ }^{283}$

- Síndrome clínica com IC aguda, dor torácica do tipo angina ou miopericardite com menos de 3 meses de duração;

- Elevação inexplicada na dosagem de troponina sérica;

- Alterações eletrocardiográficas sugestivas de isquemia miocárdica;

- Anormalidades contráteis globais ou segmentares e/ou derrame pericárdico na ecocardiografia.

- RMN com alterações características no sinal tecidual em T2, ou imagens ponderadas em T1, e presença de realce tardio com gadolínio.

Em relação à participação em programas de RCV de pacientes com miocardites após a resolução da fase aguda, o assunto é muito pouco estudado e não existem estudos científicos sobre a segurança e eficácia da intervenção. No entanto, relatos de casos de RCV nesse perfil de pacientes têm demonstrado benefícios na qualidade de vida e na aptidão física, especialmente quando há comprometimento funcional, mesmo após a melhora do quadro agudo e otimização do tratamento medicamentoso. ${ }^{288-290}$ 
Antes de iniciar a prática de exercícios, os pacientes com quadro prévio de miocardite devem ser submetidos a ecocardiograma, Holter de 24 horas e teste de exercício em um período não inferior a 3 a 6 meses após a doença aguda. ${ }^{269,283}$ Depois dessa avaliação, casos selecionados podem iniciar exercícios moderados na RCV, visando os benefícios gerais obtidos com os pacientes com IC.

No âmbito esportivo, é razoável que atletas retornem a sua rotina normal de treinamento apenas se houver: retorno da função sistólica a valores normais; marcadores de necrose miocárdica e inflamação dentro dos valores normais e ausência de arritmias clinicamente significativas no Holter e no teste de exercício. Ressalta-se que o significado clínico da permanência de realce tardio na ressonância de pacientes pós-miocardite, com resolução do quadro, ainda é desconhecido. Sendo assim, parece razoável que aqueles com pequenas áreas de realce e sem arritmias significativas no Holter e no exercício possam retornar à atividade esportiva, mantendo acompanhamento clínico. ${ }^{269}$

Em casos crônicos, em que a disfunção ventricular persiste ao longo do seguimento, o paciente deve seguir as recomendações gerais para a RCV descritas para a IC crônica (ver Tabela 6).

\subsubsection{Outras Miocardiopatias}

\subsubsection{Cardiomiopatia Arritmogênica do Ventrículo Direito}

A cardiomiopatia arritmogênica do ventrículo direito (CAVD) é uma doença hereditária que está associada à MS em jovens e atletas. Patologicamente, ocorre perda de miócitos, com substituição fibroadiposa, principalmente no miocárdio do ventrículo direito, embora o acometimento isolado do ventrículo esquerdo ou o biventricular também possam ocorrer. ${ }^{291}$

Há evidências, em modelo experimental animal, de que o exercício aumenta a penetrância e o risco de arritmias em portadores de mutações tradicionais da CAVD. ${ }^{292}$ Em indivíduos com genótipos positivos, o aumento do risco de arritmias com o exercício também já foi confirmado. Os eventos de taquiarritmias ventriculares e MS geralmente ocorrem durante o esforço, incluindo esportes e exercícios de endurance, com um aumento no risco de taquicardia, fibrilação ventricular e IC. ${ }^{293}$

Já foi demonstrado que indivíduos com CAVD envolvidos em esportes competitivos apresentaram maior ocorrência de taquiarritmias ventriculares e MS, além de início mais precoce dos sintomas, comparados com aqueles que participaram apenas de atividade física leve e sedentários. ${ }^{270}$ A redução da intensidade do exercício foi associada à diminuição substancial do risco de taquiarritmias ventriculares ou morte, principalmente nos pacientes sem mutação desmossomal detectada e com CDI para prevenção primária. ${ }^{294}$ Portanto, a evidência científica sugere que a participação em esportes e exercício intenso está associada ao início precoce dos sintomas e maior risco de arritmias ventriculares e eventos maiores em pacientes com CAVD. Sendo assim, devem ser desqualificados para a prática esportiva. ${ }^{269,276}$
Em relação à participação em programas de RCV, não há dados científicos que indiquem ou que sugiram benefícios dos exercícios físicos para os pacientes com CAVD. Por outro lado, mantê-los sedentários, contribuindo para a baixa aptidão física, também pode não ser apropriado, visto que existe associação geral de baixa aptidão física com mortalidade. ${ }^{14,21}$

Em um pequeno estudo observacional com pacientes com CAVD, não foi observada diferença na taxa de mortalidade entre os indivíduos inativos e os que realizaram apenas atividades físicas recreacionais. ${ }^{270}$ Desse modo, pode-se supor que a participação dos pacientes em um programa de RCV supervisionado, com exercícios de leve a moderada intensidade, pode não ser deletéria. Dependendo de outras características clínicas dos indivíduos, como presença de fatores de risco cardiovasculares, os exercícios físicos poderiam ser prescritos para o controle dessas condições.

Portanto, a inclusão de um paciente com CAVD em programas de RCV somente deve ser realizada após a avaliação médica pré-participação e o rigoroso ponderamento entre os riscos e benefícios dos exercícios físicos. Devem ser discutidas as opções com o paciente, expondo a ausência de benefícios comprovados versus riscos potenciais do sedentarismo e baixa aptidão física. Cabe ao paciente escolher a opção, de acordo com suas preferências pessoais.

No contexto da RCV, extrapolando os achados em atletas, sugere-se também restrição a maiores intensidades de treinamento. Os pacientes com CAVD poderiam realizar exercícios físicos supervisionados de leve a moderada intensidade.

\subsubsection{Miocardiopatia Não Compactada}

A miocardiopatia não compactada (MNC) é uma doença cardíaca que ocorre devido à interrupção embrionária da compactação miocárdica. Caracteriza-se por espessamento segmentar das paredes do ventrículo esquerdo, consistindo em duas camadas: uma epicárdica compactada e uma endocárdica com marcadas trabeculações e recessos intratrabeculares profundos, onde os espaços são preenchidos pelo fluxo sanguíneo. ${ }^{295,296}$

Sua incidência e prevalência são incertas, segundo alguns registros ecocardiográficos, em torno de 0,02 a $0,05 \% .{ }^{297}$ Clinicamente, pode ser assintomática ou cursar com sintomas de IC, arritmias ventriculares e/ou atriais, pré-excitação, eventos tromboembólicos ou MS. Não existem critérios universalmente aceitos para o diagnóstico morfológico. Contudo, a relação entre miocárdio não compactado/ compactado superior a 2,1:1 no final da sístole ao ecocardiograma ou 2,3:1 no final da sístole na RMN tem sido o critério proposto mais aceito atualmente. ${ }^{298}$

Ainda não está estabelecido como o treinamento físico pode influenciar a MNC ou a frequência de aparecimento da morfologia de não compactação na população. ${ }^{299,300}$ Em estudos recentes, atletas revelaram alta prevalência de aumento da trabeculação ventricular, quando comparados a um grupo controle (18,3 versus $7 \%$ ). Acredita-se que o aumento da trabeculação ventricular ou a existência de critérios ecocardiográficos isolados para miocardiopatias tenham, provavelmente, pequena significância e possam ser 
parte do espectro do coração de atleta. ${ }^{300,301}$ Portanto, nem todos os atletas com não compactação ventricular isolada têm o diagnóstico de MNC. Diante disso, existe a necessidade de se considerarem parâmetros funcionais, como a FEVE, para decisão de conduta. ${ }^{301}$

Não existem, até o momento, evidências de estudos com RCV ou treinamento na MNC. Sendo assim, pacientes que apresentem disfunção ventricular esquerda devem seguir as mesmas recomendações de exercício para aqueles com IC crônica (ver Tabela 6).

\subsection{Valvopatias}

Pacientes com valvopatias representam um grupo bastante heterogêneo e podem ter grande variabilidade quanto a faixa etária, etiologia, valvas acometidas e gravidade das lesões, seja por estenose, insuficiência ou lesões mistas. Entretanto, a maioria das valvopatias tem características em comum, que são as manifestações clínicas induzidas pelo esforço físico, como dor torácica, dispneia e/ou limitações funcionais. A gravidade desses sintomas em pacientes com valvopatias graves pode ser utilizada como um dos critérios para a indicação de intervenção cirúrgica ou percutânea. Além disso, a identificação de redução da aptidão aeróbica, documentada pelo TCPE ou pelo TE, também se constitui em critério utilizado para definição de indicação de intervenções. ${ }^{302-304}$

Um dos problemas no seguimento clínico dos pacientes com valvopatias é que a doença tem longa evolução. Os sintomas e limitações funcionais podem ter lenta instalação e progressão, o que pode levar o paciente a, espontaneamente, reduzir a sua prática de atividade física, em virtude de sintomatologia aos esforços. Com isso, o sedentarismo pode contribuir para a redução da aptidão física aeróbica e amplificar sintomas.

Desse modo, dúvidas podem surgir na condução clínica sobre a necessidade de intervenções quando o paciente realizar um TE ou TCPE, como: a identificação de eventuais reduções da aptidão física poderia ser decorrente da evolução da valvopatia, do sedentarismo ou de ambas as situações? Nesse contexto, a prática regular de exercícios físicos e a consequente manutenção ou até melhora da aptidão física são importantes para dirimir dúvidas no seguimento de pacientes valvopatas.

A participação de pacientes valvopatas em programas de RCV ainda é objeto de estudo sobre o significado em termos de custo-efetividade. ${ }^{305}$ Porém, o aumento da capacidade funcional dos indivíduos encaminhados à RCV tem sido consistentemente encontrado, ${ }^{306,307}$ justificando o encaminhamento a programas embasados em exercícios físicos (nível de evidência C).

A atuação da reabilitação no cenário da valvopatia pode ser subdividida em duas fases: pré e pós-intervenção, seja esta cirúrgica ou percutânea.

\subsubsection{Fase Pré-intervenção}

Pacientes com valvopatias moderadas a graves, na fase pré-intervenção, são menos comuns em programas de RCV. O treinamento é realizado principalmente em casos assintomáticos, nos quais ainda não existe indicação de correção da valvopatia.
A RCV pode ser útil por manter o paciente fisicamente ativo durante a espera pela futura intervenção. Afinal, o sedentarismo pode deteriorar sua capacidade funcional e, com isso, aumentar o risco de complicações no pós-operatório, principalmente quando a intervenção é realizada em idosos com múltiplas comorbidades e fragilidade. ${ }^{308-310}$

Além disso, o monitoramento realizado durante as sessões supervisionadas da RCV pode ser útil para observar mudanças na sintomatologia e aptidão física, as quais podem indicar uma possível progressão da valvopatia e sugerir a necessidade de reavaliações médicas.

\subsubsection{Fase Pós-intervenção}

Pacientes na fase pós-intervenção são mais comuns em programas de RCV, nos quais o exercício estruturado e sob supervisão é útil para a observação do comportamento hemodinâmico da nova condição valvar. A obtenção de informações relativas às respostas ao exercício físico pode ajudar o médico assistente em relação à necessidade de ajustes farmacológicos e/ou revisões da função valvar. Além disso, a prática supervisionada dos exercícios confere maior segurança ao paciente para retornar às suas atividades diárias, de lazer e esporte.

Apesar de não existir nenhum prazo de tempo consensualmente definido para o encaminhamento à RCV no cenário da valvopatia, quanto mais precocemente o paciente iniciar os exercícios, menores serão os prejuízos relacionados à inatividade física. ${ }^{305-307,310}$ A troca de informações entre o médico assistente e o da reabilitação configura-se como a melhor estratégia para definição do momento mais propício para o encaminhamento, e a avaliação pré-participação tem um papel fundamental na consolidação dessa decisão compartilhada.

\subsubsection{Avaliação Pré-participação}

A avaliação pré-participação sempre terá como pilares básicos e fundamentais a anamnese, o exame físico e a avaliação dos exames complementares. A história clínica deve contemplar: tempo de internação; complicações relacionadas ao procedimento, como derrame pleural, pericárdico, mediastinite e infecções; tipo e tamanho da prótese utilizada; técnica cirúrgica; e se houve CRVM associada, além de outras informações clínicas que possam ser pertinentes, relativas a outras comorbidades.

No exame físico, as auscultas cardíaca e pulmonar são importantes. Além disso, atenção deve ser dada à cicatriz cirúrgica, com verificação de sinais de inflamação e infecção, instabilidade do esterno e dor ou desconforto à palpação. Caso tenha sido realizada revascularização concomitante, deve-se observar a região da safenectomia e/ou da retirada da artéria radial. Em casos de procedimentos percutâneos, verifica-se a via de acesso em busca de sinais de complicações vasculares periféricas.

A busca por anemia no exame físico e na avaliação dos exames complementares é importante nos pacientes pós-intervenção, pois é uma situação frequente e pode impactar negativamente na capacidade funcional. ${ }^{311}$ A avaliação laboratorial da coagulação é relevante nos pacientes que receberam próteses valvares e iniciaram uso 
de anticoagulantes. A adequação do nível de anticoagulação é importante na prevenção de complicações.

O ECG de repouso deve ser realizado para avaliar a ocorrência de arritmias e distúrbios do ritmo e da condução. O exame mais comumente utilizado na avaliação das valvopatias é o ecocardiograma com Doppler, que possibilita a avaliação da função ventricular e de diâmetros cavitários, a mensuração de gradientes transvalvares, a estimativa da pressão sistólica da artéria pulmonar e as medidas dos fluxos, o que dá uma visão ampla do funcionamento do aparelho valvar e da função cardíaca em repouso. Sendo assim, o ecocardiograma deve ser realizado antes do início da RCV para avaliar o risco de complicações nos exercícios. ${ }^{312}$

A avaliação da capacidade funcional pelo TCPE ou TE é de importância ímpar na análise complementar. ${ }^{313-316}$ Esses exames, principalmente o TCPE, fornecem informações relativas à aptidão aeróbica e à repercussão hemodinâmica da lesão valvar, que pode estar subestimada pela avaliação em repouso. Além disso, identifica parâmetros que são utilizados para guiar a prescrição dos limites de intensidade e restrições causadas pela valvopatia. $\mathrm{Na}$ indisponibilidade do TCPE ou TE, a utilização de outros testes funcionais, como o teste de caminhada de 6 minutos e o teste de degraus, deve ser considerada. ${ }^{317-320}$

É importante ressaltar que o TCPE ou TE em pacientes com lesões estenóticas configuram situações de maior risco. Por esta razão, devem ser realizados somente por médicos com experiência nesse tipo de avaliação e em serviço com retaguarda de segurança. ${ }^{321}$

Além da indicação dos testes funcionais na avaliação pré-participação da RCV, sua utilização também é adequada para esclarecer dúvidas em relação à sintomatologia de pacientes valvopatas na fase pré-intervenção. A associação com o ecocardiograma ajuda a avaliar a resposta em esforço físico do gradiente transvalvar e da pressão sistólica de artéria pulmonar, principalmente quando há discrepância entre os achados do ecocardiograma em repouso e os sinais e sintomas clínicos. ${ }^{304,322,323}$

Outra questão relevante é a avaliação de pacientes idosos, que frequentemente são acometidos pelas doenças valvares e apresentam uma alta prevalência de fatores de risco e comorbidades. ${ }^{324} \mathrm{Em}$ virtude do elevado risco cirúrgico, tais pacientes têm sido submetidos a procedimentos percutâneos das valvas aórtica ${ }^{325}$ e mitral. ${ }^{326}$ Nessa situação, a RCV pode ser considerada antes da intervenção, com o objetivo de diminuir as taxas de complicações, o tempo de internação, a mortalidade e a morbidade relacionadas à síndrome da fragilidade. ${ }^{327}$ Após a realização da intervenção, a RCV permite monitorar e otimizar os resultados do procedimento em todos os seus aspectos. ${ }^{328-331}$

A utilização de instrumentos de avaliação da síndrome de fragilidade ainda é objeto de discussão na literatura, sem um consenso de qual o melhor protocolo para avaliar os resultados da RCV. A avaliação deve incluir testes objetivos e instrumentos de abordagem do risco em vários domínios: mobilidade, massa e força musculares, independência nas atividades da vida diária, função cognitiva, nutrição, ansiedade e depressão. ${ }^{304,308,332}$

\subsubsection{Particularidades na Prescrição e no Acompanhamento dos Exercícios Físicos}

Nesta seção, são abordadas as orientações e recomendações para exercícios em pacientes com lesões valvares de grau moderado ou grave, visto que não há restrição para a prática nos casos de lesões leves. A participação em esportes competitivos deve observar as publicações específicas sobre o assunto. ${ }^{276,333,334}$ A evidência científica é escassa quanto ao impacto do exercício físico regular na progressão da doença valvar e de suas complicações. Portanto, as recomendações são fundamentadas em opiniões de especialistas (nível de evidência C).

Agudamente, o exercício provoca um aumento do tônus adrenérgico e da carga hemodinâmica imposta ao sistema cardiovascular, o que causa preocupação com relação aos potenciais efeitos deletérios cardiovasculares nos pacientes com valvopatias, tais como progressão de aortopatias, deterioração funcional, hipertensão pulmonar, remodelamento cardíaco, isquemia miocárdica e arritmias.

Pacientes com doenças valvares que iniciarão um programa de RCV devem ser submetidos a um teste de esforço para avaliação e prescrição dos exercícios. A Tabela 9 resume as recomendações para pacientes assintomáticos, sem intervenção prévia, com doenças valvares moderadas ou importantes. Em geral, o treinamento será realizado com combinação dos exercícios aeróbicos e resistidos. Quando não houver restrições, as recomendações para prescrição de exercício serão as mesmas utilizadas para indivíduos sem cardiopatia.

Para pacientes sintomáticos, sem indicação de correção cirúrgica ou que não apresentam as características descritas na Tabela 9, a intensidade do exercício deve ser limitada, conforme a ocorrência de anormalidades observadas no teste de esforço, pois se assume que insultos repetidos nessa intensidade poderiam aumentar o risco dos exercícios e induzir, a longo prazo, potenciais efeitos deletérios na valvopatia. A prescrição de exercício deve ser limitada à intensidade de esforço equivalente a 10 bpm abaixo da FC em que ocorreu a anormalidade no teste de esforço. As cargas e a percepção subjetiva de esforço podem ser utilizadas em situações em que a FC não é um bom parâmetro de controle, como na fibrilação atrial ou em ritmos controlados pelo marcapasso artificial. (Tabela 10).

Em pacientes que foram submetidos à correção cirúrgica da valvopatia, os limites de intensidade da prescrição dependerão da doença de base, do resultado do procedimento, da presença de lesões residuais, da função ventricular e da resposta ao teste de exercício. Sendo assim, cada caso deve ser analisado individualmente e os limites definidos pela avaliação médica e pelos resultados dos exames complementares realizados.

\subsection{Portadores de Marcapasso cardíaco ou Cardioversor Desfibrilador Implantável}

Esta seção se destina às particularidades sobre os dispositivos implantáveis: marcapasso cardíaco (MP) e cardioversor desfibrilador implantável (CDI). O MP é indicado em função de anormalidades elétricas, que podem ser isolada (doença do nó sinusal, bloqueio atrioventricular (AV) de grau avançado) ou associada a cardiopatias estruturais. O CDI é 
Tabela 9 - Exercícios físicos em indivíduos assintomáticos com valvopatias

\begin{tabular}{|c|c|c|}
\hline Valvopatia & Exercício aeróbico & Exercício resistido \\
\hline Insuficiência aórtica & $\begin{array}{c}\text { Moderada ou importante } \\
\text { (função ventricular normal; } \\
\text { DSVE < } 50 \text { mm em homens ou }<40 \mathrm{~mm} \\
\text { em mulheres; } \\
\text { boa capacidade funcional) } \\
\text { Sem restrições }\end{array}$ & $\begin{array}{l}\text { Moderada ou importante } \\
\text { Evitar alta intensidade }\end{array}$ \\
\hline Estenose aórtica & $\begin{array}{c}\text { Moderada ou importante } \\
\text { (função ventricular normal; } \\
\text { boa capacidade funcional; } \\
\text { ausência de isquemia miocárdica, arritmia ventricular } \\
\text { complexa ou resposta em platô/queda da PAS) } \\
\text { Evitar alta intensidade }\end{array}$ & $\begin{array}{c}\text { Moderada } \\
\text { Evitar alta intesidade } \\
\text { Importante } \\
\text { Limitada a baixa intensidade para manutenção das } \\
\text { atividades cotidianas }\end{array}$ \\
\hline Insuficiência mitral & $\begin{array}{l}\text { Moderada ou importante } \\
\text { (boa função ventricular; } \\
\text { DDVE < } 60 \mathrm{~mm} \text {; } \\
\text { PSAP }<30 \mathrm{mmHg} \text { ) } \\
\text { Sem restrições }\end{array}$ & $\begin{array}{l}\text { Moderada ou importante } \\
\text { Evitar alta intensidade }\end{array}$ \\
\hline Estenose mitral & $\begin{array}{l}\text { Moderada ou importante } \\
\text { (boa capacidade funcional) } \\
\text { Evitar alta intensidade }\end{array}$ & $\begin{array}{l}\text { Moderada ou importante } \\
\text { (boa capacidade funcional) } \\
\text { Evitar alta intensidade }\end{array}$ \\
\hline
\end{tabular}

DDVE: diâmetro diastólico do ventrículo esquerdo; DSVE: diâmetro sistólico final do ventrículo esquerdo; PAS: pressão arterial sistólica; PSAP: pressão sistólica da artéria pulmonar.

Tabela 10 - Alterações no teste de exercício que indicam limites para prescrição de intensidade do treinamento em valvopatas

\begin{tabular}{|c|c|}
\hline Alterações induzidas pelo esforço & Detalhamento \\
\hline Sinais e sintomas & Início de angina, equivalente anginoso ou outros sinais/sintomas indicativos de intolerância ao exercício \\
\hline Pressão arterial & Início do comportamento em platô ou queda da PAS; ou PAS > 220 mmHg; ou PAD > 115 mmHg \\
\hline Segmento ST & Início do infradesnivelamento (horizontal ou descendente) do segmento ST superior a $1 \mathrm{~mm}$ \\
\hline Função ventricular & $\begin{array}{l}\text { Evidência de queda da função ventricular no esforço ou início de anormalidade moderada a importante da mobilidade } \\
\text { parietal do ventrículo esquerdo }\end{array}$ \\
\hline Pulso $\mathrm{O}_{2}$ no TCPE & Sinais de platô precoce ou queda no esforço, apesar do aumento da carga \\
\hline Arritmias & Bloqueio AV de graus 2 e 3 , fibrilação atrial, taquicardia supraventricular ou arritmia ventricular complexa \\
\hline
\end{tabular}

TCPE: teste cardiopulmonar de exercício; PAS: pressão arterial sistólica; PAD: pressão arterial diastólica, AV: atrioventricular.

indicado para a prevenção primária ou secundária de MS, em pacientes com doenças elétricas e/ou cardiopatias graves. Dependendo da cardiopatia presente, devem ser consideradas as recomendações sobre a RCV abordadas anteriormente.

Uma das preocupações nos exercícios físicos em portadores de MP ou CDI é relativa ao risco de complicações com o dispositivo, especialmente em atividades com chances de colisão corporal. Nos portadores de CDI, há o receio de choques, o que pode levar a modificações comportamentais nos pacientes, com redução da atividade física diária e participação em exercícios de moderada intensidade. ${ }^{335,336}$ Os profissionais de saúde também compartilham desses receios, ${ }^{337}$ o que pode reduzir as orientações para a prática de exercícios. Porém, tem sido demonstrado que o exercício físico é seguro e não está associado ao aumento do risco de choques ou de outros eventos adversos. ${ }^{338-342}$ Além disso, não têm sido observadas complicações relativas ao CDI, mesmo em atletas competitivos. ${ }^{343,344}$
Entretanto, é de fundamental importância, para a adequada liberação dos exercícios, que se conheçam o motivo do implante e os parâmetros de programação do dispositivo, que deverão ser investigados na avaliação pré-participação.

\subsubsection{Benefícios Terapêuticos dos Exercícios Físicos}

Uma meta-análise ${ }^{342}$ que englobou 14 estudos com um total de 2.681 pacientes portadores de CDI comprovou efeito benéfico do exercício físico na capacidade funcional desses indivíduos, com um aumento médio de $\mathrm{VO}_{2}$ de 2,4 ml. $\mathrm{kg}^{-1} \cdot \mathrm{min}^{-1}$. Em outra meta-análise, com cinco estudos randomizados e um não randomizado em pacientes com IC e CDI, ${ }^{341}$ o resultado na capacidade física foi semelhante, com aumento no $\mathrm{VO}_{2}$ pico de $1,98 \mathrm{ml} \cdot \mathrm{kg}^{-1} \cdot \mathrm{min}^{-1}$ em relação ao grupo controle.

Quanto às terapias por CDI e treinamento físico, uma das meta-análises não encontrou diferenças significativas. 
O percentual de choques associados aos exercício variou de 0 a 20\% entre os estudos, com uma média de 2,2\%, similar ao percentual de choques em um período de seguimento não relacionado ao exercício. ${ }^{342}$ Sendo assim, apesar dos receios previamente descritos, o treinamento físico não se associou a aumento dos choques pelo CDI e se mostrou seguro.

Outra meta-análise relatou menor probabilidade de choques ao longo do seguimento nos pacientes participantes da RCV em relação aos controles, corroborando o resultado anterior de um estudo observacional, que relatou maior incidência de choques pelo $\mathrm{CDI}$ em pacientes que não participavam de programas de RCV. ${ }^{341-345}$

Uma das possíveis explicações para a menor incidência de arritmias e choques nos pacientes em RCV seria a melhora da capacidade física, pois já foi previamente documentado que maior aptidão física está associada a menor incidência de arritmias. ${ }^{16,17,346}$ Além disso, os exercícios poderiam reduzir a arritmogenicidade miocárdica, em função do remodelamento e da menor excitabilidade simpática. ${ }^{347}$

Em um estudo nacional com 10 anos de acompanhamento, que contou com 150 pacientes com CDI em programa de RCV, submetidos a TCPE ou TE para prescrição do treinamento, ocorreram apenas três eventos de choques apropriados, o que reforça a segurança das avaliações e da RCV nesses indivíduos. ${ }^{348}$

\subsubsection{Quando Indicar Reabilitação Cardiovascular}

O exercício físico pode e deve ser indicado desde que a condição clínica do paciente seja estável e o tratamento clínico, otimizado. Além dos benefícios potenciais na cardiopatia de base, a RCV contribui para o aumento da capacidade física e pode atuar na redução das arritmias e nos choques pelo CDI (Tabela 11).

\subsubsection{Avaliação Pré-participação}

Nos portadores de dispositivos implantáveis há necessidade de conhecer o motivo do implante, a função ventricular, a presença de arritmias e, principalmente, os parâmetros de ajuste do dispositivo. Dentre os ajustes do MP, é importante saber o modo de programação, os limites programados de FC, o tipo e a adaptação do sensor de frequência. Nos pacientes com $\mathrm{CDI}$, é fundamental obter informações relativas às FC programadas para terapias de choque ou burst.

Além da avaliação clínica habitual, a avaliação ao esforço é de suma importância, sendo ideal a realização do TCPE ou TE para determinação da capacidade funcional e análise do comportamento do dispositivo em esforço. Entretanto, a impossibilidade de realização desses exames não deverá ser um fator limitante para a prática de exercícios. Nesses casos, o monitoramento das sessões poderá dar indícios da necessidade de adequações na programação do dispositivo, geralmente em relação aos ajustes da FC máxima programada e da resposta do sensor.

Durante as sessões da RCV, poderá ser utilizado o monitoramento eletrocardiográfico, que pode ser feito com o uso de sistemas de telemetria. Dispositivos para controle da FC, como os cardiofrequencímetros, também podem ser usados para monitoramento durante as sessões de RCV desses pacientes. ${ }^{350} \mathrm{Em}$ virtude das alterações do traçado, causadas pelo comando artificial, pode haver erro na determinação automática da FC, tanto pela análise eletrocardiográfica quanto pelos frequencímetros. Sendo assim, é importante atenção a esses possíveis erros, com verificação manual, se necessária.

\subsubsection{Particularidades na Prescrição e no Acompanhamento dos Exercícios Físicos}

Na prescrição e definição de limites de intensidade para o treinamento físico aeróbico, deve-se ter conhecimento da programação do CDI e limitar a intensidade a 10 a 20 bpm abaixo da FC programada para a terapêutica (choque ou burst). Esse cuidado é especialmente importante em indivíduos jovens, que podem ter FC elevada no treinamento. Em pacientes mais idosos, com IC e uso de altas doses de betabloqueadores, a FC pico observada no TE ou TCPE costuma estar abaixo da FC de terapia do CDI.

Os pacientes portadores de MP podem ter diferentes respostas cronotrópicas, observadas no TCPE ou TE, o que irá impactar na prescrição dos exercícios aeróbicos. Adicionalmente, o ritmo próprio do indivíduo, o tipo de MP e a presença de sensor influenciarão a resposta da FC ao esforço e, consequentemente, a prescrição. ${ }^{351}$

A seguir estão listados quatro tipos de possíveis respostas do MP ao esforço:

1) Resposta cronotrópica sinusal normal ou deprimida. MP sem atuação (inibido). A resposta cronotrópica em esforço é mediada pelo ritmo sinusal e pode estar normal ou deprimida (por doença do nó sinusal e/ou efeito medicamentoso). A condução ventricular ocorre pela via própria, e o MP não atua no esforço. Em alguns casos, ele pode atuar em repouso e em cargas iniciais, com comando atrial e/ou ventricular. Porém, no esforço,

Tabela 11 - Indicações de exercícios físicos e outros tratamentos em pacientes com cardiodesfibrilador implantável

\begin{tabular}{|c|c|c|}
\hline Indicação & Recomendação & Nível de evidência \\
\hline $\begin{array}{l}\text { Exercícios físicos para aumento de capacidade física em pacientes estáveis e } \\
\text { portadores de CDI }{ }^{341,342}\end{array}$ & I & A \\
\hline $\begin{array}{l}\text { Exercícios físicos para possível redução da probabilidade de choques em } \\
\text { pacientes portadores de CDI }{ }^{341}\end{array}$ & Ila & $B$ \\
\hline $\begin{array}{l}\text { Utilização de eletroestimulação neuromuscular em portadores de dispositivos com } \\
\text { sensores bipolares, quando realizada em musculaturas distantes do implante }{ }^{349}\end{array}$ & $\| \mathrm{lb}$ & B \\
\hline
\end{tabular}

CDI: cardioversor desfibrilador implantável. Considerar as recomendações em relação à cardiopatia estrutural, se presente. 
o MP se inibe, predominando as respostas sinusais e a condução ventricular pela via própria. Nesse tipo de resposta ao esforço, a prescrição de intensidade segue as rotinas habituais e não é influenciada pela presença do MP.

2) Resposta cronotrópica sinusal normal ou deprimida. MP com comando ventricular no esforço. A resposta cronotrópica em esforço é mediada pelo ritmo sinusal, que é percebida pelo MP com subsequente comando ventricular, de modo sincronizado e de acordo com os intervalos AV programados. Nesse caso, se a programação do limite máximo de resposta de FC do MP for adequada à resposta sinusal do paciente, não haverá problema para a prescrição de intensidade por FC, pois o ventrículo estará pareado com a atividade sinusal. Porém, se a FC máxima programada do MP for inferior à resposta sinusal do paciente, em moderada a alta carga haverá uma perda do pareamento da atividade ventricular com a sinusal. Então, o MP bloqueará alguns estímulos sinusais por meio de um Wenckebach mediado pelo dispositivo ou eletrônico, ${ }^{352}$ de modo a manter a FC ventricular dentro do limite programado, havendo um platô na resposta cronotrópica ao esforço. Nessas situações, a perda do pareamento do ritmo sinusal com a frequência ventricular limitará a utilização da FC para controle de intensidade. A prescrição deverá ser feita por cargas relativas e/ou sensação subjetiva de esforço.

No caso do Wenckebach eletrônico, é necessária a extrema atenção no TCPE ou TE, após iniciar a sua ocorrência. É fundamental ter a informação precisa de qual é a FC atrial em que o MP inicia o bloqueio 2:1, pois nela o comando ventricular será na proporção $2: 1$, podendo ocorrer queda súbita da FC em esforço, a qual pode ser sintomática, por redução abrupta do débito cardíaco. Sendo assim, a menos que as FC programadas de Wenckebach eletrônico e de bloqueio 2:1 sejam muito distantes, a FC do Wenckebach eletrônico poderá tornar-se um limite para o TCPE ou TE e para a prescrição dos exercícios.

Nesses casos, deve-se considerar e discutir com o médico assistente a reprogramação do MP, para melhor pareamento com a resposta sinusal do paciente. Outra opção, a depender do quadro clínico, é a otimização de medicações cronotrópicas negativas, como os betabloqueadores. Com isso, a menor resposta sinusal poderá evitar a ocorrência descrita.

3) Resposta cronotrópica mediada pelo MP e fixa, com ausência de sensor. Alguns pacientes podem não ter atividade sinusal, como na fibrilação atrial. Nesses casos, em indivíduos com bloqueio AV completo, haverá total dependência de comando ventricular pelo MP. Se não houver sensor, ou se este estiver desativado, haverá ausência de resposta cronotrópica ao esforço e o MP terá FC fixa. Esse tipo de MP ou programação é muito raro atualmente e tal resposta limita completamente a utilização da FC na prescrição, que deve se basear na determinação da intensidade por cargas e/ou pela sensação subjetiva do esforço.
4) Resposta cronotrópica mediada pelo MP com presença de sensor. Nos pacientes com fibrilação atrial e bloqueio $\mathrm{AV}$, conforme descrito anteriormente, mas com o sensor do MP presente e ativado, haverá dependência do comando ventricular, mas a ativação do sensor no esforço conduzirá a uma resposta cronotrópica mediada pelo MP. Em pacientes com ritmo sinusal, mas com grande déficit cronotrópico, por doença do nó sinusal e/ou efeito medicamentoso, poderá ocorrer resposta cronotrópica ao esforço também mediada pelo sensor do MP, com comando atrial seguido ou não de comando ventricular. A velocidade e magnitude da resposta do sensor ao esforço são programáveis, com possibilidades de ajustes do limiar da ativação do sensor, da velocidade de incremento da FC ao esforço e sua redução na recuperação, bem como do limite máximo da FC do sensor. Na realização do TCPE ou TE, poderá ser verificada a adequação da resposta, com identificação de possíveis necessidades de reprogramações do MP, que devem ser discutidas com o médico assistente.

Nesses casos, como a resposta cronotrópica será mediada artificialmente pelo dispositivo, a prescrição de intensidade de exercícios por FC poderá ser imprecisa. Sendo assim, a utilização das cargas relativas e/ou a percepção do esforço serão preferenciais.

Dispositivos com sensores do tipo acelerômetro e detecção do movimento axial, que são os mais usuais, têm boa resposta ao esforço na esteira, caminhada ou corrida. Porém, na bicicleta estacionária não há movimento vertical e o sensor não ativa ou é pouco ativado. Com isso, há menor resposta cronotrópica no ergômetro, que pode variar de acordo com a resposta individual do paciente.

\subsubsection{Treinamento Resistido}

A prática de exercícios resistidos é importante na RCV em diversas cardiopatias. Entretanto, após o implante do dispositivo, alguns cuidados são necessários até a completa cicatrização, a fim de evitar lesão vascular, deslocamento do gerador e fratura de eletrodos. Recomenda-se, por exemplo, cautela ao executar exercícios com pesos e elevação excessiva dos MMSS durante as primeiras seis semanas após o implante. Além disso, movimentos repetitivos e intensos com o membro relacionado ao implante do marcapasso devem ser evitados.

Entretanto, tais orientações estão mais ligadas a pacientes envolvidos com esportes, sendo improváveis no caso de exercícios realizados em centros de RCV. Em um estudo com mobilização precoce e supervisionada da cintura escapular após o implante imediato de MP, não foram observadas complicações ao dispositivo..$^{353}$

\subsubsection{Estimulação Elétrica Neuromuscular}

A utilização da eletroestimulação neuromuscular (ENM) em pacientes com IC tem sido difundida, principalmente naqueles impossibilitados de praticar exercícios físicos pela gravidade clínica. A ENM pode melhorar a capacidade aeróbica, a força muscular e a área transversa da musculatura do quadríceps, demonstrando ser uma efetiva opção de exercício passivo 
nessa população. ${ }^{354-356}$ Entretanto, também é crescente o uso de dispositivos eletrônicos nesses pacientes (CDI, MP e ressincronizadores), o que causa preocupação quanto ao uso da ENM, pela possibilidade de interferência eletromagnética.

Uma revisão sistemática ${ }^{349}$ demonstrou que a ENM na musculatura de quadríceps parece ser segura e viável em pacientes com IC e CDI com sensores bipolares. Entretanto, a própria revisão ressalta que o número de estudos e pacientes avaliados é muito pequeno para conclusões mais abrangentes e conclui que o uso pode ser feito se forem satisfeitas as seguintes condições:

1) Se os riscos individuais (dependência do MP, IC aguda, angina instável, arritmia ventricular nos últimos 3 meses) tiverem sido excluídos antes de iniciar a ENM.

2) Se o uso da ENM for realizado apenas nos músculos de quadríceps e glúteos.

3) Se o tratamento for regularmente supervisionado por um médico e o dispositivo for avaliado após o uso da ENM.

Portanto, no momento, apesar de parecer ser segura a utilização da ENM em portadores de dispositivos com sensores bipolares, quando realizada em musculaturas distantes do implante, ainda há necessidade de estudos com maior número de pacientes, para que haja possibilidade de uso amplo sem avaliação detalhada do dispositivo.

\subsection{Doença Arterial Obstrutiva Periférica}

O AVC tem sido justamente tratado como doença grave e de grande repercussão em saúde pública. Porém, outras doenças arteriais periféricas também são muito prevalentes e apresentam grande morbimortalidade, embora não tenham sido devidamente abordadas, prejudicando a prevenção, o diagnóstico e o efetivo tratamento. ${ }^{357,358}$ Nesse contexto, destaca-se a doença arterial obstrutiva periférica (DAOP) de MMII, que, em seu estágio mais grave, a isquemia crítica, apresenta elevado risco de eventos cardiovasculares, amputação de MMII e morte. A isquemia crítica dos MMII, com o crescimento de fatores de risco, tais como idade, diabetes e tabagismo, tem aumentado a sua prevalência e acomete, atualmente, cerca de 2 milhões de indivíduos somente nos EUA. ${ }^{359}$

A presença de DAOP é suspeitada quando há dor em MMII ao esforço, sem aparente etiologia ortopédica, e o índice tornozelo-braquial (ITB) é menor que 0,90 em repouso. ${ }^{360,361}$ O ITB tem sido recomendado como recurso diagnóstico a ser usado anteriormente à realização de métodos de imagem. ${ }^{362}$ Testes funcionais em esforço podem ser necessários para auxiliar no diagnóstico, especialmente quando o ITB for maior que 0,91 , e também para classificação funcional e prescrição de exercícios na RCV.

A caminhada pode ser avaliada por meio de testes de campo, que possibilitam o diagnóstico de claudicação intermitente, com determinação das distâncias percorridas para o início da sintomatologia (claudicação inicial) e para o surgimento da total limitação funcional (claudicação absoluta).

Em esteira, tem sido proposta a utilização diagnóstica de teste funcional em esforço, com medida do ITB em repouso e após exercício. A presença de DAOP é sugerida quando ocorre redução do ITB pós-exercício superior a 20\% em relação ao repouso, ou diminuição da pressão pós-exercício maior que $30 \mathrm{mmHg}$ em relação ao repouso. ${ }^{363}$ Outro estudo relatou notas de corte menores, sendo sugerida DAOP quando há redução do ITB pós-exercício acima de 18,5\% e diminuição da pressão pós-exercício maior que $15 \mathrm{mmHg}$. ${ }^{364}$

Considerando o risco cardiovascular global desses pacientes, o tratamento clínico otimizado deve sempre ser instituído. Além disso, a interrupção do tabagismo e a terapia farmacológica com estatinas e antiagregantes plaquetários devem ser consideradas, bem como o adequado controle glicêmico e pressórico. Em relação ao uso do Cilostazol, não há um consenso nas diretrizes de sociedades médicas. ${ }^{362,363}$

Em pacientes sintomáticos, os exercícios têm potencial para influenciar na morbimortalidade, com redução dos sintomas, melhora da qualidade de vida e aumento da distância máxima caminhada (Tabela 12). ${ }^{365}$ As atividades físicas realizadas sob supervisão direta têm se mostrado mais efetivas do que sem supervisão. ${ }^{366}$

Em 14 ensaios clínicos (1.002 participantes), com intervenção entre 6 semanas e 12 meses, a caminhada livre de dor aumentou cerca de 180 metros a mais no treinamento sob supervisão direta, quando comparado ao treinamento sob supervisão indireta. $\mathrm{O}$ treinamento físico tem se mostrado seguro. Na maioria dos estudos são realizados exercícios de caminhadas, com indução do sintoma de claudicação, em programas com duração mínima de 3 meses e, pelo menos, três sessões semanais. ${ }^{367}$

Nos paciente com DAOP, o treinamento sob supervisão direta tem sido superior em termos de custo-efetividade, ${ }^{368}$ embora aquele sob supervisão indireta (RCV domiciliar) tenha se mostrado uma boa alternativa, com efeitos positivos sobre a qualidade de vida e a tolerância à caminhada, sendo significativamente superior à mera recomendação para caminhar. ${ }^{369,370}$

Quando a caminhada não puder ser realizada, outros tipos de atividades, como ciclismo, exercícios resistidos e ergômetro

Tabela 12 - Tratamento da doença arterial obstrutiva periférica de membros inferiores

\begin{tabular}{|c|c|c|}
\hline Indicação & Recomendação & Nível de evidência \\
\hline $\begin{array}{l}\text { Exercício físico supervisionado para melhora funcional, da qualidade de vida } \\
\text { e redução da claudicação } 365,369,375,376\end{array}$ & I & $A$ \\
\hline $\begin{array}{l}\text { Exercício físico domiciliar ou outras modalidades de treinamento para } \\
\text { melhora funcional }{ }^{366,370,371}\end{array}$ & Ila & $A$ \\
\hline $\begin{array}{l}\text { Em pacientes sintomáticos, um programa de exercícios físicos supervisionados } \\
\text { deve ser discutido como opção de tratamento antes da revascularização }\end{array}$ & I & $B$ \\
\hline
\end{tabular}


de MMSS, têm se mostrado efetivos. ${ }^{371}$ Cabe ainda ressaltar que exercícios físicos não podem ser realizados por pacientes com isquemia crítica, mas devem ser considerados o mais breve possível após tratamento intervencionista com sucesso. ${ }^{371-373}$

Uma revisão sistemática de 12 ensaios clínicos, com um total de 1.548 pacientes, comparando os claudicantes em tratamento farmacológico (em treinamento físico), os com intervenção endovascular e os com cirurgia aberta, mostrou que todas as alternativas proporcionaram aumento da distância caminhada, redução de sintomas e melhora da qualidade de vida. ${ }^{374} \mathrm{~A}$ intervenção endovascular e a cirurgia aberta têm comprovadamente se mostrado eficazes para o alívio de sintomas, aumento da distância caminhada e melhora da qualidade de vida. Além disso, estão indicadas quando, após a realização do tratamento clínico pleno ou otimizado (exercícios físicos e tratamento farmacológico otimizado), persistirem sintomas graves que influenciem negativamente na vida diária.

Em um ensaio clínico randomizado com 111 pacientes com DAOP aortoilíaca e seguimento de 6 meses, foi evidenciado que o aumento do tempo de exercício no TE incremental foi maior no grupo que realizou exercícios supervisionados do que no que realizou revascularização com stent. ${ }^{375}$ Entretanto, após 18 meses de seguimento, os benefícios funcionais e na qualidade de vida foram equivalentes nos grupos com treinamento ou com revascularização e, em ambos os casos, foram superiores aos do grupo que realizou somente tratamento farmacológico. ${ }^{376}$

Vários ensaios clínicos compararam a eficácia e efetividade do exercício físico supervisionado, a angioplastia e o tratamento clínico otimizado, utilizando uma infinidade de desenhos diferentes. A maioria dos ensaios consistia em dois braços de tratamento. Revisões sistemáticas já citadas sugeriram que o exercício físico supervisionado pode ser superior ao tratamento farmacológico otimizado ou à angioplastia. Essas meta-análises, no entanto, incluíram estudos com comparações diretas entre dois braços de tratamento específicos (p. ex., angioplastia versus treinamento físico supervisionado) ou utilizaram uma abordagem que não permitia a inclusão e a comparação direta de todos os tratamentos disponíveis da claudicação intermitente. ${ }^{377}$

Por esses motivos, uma recente meta-análise buscou estabelecer todas as comparações entre os tratamentos disponíveis, no intuito de verificar a melhor conduta no manejo do paciente com DAOP sintomática. Foram incluídos 2.983 pacientes com claudicação intermitente (média de idade de 68 anos e 54,5\% de homens). As comparações foram realizadas entre tratamento clínico otimizado $(n=688)$, treinamento físico supervisionado $(n=1.189)$, angioplastia ( $n=511$ ) e angioplastia mais treinamento físico supervisionado $(n=395)$. O seguimento médio foi de 12 meses. Comparados ao tratamento medicamentoso otimizado isoladamente, a angioplastia e o treinamento físico supervisionado superaram todas as outras estratégias terapêuticas, havendo ganho de distância máxima de caminhada de 290 m (IC 95\%: 180 a $390 \mathrm{~m} ; \mathrm{p}<0,001)$ ou ganho proporcional de 141\% (IC 95\%: 86,85 a 188,3\%; p < 0,001), com período médio de acompanhamento de 12 meses. ${ }^{378}$

O treinamento físico supervisionado isoladamente e a angioplastia associada ao treinamento físico supervisionado novamente superaram as demais modalidades de tratamento, com ganho de distância máxima de caminhada de $110 \mathrm{~m}$ (IC 95\%: 16 a 200 m; p < 0,001) ou incremento proporcional de 66\% (IC 95\%: 9,66 a 121\%; p < 0,001). O treinamento físico supervisionado, com aumento de distância máxima de caminhada de 180 m (IC 95\%: 130 a 230 m) e ganho proporcional de 87\% (IC 95\%: 63 a 111\%) foi superior à angioplastia isolada, mas inferior ao treinamento físico supervisionado associado à angioplastia, no quesito distância máxima de caminhada. ${ }^{378}$

Esses estudos de revisão têm implicações importantes para a prática clínica. Isso porque todos os pacientes com claudicação intermitente devem receber tratamento clínico otimizado, tendo em vista as evidências que demonstram redução de eventos cardiovasculares futuros e melhora de desfechos relacionados aos membros. ${ }^{379,380}$ Nesse contexto, o treinamento físico supervisionado e a angioplastia são fundamentais para melhorar a distância de caminhada e a qualidade de vida. Essa recente meta-análise citada sugere fortemente que o treinamento físico supervisionado, associado à angioplastia, deve fazer parte do tratamento de primeira linha, sempre no contexto da terapia medicamentosa otimizada. A oferta de angioplastia sem treinamento físico otimizado deve ser evitada sempre que possível. ${ }^{378}$ Porém, frequentemente, os centros de tratamento da DAOP oferecem primeiramente a angioplastia, devido à carência de centros voltados ao treinamento físico supervisionado. Não se pode negligenciar que o treinamento físico supervisionado enfrenta resistência por parte do próprio paciente, provocando pouca adesão ao tratamento, o que justifica, em parte, a conduta majoritária pelo tratamento percutâneo. ${ }^{381}$

Entretanto, esses estudos recentes, que investigaram as modalidades de tratamento da DAOP sintomática com treinamento físico isolado ou associado à angioplastia, têm demonstrando os benefícios da combinação dos tratamentos, o que pode aumentar a probabilidade de que a RCV se torne cada vez mais difundida e acessível. ${ }^{378,382}$

Sendo assim, além do tratamento clínico otimizado, a angioplastia combinada ao treinamento físico supervisionado parece ser a estratégia ideal para tratamento inicial dos pacientes com claudicação intermitente, tanto para melhorar a máxima distância de caminhada, como para a qualidade de vida. No entanto, os dados dessas últimas revisões são incapazes de afirmar se primeiramente deve ser proposto o treinamento físico supervisionado e, posteriormente, a angioplastia, ou vice-versa. 


\section{Referências}

1. Anderson L, Oldridge N, Thompson DR, Zwisler AD, Rees K, Martin N, et al. Exercise-Based Cardiac Rehabilitation for Coronary Heart Disease: Cochrane Systematic Review and Meta-Analysis. J Am Coll Cardiol. 2016;67(1):1-12.

2. Taylor RS, Sagar VA, Davies EJ, Briscoe S, Coats AJ, Dalal H, et al. Exercisebased rehabilitation for heart failure. Cochrane Database Syst Rev. 2014(4):CD003331.

3. Piepoli MF, Hoes AW, Agewall S, Albus C, Brotons C, Catapano AL, et al. 2016 European Guidelines on cardiovascular disease prevention in clinical practice: The Sixth Joint Task Force of the European Society of Cardiology and Other Societies on Cardiovascular Disease Prevention in Clinical Practice (constituted by representatives of 10 societies and by invited experts)Developed with the special contribution of the European Association for Cardiovascular Prevention \& Rehabilitation (EACPR). Eur Heart J. 2016;37(29):2315-81.

4. Fletcher GF, Ades PA, Kligfield P, Arena R, Balady GJ, Bittner VA, et al. Exercise standards for testing and training: a scientific statement from the American Heart Association. Circulation. 2013;128(8):873-934.

5. Task Force M, Montalescot G, Sechtem U, Achenbach S, Andreotti F, Arden C, et al. 2013 ESC guidelines on the management of stable coronary artery disease: the Task Force on the management of stable coronary artery disease of the European Society of Cardiology. Eur Heart J. 2013;34(38):2949-3003.

6. Herdy AH, Lopez-Jimenez F, Terzic CP, Milani M, Stein R, Carvalho T, et al. Consenso Sul-Americano de Prevenção e Reabilitação Cardiovascular. Arq Bras Cardiol. 2014;103(2 Suppl 1):1-31.

7. Ding D. Surveillance of global physical activity: progress, evidence, and future directions. Lancet Glob Health. 2018;6(10):e1046-e7.

8. Guthold R, Stevens GA, Riley LM, Bull FC. Worldwide trends in insufficient physical activity from 2001 to 2016: a pooled analysis of 358 populationbased surveys with 1.9 million participants. Lancet Glob Health. 2018;6(10):e1077-e86.

9. Powell KE, Paluch AE, Blair SN. Physical activity for health: What kind? How much? How intense? On top of what? Annu Rev Public Health. 2011;32:349-65.

10. Arem H, Moore SC, Patel A, Hartge P, Berrington de Gonzalez A, Visvanathan K, et al. Leisure time physical activity and mortality: a detailed pooled analysis of the dose-response relationship. JAMA Intern Med. 2015;175(6):959-67.

11. De Ferrari GM, Dusi V, Ruffinazzi M, Gionti V, Cacciavillani L, Noussan P, et al. Physical Inactivity Is a Risk Factor for Primary Ventricular Fibrillatton. JACC. 2019;73(16):2117-18.

12. Saint-Maurice PF, Coughlan D, Kelly SP, Keadle SK, Cook MB, Carlson SA, et al. Association of Leisure-Time Physical Activity Across the Adult Life Course With All-Cause and Cause-Specific Mortality. JAMA Netw Open. 2019;2(3):e190355.

13. Stamatakis E, Gale J, Bauman A, Ekelund U, Hamer M, Ding D. Sitting Time, Physical Activity, and Risk os Mortality in Adults. JAAC. 2019;73(16):2062-72.

14. Brito LB, Ricardo DR, Araujo DS, Ramos PS, Myers J, Araujo CG. Ability to sit and rise from the floor as a predictor of all-cause mortality. Eur J Prev Cardiol. 2014;21(7):892-8.

15. Kokkinos P, Myers J, Faselis C, Panagiotakos DB, Doumas M, Pittaras A, et al. Exercise capacity and mortality in older men: a 20-year follow-up study. Circulation. 2010;122(8):790-7.

16. Laukkanen JA, Kujala UM. Low Cardiorespiratory Fitness Is a Risk Factor for Death: Exercise Intervention May Lower Mortality? J Am Coll Cardiol. 2018;72(19):2293-6.
17. Laukkanen JA, Makikallio TH, Rauramaa R, Kiviniemi V, Ronkainen $\mathrm{K}, \mathrm{Kurl} \mathrm{S}$. Cardiorespiratory fitness is related to the risk of sudden cardiac death: a population-based follow-up study. J Am Coll Cardiol. 2010;56(18):1476-83.

18. Metter EJ, Talbot LA, Schrager M, Conwit RA. Arm-cranking muscle power and arm isometric muscle strength are independent predictors of all-cause mortality in men. J Appl Physiol (1985). 2004;96(2):814-21.

19. Myers J, Prakash M, Froelicher V, Do D, Partington S, Atwood JE. Exercise capacity and mortality among men referred for exercise testing. N Engl J Med. 2002;346(11):793-801.

20. Blair SN, Kohl HW, 3rd, Barlow CE, Paffenbarger RS, Jr., Gibbons LW, Macera CA. Changes in physical fitness and all-cause mortality. A prospective study of healthy and unhealthy men. JAMA. 1995;273(14):1093-8.

21. Eriksson JG, Kajantie E, Lampl M, Osmond C, Barker DJ. Markers of biological fitness as predictors of all-cause mortality. Ann Med. 2013;45(2):156-61.

22. Alter DA, Yu B, Bajaj RR, Oh PI. Relationship Between Cardiac Rehabilitation Participation and Health Service Expenditures Within a Universal Health Care System. Mayo Clin Proc. 2017.

23. Papadakis S, Oldridge NB, Coyle D, Mayhew A, Reid RD, Beaton L, et al. Economic evaluation of cardiac rehabilitation: a systematic review. Eur J Cardiovasc Prev Rehabil. 2005;12(6):513-20.

24. Murray J, Craigs CL, Hill KM, Honey S, House A. A systematic review of patient reported factors associated with uptake and completion of cardiovascular lifestyle behaviour change. BMC Cardiovasc Disord. $2012 ; 12: 120$.

25. Herber OR, Smith K, White M, Jones MC. 'Just not for me' - contributing factors to nonattendance/noncompletion at phase III cardiac rehabilitation in acute coronary syndrome patients: a qualitative enquiry. J Clin Nurs. 2017;26(21-22):3529-42.

26. de Melo Ghisi GL, Oh P, Benetti M, Grace SL. Barriers to cardiac rehabilitation use in Canada versus Brazil. J Cardiopulm Rehabil Prev. 2013;33(3):173-9.

27. Ghisi GL, dos Santos RZ, Aranha EE, Nunes AD, Oh P, Benetti M, et al. Perceptions of barriers to cardiac rehabilitation use in Brazil. Vasc Health Risk Manag. 2013;9:485-91.

28. Godoy M. I Consenso Nacional de Reabilitação Cardiovascular. Arq Bras Cardiol. 1997;69(4):267-91.

29. Araujo CG, Carvalho T, Castro CL, Costa RV, Moraes RS, Oliveira Filho JA, et al. Normatização dos Equipamentos e Técnicas da Reabilitação Cardiovascular Supervisionada. Arq Bras Cardiol. 2004;83(5):448-52.

30. Moraes RS, Nobrega AC, Castro RRT, Negrão CE, Stein R, Serra SM, et al. Diretriz de Reabilitação Cardíaca. Arq Bras Cardiol. 2005;84(5):431-40.

31. Carvalho T, Cortez AA, Ferraz A, Nóbrega ACL, Brunetto AF, Herdy AH, et al. Diretriz de Reabilitação cardiopulmonar e meatabólica: aspectos práticos e responsabilidades. Arq Bras Cardiol. 2006;86(1):74-82.

32. Balady GJ, Williams MA, Ades PA, Bittner V, Comoss P, Foody JM, et al. Core components of cardiac rehabilitation/secondary prevention programs: 2007 update: a scientific statement from the American Heart Association Exercise, Cardiac Rehabilitation, and Prevention Committee, the Council on Clinical Cardiology; the Councils on Cardiovascular Nursing, Epidemiology and Prevention, and Nutrition, Physical Activity, and Metabolism; and the American Association of Cardiovascular and Pulmonary Rehabilitation. Circulation. 2007;115(20):2675-82.

33. King M, Bittner V, Josephson R, Lui K, Thomas RJ, Williams MA. Medical director responsibilities for outpatient cardiac rehabilitation/ secondary prevention programs: 2012 update: a statement for health 
care professionals from the American Association of Cardiovascular and Pulmonary Rehabilitation and the American Heart Association. Circulation. 2012;126(21):2535-43.

34. Hamm LF, Sanderson BK, Ades PA, Berra K, Kaminsky LA, Roitman JL, et al. Core competencies for cardiac rehabilitation/secondary prevention professionals: 2010 update: position statement of the American Association of Cardiovascular and Pulmonary Rehabilitation. J Cardiopulm Rehabil Prev. 2011;31(1):2-10.

35. Gonzalez MM, Timerman S, Gianotto-Oliveira R, Polastri TF, Canesin MF, Schimidt A, et al. I Diretriz de Ressuscitação Cardiopulmonar e Cuidados Cardiovasculares de Emergência da Sociedade Brasileira de Cardiologia. Arq Bras Cardiol. 2013;101(2 Suppl 3):1-221.

36. Bernoche C, Timerman S, Polastri TF, Giannetti NS, Siqueira AWS, Piscopo A, et al. Atualização da Diretriz de Ressuscitação Cardiopulmonar e Cuidados Cardiovasculares de Emergência da Sociedade Brasileira de Cardiologia - 2019. Arq Bras Cardiol. 2019;113(3):449-663.

37. Medicine ACoS. ACSM's Guidelines for Exercise Testing and Prescription. 10th ed. Philadelphia: Lippincott Williams \& Wilkins; 2017.

38. Xu K, Soucat A, Kutzin I, Brindley C, Maele NV, Toure H, et al. Public Spending on Health: A Closer Look at Global Trends: Geneva: World Health Organization; 2018.

39. Benjamin EJ, Blaha MJ, Chiuve SE, Cushman M, Das SR, Deo R, et al. Heart Disease and Stroke Statistics-2017 Update: A Report From the American Heart Association. Circulation. 2017;135(10):e146-e603.

40. Siqueira ASE, Siqueira-Filho AG, Land MGP. Análise do Impacto Econômico das Doenças Cardiovasculares nos Últimos Cinco Anos no Brasil. Arq Bras Cardiol. 2017;109(1):39-46.

41. Brasil.Ministério da Saúde. Datasus. Sistema de informações hospitalares. Internações e valor total de internações segundo capítulo CID-10. Brasilia;2018.

42. Duncan BB, Stevens A, Schmidt MI. Mortalidade por doenças crônicas no Brasil: situação em 2010 e tendências de 1991 a 2010. 2012. In: Brasil. Ministério da Saúde Saúde Brasil 2011: uma análise da situação de saúde e a vigilância da saúde da mulher. Brasilia; 2018.

43. Marques LP, Confortin SC. Doenças do Aparelho Circulatório: Principal Causa de Internações de Idosos no Brasil entre 2003 e 2012. Rev Bras Ciênc Saúde.2015;16(4):567-75.

44. Soto PHT, Raitz GM, Bolsoni LL, Costa CKF, Yamaguchi MU, Massuda EM Morbidades e custos hospitalares do Sistema Único de Saúde para doenças crônicas. Rev Rene. 2015;16(4):567-75

45. Global Burden of Disease Study. Global, regional, and national incidence, prevalence, and years lived with disability for 301 acute and chronic diseases and injuries in 188 countries, 1990-2013: a systematic analysis for the Global Burden of Disease Study 2013. Lancet. 2015;386(9995):743-800.

46. Moghei M, Turk-Adawi K, Isaranuwatchai W, Sarrafzadegan N, Oh P, Chessex C, et al. Cardiac rehabilitation costs. Int J Cardiol. 2017:244:322-8.

47. Turk-Adawi K, Sarrafzadegan N, Grace SL. Global availability of cardiac rehabilitation. Nat Rev Cardiol. 2014:11(10):586-96.

48. Bailly L, Mosse P, Diagana S, Fournier M, d'Arripe-Longueville F, Diagana $\mathrm{O}$, et al. "As du Coeur" study: a randomized controlled trial on quality of life impact and cost effectiveness of a physical activity program in patients with cardiovascular disease. BMC Cardiovasc Disord. 2018;18(1):225.

49. Rebelo FP, Garcia Ados S, Andrade DF, Werner CR, Carvalho T. Resultado clínico e econômico de um programa de reabilitação cardiopulmonar e metabólica. Arq Bras Cardiol. 2007;88(3):321-8.

50. Edwards K, Jones N, Newton J, Foster C, Judge A, Jackson K, et al. The costeffectiveness of exercise-based cardiac rehabilitation: a systematic review of the characteristics and methodological quality of published literature. Health Econ Rev. 2017:7(1):37.
51. Brasil. Ministério da Saúde. Avaliação econômica em saúde: desafios para a gestão no Sistema Único de Saúde. 2008. Brasília;2018.

52. Secoli SR, Eidi Nita M, Ono-Nita SK, Nobre M. Avaliação de tecnologia em saúde. II. A análise de custo-efetividade. Arq Gastroenterol. 2010;47(4):329-33

53. Georgiou D, Chen Y, Appadoo S, Belardinelli R, Greene R, Parides MK, et al. Cost-effectiveness analysis of long-term moderate exercise training in chronic heart failure. Am J Cardiol. 2001;87(8):984-8; A4 .

54. Shields GE, Wells A, Doherty P, Heagerty A, Buck D, Davies LM. Costeffectiveness of cardiac rehabilitation: a systematic review. Heart. 2018;104(17):1403-10

55. Hearts: technical package for cardiovascular disease management in primary health care.: Geneva: World Health Organization; 2016

56. Oldridge NB, Pakosh MT, Thomas RJ. Cardiac rehabilitation in low- and middle-income countries: a review on cost and cost-effectiveness. Int Health. 2016;8(2):77-82.

57. Kuhr EM, Ribeiro RA, Rohde LE, Polanczyk CA. Cost-effectiveness of supervised exercise therapy in heart failure patients. Value Health. 2011;14(5 Suppl 1):S100-7.

58. Kotseva K, Ryden L, De Backer G, De Bacquer D, Wood D. EURObservational research programme: EUROASPIRE. Eur Heart J. 2015;36(16):950-1.

59. Wenger NK. Current status of cardiac rehabilitation. J Am Coll Cardiol. 2008;51(17):1619-31.

60. Ades PA, Pashkow FJ, Fletcher G, Pina IL, Zohman LR, Nestor JR. A controlled trial of cardiac rehabilitation in the home setting using electrocardiographic and voice transtelephonic monitoring. Am Heart J. 2000;139(3):543-8.

61. Anderson L, Sharp GA, Norton RJ, Dalal H, Dean SG, Jolly K, et al. Homebased versus centre-based cardiac rehabilitation. Cochrane Database Syst Rev. 2017;6:CD007130

62. Jolly K, Taylor R, Lip GY, Greenfield S, Raftery J, Mant J, et al. The Birmingham Rehabilitation Uptake Maximisation Study (BRUM). Homebased compared with hospital-based cardiac rehabilitation in a multiethnic population: cost-effectiveness and patient adherence. Health Technol Assess. 2007;11(35):1-118.

63. Dalal HM, Zawada A, Jolly K, Moxham T, Taylor RS. Home based versus centre based cardiac rehabilitation: Cochrane systematic review and meta-analysis. BMJ. 2010;340:b5631.

64. Kraal JJ, Van den Akker-Van Marle ME, Abu-Hanna A, Stut W, Peek N, Kemps HM. Clinical and cost-effectiveness of home-based cardiac rehabilitation compared to conventional, centre-based cardiac rehabilitation: Results of the FIT@Home study. Eur J Prev Cardiol. 2017;24(12):1260-73.

65. Lear SA, Singer J, Banner-Lukaris D, Horvat D, Park JE, Bates J, et al. Randomized trial of a virtual cardiac rehabilitation program delivered at a distance via the Internet. Circ Cardiovasc Qual Outcomes. 2014;7(6):952-9

66. Milewski K, Malecki A, Orszulik-Baron D, Kachel M, Hirnle P, Orczyk $\mathrm{M}$, et al. The use of modern telemedicine technologies in an innovative optimal cardiac rehabilitation program for patients after myocardia revascularization: Concept and design of RESTORE, a randomized clinical trial. Cardiol J. 2019:26(5):594-603

67. National Audit of Cardiac Rehabilitation (NACR) Quality and Outcomes Report 2018: New york: The British Heart Foundation; 2018.

68. Endo N, Goto A, Suzuki T, Matsuda S, Yasumura S. Factors associated with enrollment and adherence in outpatient cardiac rehabilitation in Japan. Cardiopulm Rehabil Prev. 2015;35(3):186-92.

69. Phillips LM, Hachamovitch R, Berman DS, Iskandrian AE, Min JK, Picard $\mathrm{MH}$, et al. Lessons learned from MPI and physiologic testing in randomized trials of stable ischemic heart disease: COURAGE, BARI 2D, FAME, and ISCHEMIA. J Nucl Cardiol. 2013;20(6):969-75. 
70. Al-Lamee R, Thompson D, Dehbi HM, Sen S, Tang K, Davies J, et al. Percutaneous coronary intervention in stable angina (ORBITA): a doubleblind, randomised controlled trial. Lancet. 2018;391(10115):31-40.

71. Smith SC Jr., Benjamin EJ, Bonow RO, Braun LT, Creager MA, Franklin BA, et al. AHA/ACCF Secondary Prevention and Risk Reduction Therapy for Patients with Coronary and other Atherosclerotic Vascular Disease: 2011 update: a guideline from the American Heart Association and American College of Cardiology Foundation. Circulation. 2011;124(22):2458-73.

72. Malachias MVB, Paulo Cesar Veiga Jardim PCVJ, Almeida FA, Lima EJ, Feitosa GS. VII Diretriz Brasileira de Hipertensão Arterial. Arq Bras Cardiol. 2016;107(3 Suppl 3):35-43.

73. Williams B, Mancia G, Spiering W, Agabiti Rosei E, Azizi M, Burnier M, et al. 2018 ESC/ESH Guidelines for the management of arterial hypertension. Eur Heart J. 2018;39(33):3021-104.

74. Belsey J, Savelieva I, Mugelli A, Camm AJ. Relative efficacy of antianginal drugs used as add-on therapy in patients with stable angina: A systematic review and meta-analysis. Eur J Prev Cardiol. 2015;22(7):837-48.

75. Marazia S, Urso L, Contini M, Pano M, Zaccaria S, Lenti V, et al. The Role of Ivabradine in Cardiac Rehabilitation in Patients With Recent Coronary Artery Bypass Graft. J Cardiovasc Pharmacol Ther. 2015;20(6):547-53.

76. Patterson R, McNamara E, Tainio M, de Sa TH, Smith AD, Sharp SJ, et al. Sedentary behaviour and risk of all-cause, cardiovascular and cancer mortality, and incident type 2 diabetes: a systematic review and dose response meta-analysis. Eur J Epidemiol. 2018;33(9):811-29.

77. Arnett DK, Blumenthal RS, Albert MA, Buroker AB, Goldberger ZD, Hahn EJ, et al. 2019 ACC/AHA Guideline on the Primary Prevention of Cardiovascular Disease. Circulation. 2019;140(11):e596-e646.

78. Ekelund U, Steene-Johannessen J, Brown WJ, Fagerland MW, Owen $\mathrm{N}$, Powell KE, et al. Does physical activity attenuate, or even eliminate, the detrimental association of sitting time with mortality? A harmonised meta-analysis of data from more than 1 million men and women. Lancet. 2016;388(10051):1302-10.

79. Hamer M, Chida Y. Walking and primary prevention: a meta-analysis of prospective cohort studies. Br J Sports Med. 2008;42(4):238-43.

80. Kyu HH, Bachman VF, Alexander LT, Mumford JE, Afshin A, Estep K, et al. Physical activity and risk of breast cancer, colon cancer, diabetes, ischemic heart disease, and ischemic stroke events: systematic review and doseresponse meta-analysis for the Global Burden of Disease Study 2013. BMJ. 2016;354:i3857.

81. Sattelmair J, Pertman J, Ding EL, Kohl HW 3rd, Haskell W, Lee IM. Dose response between physical activity and risk of coronary heart disease: a meta-analysis. Circulation. 2011;124(7):789-95.

82. Zheng H, Orsini N, Amin J, Wolk A, Nguyen VT, Ehrlich F. Quantifying the dose-response of walking in reducing coronary heart disease risk: metaanalysis. Eur J Epidemiol. 2009;24(4):181-92.

83. Wahid A, Manek N, Nichols M, Kelly P, Foster C, Webster P, et al. Quantifying the Association Between Physical Activity and Cardiovascular Disease and Diabetes: A Systematic Review and Meta-Analysis. J Am Heart Assoc. 2016;5(9):pii e002495.

84. Hambrecht R, Niebauer J, Marburger C, Grunze M, Kalberer B, Hauer $\mathrm{K}$, et al. Various intensities of leisure time physical activity in patients with coronary artery disease: effects on cardiorespiratory fitness and progression of coronary atherosclerotic lesions. J Am Coll Cardiol. 1993;22(2):468-77.

85. Carvalho T, Gonzales AI, Sties SW, Carvalho GM. Cardiovascular rehabilitation, ballroom dancing and sexual dysfunction. Arq Bras Cardiol. 2013;101(6):e107-8

86. Nery RM, Zanini M, de Lima JB, Buhler RP, da Silveira AD, Stein R. Tai Chi Chuan improves functional capacity after myocardial infarction: A randomized clinical trial. Am Heart J. 2015;169(6):854-60.
87. Nishijuka FA, Silva C, Duarte CV, Araujo CGS. Pre-Participation Physical Fitness does not Influence Adherence to a Supervised Exercise Program. Arq Bras Cardiol. 2017;109(4):340-7.

88. Stein R, Sardinha A, Araujo CG. Sexual Activity and Heart Patients: A Contemporary Perspective. Can J Cardiol. 2016;32(4):410-20.

89. NCD Risk Factors Collaboration (NCD-RisC). Contributions of mean and shape of blood pressure distribution to worldwide trends and variations in raised blood pressure: a pooled analysis of 1018 population-based measurement studies with 88.6 million participants. Int J Epidemiol. 2018 Mar 19; [ahead of print]

90. NCD Risk Factors Collaboration (NCD-RisC). Worldwide trends in blood pressure from 1975 to 2015: a pooled analysis of 1479 populationbased measurement studies with 19.1 million participants. Lancet. 2017;389(10064):37-55

91. Aronow WS, Fleg JL, Pepine CJ, Artinian NT, Bakris G, Brown AS, et al. ACCF/AHA 2011 expert consensus document on hypertension in the elderly: a report of the American College of Cardiology Foundation Task Force on Clinical Expert Consensus documents developed in collaboration with the American Academy of Neurology, American Geriatrics Society, American Society for Preventive Cardiology, American Society of Hypertension, American Society of Nephrology, Association of Black Cardiologists, and European Society of Hypertension. J Am Coll Cardiol. 2011;57(20):2037-114

92. Masson GS, Michelini LC. Autonomic Dysfunction, Sympathetic Hyperactivity and the Development of End-Organ Damage in Hypertension: Multiple Benefits of Exercise Training. Heart Res Open J. 2015;2(2):60-9.

93. Herrod PJJ, Doleman B, Blackwell JEM, O'Boyle F, Williams JP, Lund JN, et al. Exercise and other nonpharmacological strategies to reduce blood pressure in older adults: a systematic review and meta-analysis. J Am Soc Hypertens. 2018;12(4):248-67.

94. Jordao MT, Ladd FV, Coppi AA, Chopard RP, Michelini LC. Exercise training restores hypertension-induced changes in the elastic tissue of the thoracic aorta. J Vasc Res. 2011;48(6):513-24.

95. Dharmashankar K, Widlansky ME. Vascular endothelial function and hypertension: insights and directions. Curr Hypertens Rep. 2010;12(6):448-55

96. Neves JA, Neves JA, Oliveira RCM. Biomarcadores de função endotelial em doenças cardiovasculares: hipertensão. J Vasc Bras. 2016;15(3):224-33.

97. Jasperse JL, Laughlin $\mathrm{MH}$. Endothelial function and exercise training: evidence from studies using animal models. Med Sci Sports Exerc. 2006;38(3):445-54

98. Park SK, La Salle DT, Cerbie J, Cho JM, Bledsoe A, Nelson A, et al. Elevated arterial shear rate increases indexes of endothelial cell autophagy and nitric oxide synthase activation in humans. Am J Physiol Heart Circ Physiol. 2019;316(1):H106-H12.

99. Black JM, Stohr EJ, Shave R, Esformes JI. Influence of exercise training mode on arterial diameter: A systematic review and meta-analysis. J Sci Med Sport. 2016;19(1):74-80.

100. Tanahashi K, Kosaki K, Sawano Y, Yoshikawa T, Tagawa K, Kumagai H, et al. Impact of Age and Aerobic Exercise Training on Conduit Artery Wall Thickness: Role of the Shear Pattern. J Vasc Res. 2017;54(5):272-9.

101. Pescatello LS, MacDonald HV, Ash GI, Lamberti LM, Farquhar WB, Arena $\mathrm{R}$, et al. Assessing the Existing Professional Exercise Recommendations for Hypertension: A Review and Recommendations for Future Research Priorities. Mayo Clin Proc. 2015;90(6):801-12.

102. Naci H, Salcher-Konrad M, Dias S, Blum MR, Sahoo SA, Nunan D, et al. How does exercise treatment compare with antihypertensive medications? A network meta-analysis of 391 randomised controlled trials assessing exercise and medication effects on systolic blood pressure. $\mathrm{Br}$ J Sports Med. 2019;53(14):859-69 
103. Cornelissen VA, Smart NA. Exercise training for blood pressure: a systematic review and meta-analysis. J Am Heart Assoc. 2013;2(1):e004473.

104. Gomes MFP, Borges ME, Rossi VA, Moura EOC, Medeiros A. The Effect of Physical Resistance Training on Baroreflex Sensitivity of Hypertensive Rats. Arq Bras Cardiol. 2017;108(6):539-45.

105. Millar PJ, Levy AS, McGowan CL, McCartney N, MacDonald MJ. Isometric handgrip training lowers blood pressure and increases heart rate complexity in medicated hypertensive patients. Scand J Med Sci Sports. 2013;23(5):620-6

106. Lawrence MM, Cooley ID, Huet YM, Arthur ST, Howden R. Factors influencing isometric exercise training-induced reductions in resting blood pressure. Scand J Med Sci Sports. 2015;25(2):131-42.

107. Farah BQ, Germano-Soares AH, Rodrigues SLC, Santos CX, Barbosa SS, Vianna LC, et al. Acute and Chronic Effects of Isometric Handgrip Exercise on Cardiovascular Variables in Hypertensive Patients: A Systematic Review. Sports (Basel). 2017Aug;5(3).pii E-55.

108. Inder JD, Carlson DJ, Dieberg G, McFarlane JR, Hess NC, Smart NA. Isometric exercise training for blood pressure management: a systematic review and meta-analysis to optimize benefit. Hypertens Res. 2016;39(2):88-94

109. Leary AC, Donnan PT, MacDonald TM, Murphy MB. The influence of physical activity on the variability of ambulatory blood pressure. Am J Hypertens. 2000;13(10):1067-73.

110. Liu J, Sui X, Lavie CJ, Zhou H, Park YM, Cai B, et al. Effects of cardiorespiratory fitness on blood pressure trajectory with aging in a cohort of healthy men. J Am Coll Cardiol. 2014;64(12):1245-53.

111. Fagard RH. Physical activity, physical fitness and the incidence of hypertension. J Hypertens. 2005;23(2):265-7.

112. Pescatello LS, Buchner DM, Jakicic JM, Powell KE, Kraus WE, Bloodgood B, et al. Physical Activity to Prevent and Treat Hypertension: A Systematic Review. Med Sci Sports Exerc. 2019;51(6):1314-23.

113. Dunn AL, Marcus BH, Kampert JB, Garcia ME, Kohl HW 3rd, Blair $\mathrm{SN}$. Comparison of lifestyle and structured interventions to increase physical activity and cardiorespiratory fitness: a randomized trial. JAMA. 1999;281(4):327-34.

114. Blair SN. Physical inactivity: the biggest public health problem of the 21st century. Br J Sports Med. 2009;43(1):1-2.

115. Lee IM, Shiroma EJ, Lobelo F, Puska P, Blair SN, Katzmarzyk PT, et al. Effect of physical inactivity on major non-communicable diseases worldwide: an analysis of burden of disease and life expectancy. Lancet. 2012:380(9838):219-29

116. Katzmarzyk PT, Church TS, Craig CL, Bouchard C. Sitting time and mortality from all causes, cardiovascular disease, and cancer. Med Sci Sports Exerc. 2009;41(5):998-1005.

117. Thorp AA, Healy GN, Owen N, Salmon J, Ball K, Shaw JE, et al. Deleterious associations of sitting time and television viewing time with cardiometabolic risk biomarkers: Australian Diabetes, Obesity and Lifestyle (AusDiab) study 2004-2005. Diabetes Care. 2010;33(2):327-34.

118. Whelton PK, Carey RM, Aronow WS, Casey DE Jr, Collins KJ, Dennison Himmelfarb C, et al. 2017 ACC/AHA/AAPA/ABC/ACPM/AGS/APhA/ ASH/ASPC/NMA/PCNA Guideline for the Prevention, Detection, Evaluation, and Management of High Blood Pressure in Adults: Executive Summary: A Report of the American College of Cardiology/American Heart Association Task Force on Clinical Practice Guidelines. Circulation. 2018;138(17):e426-e83.

119. Babu AS, Grace SL. Cardiac Rehabilitation for Hypertension Assessment and Control: Report From the International Council of Cardiovascular Prevention and Rehabilitation. J Clin Hypertens (Greenwich). 2015;17(11):831-6.

120. Eicher JD, Maresh CM, Tsongalis GJ, Thompson PD, Pescatello LS. The additive blood pressure lowering effects of exercise intensity on postexercise hypotension. Am Heart J. 2010;160(3):513-20.
121. Guimaraes GV, de Barros Cruz LG, Fernandes-Silva MM, Dorea EL, Bocchi EA. Heated water-based exercise training reduces 24 -hour ambulatory blood pressure levels in resistant hypertensive patients: a randomized controlled trial (HEx trial). Int J Cardiol. 2014;172(2):434-41.

122. Mansur A de P, Favarato D. Mortality due to cardiovascular diseases in Brazil and in the metropolitan region of Sao Paulo: a 2011 update. Arq Bras Cardiol. 2012;99(2):755-61.

123. Mansur A de P, Favarato D. Trends in Mortality Rate from Cardiovascular Disease in Brazil, 1980-2012. Arq Bras Cardiol. 2016;107(1):20-5.

124. Mansur AP, Favarato D, Souza MF, Avakian SD, Aldrighi JM, Cesar LA, et al. Trends in death from circulatory diseases in Brazil between 1979 and 1996. Arq Bras Cardiol. 2001;76(6):497-510.

125. Daly CA, De Stavola B, Sendon JL, Tavazzi L, Boersma E, Clemens F, et al. Predicting prognosis in stable angina--results from the Euro heart survey of stable angina: prospective observational study. BMJ. 2006;332(7536):262-7.

126. Boden WE, O'Rourke RA, Teo KK, Hartigan PM, Maron DJ, Kostuk WJ, etal Optimal medical therapy with or without PCI for stable coronary disease. N Engl J Med. 2007;356(15):1503-16.

127. Stergiopoulos K, Brown DL. Initial coronary stent implantation with medical therapy vs medical therapy alone for stable coronary artery disease: meta-analysis of randomized controlled trials. Arch Intern Med. 2012;172(4):312-9.

128. Windecker S, Kolh P, Alfonso F, Collet JP, Cremer J, Falk V, et al. 2014 ESC/EACTS Guidelines on myocardial revascularization: The Task Force on Myocardial Revascularization of the European Society of Cardiology (ESC) and the European Association for Cardio-Thoracic Surgery (EACTS) Developed with the special contribution of the European Association of Percutaneous Cardiovascular Interventions (EAPCI). Eur Heart J. 2014:35(37):2541-619.

129. Ibanez B, James S, Agewall S, Antunes MJ, Bucciarelli-Ducci C, Bueno $H$, et al. 2017 ESC Guidelines for the management of acute myocardia infarction in patients presenting with ST-segment elevation: The Task Force for the management of acute myocardial infarction in patients presenting with ST-segment elevation of the European Society of Cardiology (ESC). Eur HeartJ. 2018;39(2):119-77.

130. O'Gara PT, Kushner FG, Ascheim DD, Casey DE, Jr., Chung MK, de Lemos JA, et al. 2013 ACCF/AHA guideline for the management of ST-elevation myocardial infarction: a report of the American College of Cardiology Foundation/American Heart Association Task Force on Practice Guidelines. J Am Coll Cardiol. 2013;61(4):e78-e140.

131. Avezum Jr A, Feldman A, Carvalho AC, Sousa AC, Mansur A de P, Bozza AE, et al. $\vee$ Diretriz da Sociedade Brasileira de Cardiologia sobre Tratamento do Infarto Agudo do Miocárdio com Supradesnível do Segmento ST. Arq Bras Cardiol. 2015;105(2 Suppl 1):1-105.

132. Ehsani AA, Heath GW, Hagberg JM, Sobel BE, Holloszy JO. Effects of 12 months of intense exercise training on ischemic ST-segment depression in patients with coronary artery disease. Circulation. 1981;64(6):1116-24.

133. Clausen JP, Trap-Jensen J. Heart rate and arterial blood pressure during exercise in patients with angina pectoris. Effects of training and of nitroglycerin. Circulation. 1976;53(3):436-42.

134. Mobius-Winkler S, Uhlemann M, Adams V, Sandri M, Erbs S, Lenk K, et al. Coronary Collateral Growth Induced by Physical Exercise: Results of the Impact of Intensive Exercise Training on Coronary Collateral Circulation in Patients With Stable Coronary Artery Disease (EXCITE) Trial. Circulation. 2016;133(15):1438-48. discussion 48

135. Rogers MA, Yamamoto C, Hagberg JM, Holloszy JO, Ehsani AA. The effect of 7 years of intense exercise training on patients with coronary artery disease. J Am Coll Cardiol. 1987:10(2):321-6.

136. Milani M, Kozuki RT, Crescêncio JC, Papa V, Santos MDB, Bertini CQ, et al. Efeito do treinamento físico aeróbico em coronariopatas submetidos a um Programa de Reabilitação Cardiovascular. Medicina (Ribeirão Preto) 2007:40(3):403-11. 
137. Kendziorra K, Walther C, Foerster M, Mobius-Winkler S, Conradi K Schuler G, et al. Changes in myocardial perfusion due to physical exercise in patients with stable coronary artery disease. Eur J Nucl Med Mol Imaging. 2005;32(7):813-9.

138. El Demerdash S, Khorshid H, Salah I, Abdel-Rahman MA, Salem AM. Cardiac rehabilitation improves the ischemic burden in patients with ischemic heart disease who are not suitable for revascularization. Cardiovasc Revasc Med. 2015;16(5):280-3

139. Giallauria F, Acampa W, Ricci F, Vitelli A, Maresca L, Mancini M, et al Effects of exercise training started within 2 weeks after acute myocardial infarction on myocardial perfusion and left ventricular function: a gated SPECT imaging study. Eur J Prev Cardiol. 2012;19(6):1410-9.

140. Hambrecht R, Walther C, Mobius-Winkler S, Gielen S, Linke A, Conradi $\mathrm{K}$, et al. Percutaneous coronary angioplasty compared with exercise training in patients with stable coronary artery disease: a randomized trial. Circulation. 2004;109(11):1371-8.

141. Murtagh EM, Nichols L, Mohammed MA, Holder R, Nevill AM, Murphy $\mathrm{MH}$. The effect of walking on risk factors for cardiovascular disease: an updated systematic review and meta-analysis of randomised control trials. Prev Med. 2015 Mar;72:34-43.

142. Umpierre D, Ribeiro PA, Schaan BD, Ribeiro JP. Volume of supervised exercise training impacts glycaemic control in patients with type 2 diabetes: a systematic review with meta-regression analysis. Diabetologia. 2013;56(2):242-51.

143. Vanhees L, Geladas N, Hansen D, Kouidi E, Niebauer J, Reiner Z, et al. Importance of characteristics and modalities of physical activity and exercise in the management of cardiovascular health in individuals with cardiovascular risk factors: recommendations from the EACPR. Part II. Eur J Prev Cardiol. 2012;19(5):1005-33.

144. Taylor RS, Brown A, Ebrahim S, Jolliffe J, Noorani H, Rees K, et al. Exercisebased rehabilitation for patients with coronary heart disease: systematic review and meta-analysis of randomized controlled trials. Am J Med. 2004;116(10):682-92.

145. Seki E, Watanabe Y, Sunayama S, Iwama Y, Shimada K, Kawakami K, et al. Effects of phase III cardiac rehabilitation programs on health-related quality of life in elderly patients with coronary artery disease: Juntendo Cardiac Rehabilitation Program (J-CARP). Circ J. 2003;67(1):73-7.

146. Oldridge N. Exercise-based cardiac rehabilitation in patients with coronary heart disease: meta-analysis outcomes revisited. Future Cardiol. 2012;8(5):729-51

147. Lavie CJ, Arena R, Franklin BA. Cardiac Rehabilitation and Healthy LifeStyle Interventions: Rectifying Program Deficiencies to Improve Patient Outcomes. J Am Coll Cardiol. 2016;67(1):13-5.

148. Heran BS, Chen JM, Ebrahim S, Moxham T, Oldridge N, Rees K, et al. Exercise-based cardiac rehabilitation for coronary heart disease. Cochrane Database Syst Rev. 2011(7):CD001800.

149. Hambrecht R, Wolf A, Gielen S, Linke A, Hofer J, Erbs S, et al. Effect of exercise on coronary endothelial function in patients with coronary artery disease. N Engl J Med. 2000;342(7):454-60.

150. Traverse JH, Wang YL, Du R, Nelson D, Lindstrom P, Archer SL, et al. Coronary nitric oxide production in response to exercise and endothelium-dependent agonists. Circulation. 2000;101(21):2526-31.

151. Hambrecht R, Adams V, Erbs S, Linke A, Krankel N, Shu Y, et al. Regular physical activity improves endothelial function in patients with coronary artery disease by increasing phosphorylation of endothelial nitric oxide synthase. Circulation. 2003;107(25):3152-8.

152. Bruning RS, Sturek M. Benefits of exercise training on coronary blood flow in coronary artery disease patients. Prog Cardiovasc Dis. 2015;57(5):443-53.

153. Schuler G, Hambrecht R, Schlierf G, Grunze M, Methfessel S, Hauer K, et al. Myocardial perfusion and regression of coronary artery disease in patients on a regimen of intensive physical exercise and low fat diet. J Am Coll Cardiol. 1992;19(1):34-42.
154. Martin BJ, Arena R, Haykowsky M, Hauer T, Austford LD, Knudtson M, et al. Cardiovascular fitness and mortality after contemporary cardiac rehabilitation. Mayo Clin Proc. 2013;88(5):455-63.

155. Dorn J, Naughton J, Imamura D, Trevisan M. Results of a multicenter randomized clinical trial of exercise and long-term survival in myocardial infarction patients: the National Exercise and Heart Disease Project (NEHDP). Circulation. 1999;100(17):1764-9.

156. Feuerstadt P, Chai A, Kligfield P. Submaximal effort tolerance as a predictor of all-cause mortality in patients undergoing cardiac rehabilitation. Clin Cardiol. 2007;30(5):234-8.

157. Belardinelli R, Paolini I, Cianci G, Piva R, Georgiou D, Purcaro A. Exercise training intervention after coronary angioplasty: the ETICA trial. J Am Coll Cardiol. 2001;37(7):1891-900

158. Giallauria F, Acampa W, Ricci F, Vitelli A, Torella G, Lucci R, et al. Exercise training early after acute myocardial infarction reduces stress-induced hypoperfusion and improves left ventricular function. Eur J Nucl Med Mol Imaging. 2013;40(3):315-24

159. Zhang YM, Lu Y, Tang Y, Yang D, Wu HF, Bian ZP, et al. The effects of different initiation time of exercise training on left ventricular remodeling and cardiopulmonary rehabilitation in patients with left ventricular dysfunction after myocardial infarction. Disabil Rehabil. 2016;38(3):268-76.

160. Haykowsky M, Scott J, Esch B, Schopflocher D, Myers J, Paterson I, et al. A meta-analysis of the effects of exercise training on left ventricular remodeling following myocardial infarction: start early and go longer for greatest exercise benefits on remodeling. Trials. 2011 Apr 4;12:92.

161. Asbury EA, Webb CM, Probert H, Wright C, Barbir M, Fox K, et al. Cardiac rehabilitation to improve physical functioning in refractory angina: a pilot study. Cardiology. 2012;122(3):170-7.

162. Cardiac Rehabilitation in Patients With Refractory Angina. Clinicaltrials. gov;2017. [Internet]. [Cited in 2018 Dec 12]. Available from: clinicaltrials. gov/ct2/help/how-read-study[Available from: https://clinicaltrials.gov/ct2/ show/NCT03218891.

163. Kubo N, Ohmura N, Nakada I, Yasu T, Katsuki T, Fujii M, et al. Exercise at ventilatory threshold aggravates left ventricular remodeling in patients with extensive anterior acute myocardial infarction. Am Heart J. 2004;147(1):113-20.

164. Giannuzzi P, Temporelli PL, Corra U, Gattone M, Giordano A, Tavazzi L. Attenuation of unfavorable remodeling by exercise training in postinfarction patients with left ventricular dysfunction: results of the Exercise in Left Ventricular Dysfunction (ELVD) trial. Circulation. 1997;96(6):1790-7.

165. Grace SL, Russell KL, Reid RD, Oh P, Anand S, Rush J, et al. Effect of cardiac rehabilitation referral strategies on utilization rates: a prospective, controlled study. Arch Intern Med. 2011;171(3):235-41.

166. Balady GJ, Ades PA, Bittner VA, Franklin BA, Gordon NF, Thomas RJ, et al. Referral, enrollment, and delivery of cardiac rehabilitation/secondary prevention programs at clinical centers and beyond: a presidential advisory from the American HeartAssociation. Circulation. 2011;124(25):2951-60.

167. Brown TM, Hernandez AF, Bittner V, Cannon CP, Ellrodt G, Liang L, et al. Predictors of cardiac rehabilitation referral in coronary artery disease patients: findings from the American Heart Association's Get With The Guidelines Program. J Am Coll Cardiol. 2009;54(6):515-21.

168. Grace SL, Scholey P, Suskin N, Arthur HM, Brooks D, Jaglal S, et al. A prospective comparison of cardiac rehabilitation enrollment following automatic vs usual referral. J Rehabil Med. 2007;39(3):239-45.

169. Belardinelli R, Lacalaprice F, Tiano L, Mucai A, Perna GP. Cardiopulmonary exercise testing is more accurate than ECG-stress testing in diagnosing myocardial ischemia in subjects with chest pain. Int J Cardiol. $2014 ; 174(2): 337-42$.

170. Mezzani A, Hamm LF, Jones AM, McBride PE, Moholdt T, Stone JA, et al. Aerobic exercise intensity assessment and prescription in cardiac rehabilitation: a joint position statement of the European Association 
for Cardiovascular Prevention and Rehabilitation, the American Association of Cardiovascular and Pulmonary Rehabilitation and the Canadian Association of Cardiac Rehabilitation. Eur J Prev Cardiol. 2013;20(3):442-67.

171. Chaudhry S, Arena R, Wasserman K, Hansen JE, Lewis GD, Myers J, et al. Exercise-induced myocardial ischemia detected by cardiopulmonary exercise testing. Am J Cardiol. 2009;103(5):615-9.

172. Ennis S, Lobley G, Worrall S, Powell R, Kimani PK, Khan AJ, et al. Early initiation of post-sternotomy cardiac rehabilitation exercise training (SCAR): study protocol for a randomised controlled trial and economic evaluation. BMJ Open. 2018;8(3):e019748.

173. Hojskov IE, Moons P, Hansen NV, La Cour S, Olsen PS, Gluud C, et al, SheppHeartCABG trial-comprehensive early rehabilitation after coronary artery bypass grafting: a protocol for a randomised clinical trial. BMJ Open. 2017;7(1):e013038

174. McGillion M, Arthur HM, Cook A, Carroll SL, Victor JC, L'Allier P L, et al. Management of patients with refractory angina: Canadian Cardiovascular Society/Canadian Pain Society joint guidelines. Can J Cardiol. 2012;28(2 Suppl):S20-41.

175. Mannheimer C, Camici P, Chester MR, Collins A, DeJongste M, Eliasson $\mathrm{T}$, et al. The problem of chronic refractory angina; report from the ESC Joint Study Group on the Treatment of Refractory Angina. Eur Heart J. 2002;23(5):355-70

176. Dourado LO, Poppi NT, Adam EL, Leite TN, Pereira A da C, Krieger JE, et al. The effectiveness of intensive medical treatment in patients initially diagnosed with refractory angina. Int J Cardiol. 2015;186:29-31.

177. Moore RK, Groves D, Bateson S, Barlow P, Hammond C, Leach AA, et al. Health related quality of life of patients with refractory angina before and one year after enrolment onto a refractory angina program. Eur J Pain. 2005;9(3):305-10

178. Moore RK, Groves DG, Bridson JD, Grayson AD, Wong H, Leach A, et al. A brief cognitive-behavioral intervention reduces hospital admissions in refractory angina patients. J Pain Symptom Manag. 2007;33(3):310-6.

179. Poppi NT, Gowdak LH, Dourado LO, Adam EL, Leite TN, Mioto BM, et al. A prospective study of patients with refractory angina: outcomes and the role of high-sensitivity troponin T. Clin Cardiol. 2017;40(1):11-7.

180. Thompson PD. Exercise prescription and proscription for patients with coronary artery disease. Circulation. 2005;112(15):2354-63.

181. Meneghelo RS, Magalhaes HM, Smanio PE, Fuchs AR, Ferraz AS, Buchler $\mathrm{RD}$, et al. Evaluation of prescription of exercise, for rehabilitation of coronary artery disease patients by myocardial scintigraphy. Arq Bras Cardiol. 2008;91(4):223-8, 45-51.

182. Fuchs AR, Meneghelo RS, Stefanini E, De Paola AV, Smanio PE, Mastrocolla $L E$, et al. Exercise may cause myocardial ischemia at the anaerobic threshold in cardiac rehabilitation programs. Braz I Med Biol Res. 2009;42(3):272-8

183. Gianrossi R, Detrano R, Mulvihill D, Lehmann K, Dubach P, Colombo A, et al. Exercise-induced ST depression in the diagnosis of coronary artery disease. A meta-analysis. Circulation. 1989;80(1):87-98.

184. Upton MT, Rerych SK, Newman GE, Port S, Cobb FR, Jones RH. Detecting abnormalities in left ventricular function during exercise before angina and ST-segment depression. Circulation. 1980;62(2):341-9.

185. Juneau M, Roy N, Nigam A, Tardif JC, Larivee L. Exercise above the ischemic threshold and serum markers of myocardial injury. Can J Cardiol. 2009;25(10):e338-41.

186. Noel M, Jobin J, Marcoux A, Poirier P, Dagenais GR, Bogaty P. Can prolonged exercise-induced myocardial ischaemia be innocuous? Eur Heart J. 2007;28(13):1559-65.

187. Rognmo O, Moholdt T, Bakken H, Hole T, Molstad P, Myhr NE, et al. Cardiovascular risk of high- versus moderate-intensity aerobic exercise in coronary heart disease patients. Circulation. 2012;126(12):1436-40.
188. Cornish AK, Broadbent S, Cheema BS. Interval training for patients with coronary artery disease: a systematic review. Eur J Appl Physiol. 2011;111(4):579-89.

189. Marzolini S, Oh PI, Brooks D. Effect of combined aerobic and resistance training versus aerobic training alone in individuals with coronary artery disease: a meta-analysis. Eur J Prev Cardiol. 2012;19(1):81-94.

190. Winzer EB, Woitek F, Linke A. Physical Activity in the Prevention and Treatment of Coronary Artery Disease. J Am Heart Assoc. 2018;7(4). pii e007725

191. Sokoreli I, de Vries IJ, Riistama JM, Pauws SC, Steyerberg EW, Tesanovic A, et al. Depression as an independent prognostic factor for all-cause mortality after a hospital admission for worsening heart failure. Int Cardiol. 2016;220:202-7.

192. Nakamura M, Ishikawa M, Funakoshi T, Hashimoto K, Chiba M, Hiramori K. Attenuated endothelium-dependent peripheral vasodilation and clinical characteristics in patients with chronic heart failure. Am Heart J. 1994:128(6 Pt 1):1164-9.

193. Gullestad L, Ueland T, Vinge LE, Finsen A, Yndestad A, Aukrust P. Inflammatory cytokines in heart failure: mediators and markers. Cardiology. 2012;122(1):23-35.

194. Coats AJ, Adamopoulos S, Meyer TE, Conway J, Sleight P. Effects of physical training in chronic heart failure. Lancet. 1990;335(8681):63-6.

195. Ferraz AS, Bocchi EA. Efeitos do treinamento físico na morbidade e mortalidade em pacientes com insuficiência cardíaca: como implementar sua aplicação na prática clínica. Rev Soc Cardiol Estado de São Paulo 2008;18(1):23-36

196. Belardinelli R, Georgiou D, Cianci G, Purcaro A. Randomized, controlled trial of long-term moderate exercise training in chronic heart failure: effects on functional capacity, quality of life, and clinical outcome. Circulation. 1999;99(9):1173-82.

197. Piepoli MF, Davos C, Francis DP, Coats AJ, ExTra MC. Exercise training meta-analysis of trials in patients with chronic heart failure (ExTraMATCH). BMJ. 2004;328(7433):189.

198. O'Connor CM, Whellan DJ, Lee KL, Keteyian SJ, Cooper LS, Ellis SJ, et al Efficacy and safety of exercise training in patients with chronic heart failure: HF-ACTION randomized controlled trial. JAMA. 2009;301(14):1439-50.

199. Cooper LB, Mentz RJ, Sun JL, Schulte PJ, Fleg JL, Cooper LS, et al. Psychosocial Factors, Exercise Adherence, and Outcomes in Heart Failure Patients: Insights From Heart Failure: A Controlled Trial Investigating Outcomes of Exercise Training (HF-ACTION). Circ Heart Fail. 2015;8(6):1044-51.

200. Pina IL, Bittner V, Clare RM, Swank A, Kao A, Safford R, et al. Effects of exercise training on outcomes in women with heart failure: analysis of HF-ACTION (Heart Failure-A Controlled Trial Investigating Outcomes of Exercise TraiNing) by sex. JACC Heart Fail. 2014;2(2):180-6.

201. Oliveira MF, Santos RC, Artz SA, Mendez VMF, Lobo DML, Correia EB, et al. Safety and Efficacy of Aerobic Exercise Training Associated to NonInvasive Ventilation in Patients with Acute Heart Failure. Arq Bras Cardiol. 2018;110(5):467-75

202. Tucker WI, Nelson MD, Beaudry RI, Halle M, Sarma S, Kitzman DW, et al. Impact of Exercise Training on Peak Oxygen Uptake and its Determinants in Heart Failure with Preserved Ejection Fraction. Card Fail Rev. 2016;2(2):95-101.

203. Pandey A, Parashar A, Kumbhani D, Agarwal S, Garg J, Kitzman D, et al Exercise training in patients with heart failure and preserved ejection fraction: meta-analysis of randomized control trials. Circ Heart Fail. 2015;8(1):33-40.

204. Nolte K, Herrmann-Lingen C, Wachter R, Gelbrich G, Dungen HD Duvinage $A$, et al. Effects of exercise training on different quality of life dimensions in heart failure with preserved ejection fraction: the Ex-DHF-P trial. Eur J Prev Cardiol. 2015;22(5):582-93. 
205. Edelmann F, Gelbrich G, Dungen HD, Frohling S, Wachter R, Stahrenberg $\mathrm{R}$, et al. Exercise training improves exercise capacity and diastolic function in patients with heart failure with preserved ejection fraction: results of the Ex-DHF (Exercise training in Diastolic Heart Failure) pilot study. J Am Coll Cardiol. 2011;58(17):1780-91.

206. Pearson MJ, Mungovan SF, Smart NA. Effect of exercise on diastolic function in heart failure patients: a systematic review and meta-analysis. Heart Fail Rev. 2017;22(2):229-42.

207. Ades PA, Keteyian SJ, WrightJS, Hamm LF, Lui K, Newlin K, et al. Increasing Cardiac Rehabilitation Participation From 20\% to 70\%: A Road Map From the Million Hearts Cardiac Rehabilitation Collaborative. Mayo Clin Proc. 2017;92(2):234-42.

208. Bellet RN, Adams L, Morris NR. The 6-minute walk test in outpatient cardiac rehabilitation: validity, reliability and responsiveness--a systematic review. Physiotherapy. 2012;98(4):277-86.

209. Wisloff U, Stoylen A, Loennechen JP, Bruvold M, Rognmo O, Haram PM, et al. Superior cardiovascular effect of aerobic interval training versus moderate continuous training in heart failure patients: a randomized study. Circulation. 2007;115(24):3086-94.

210. Haykowsky MJ, Timmons MP, Kruger C, McNeely M, Taylor DA, ClarkAM. Meta-analysis of aerobic interval training on exercise capacity and systolic function in patients with heart failure and reduced ejection fractions. Am J Cardiol. 2013;111(10):1466-9.

211. Ellingsen O, Halle M, Conraads V, Stoylen A, Dalen H, Delagardelle C, et al. High-Intensity Interval Training in Patients With Heart Failure With Reduced Ejection Fraction. Circulation. 2017;135(9):839-49.

212. Meyer P, Gayda M, Juneau M, Nigam A. High-intensity aerobic interval exercise in chronic heart failure. Curr Heart Fail Rep. 2013;10(2):130-8.

213. Meyer P, Normandin E, Gayda M, Billon G, Guiraud T, Bosquet L, et al. High-intensity interval exercise in chronic heart failure: protocol optimization. J Card Fail. 2012;18(2):126-33.

214. Sagar VA, Davies EJ, Briscoe S, Coats AJ, Dalal HM, Lough F, et al. Exercisebased rehabilitation for heart failure: systematic review and meta-analysis. Open Heart. 2015;2(1):e000163.

215. Winkelmann ER, Chiappa GR, Lima CO, Viecili PR, Stein R, Ribeiro JP. Addition of inspiratory muscle training to aerobic training improves cardiorespiratory responses to exercise in patients with heart failure and inspiratory muscle weakness. Am Heart J. 2009;158(5):768 e1-7.

216. Smart NA, Giallauria F, Dieberg G. Efficacy of inspiratory muscle training in chronic heart failure patients: a systematic review and meta-analysis. Int J Cardiol. 2013;167(4):1502-7.

217. Cornelis J, Beckers P, Taeymans J, Vrints C, Vissers D. Comparing exercise training modalities in heart failure: A systematic review and meta-analysis. Int J Cardiol. 2016;221:867-76.

218. Associação Brasileira de Transplantess de Orgãos (ABTO). Registro Brasileiro de Transplantes. São Paulo; 2019.

219. Harris C, Cao C, Croce B, Munkholm-Larsen S. Heart transplantation. Ann Cardiothorac Surg. 2018;7(1):172.

220. Hsich EM. Matching the Market for Heart Transplantation. Circ Heart Fail. 2016;9(4):e002679.

221. Wilhelm MJ. Long-term outcome following heart transplantation: current perspective. J Thorac Dis. 2015;7(3):549-51.

222. Alraies MC, Eckman P. Adult heart transplant: indications and outcomes. J Thorac Dis. 2014;6(8):1120-8.

223. Marconi C. Pathophysiology of cardiac transplantation and the challenge of exercise. Int J Sports Med. 2000;21 (Suppl 2):S106-8.

224. Nytroen K, Rustad LA, Erikstad I, Aukrust P, Ueland T, Lekva T, et al. Effect of high-intensity interval training on progression of cardiac allograft vasculopathy. J Heart Lung Transplant. 2013;32(11):1073-80.
225. Awad M, Czer LS, Hou M, Golshani SS, Goltche M, De Robertis M, et al. Early Denervation and Later Reinnervation of the Heart Following Cardiac Transplantation: A Review. J Am Heart Assoc. 2016;5(11). pii e004070

226. Lampert E, Mettauer B, Hoppeler H, Charloux A, Charpentier A, Lonsdorfer J. Structure of skeletal muscle in heart transplant recipients. J Am Coll Cardiol. 1996;28(4):980-4.

227. Salles AF, Oliveira JA. Adaptation to exercise following cardiac transplantation. Arq Bras Cardiol. 2000;75(1):70-90.

228. Shephard RJ. Responses to acute exercise and training after cardiac transplantation: a review. Can J Sport Sci. 1991;16(1):9-22.

229. Scott JM, Esch BT, Haykowsky MJ, Warburton DE, Toma M, Jelani A, et al. Cardiovascular responses to incremental and sustained submaximal exercise in heart transplant recipients. Am J Physiol Heart Circ Physiol. 2009;296(2):H350-8.

230. Nytroen K, Myers J, Chan KN, Geiran OR, Gullestad L. Chronotropic responses to exercise in heart transplant recipients: 1-yr follow-up. Am J Phys Med Rehabil. 2011;90(7):579-88.

231. Soderlund C, Radegran G. Immunosuppressive therapies after heart transplantation--The balance between under- and overimmunosuppression. Transplant Rev (Orlando). 2015;29(3):181-9.

232. Taylor DO, Edwards LB, Boucek MM, Trulock EP, Aurora P, Christie J, et al. Registry of the International Society for Heart and Lung Transplantation: twenty-fourth official adult heart transplant report--2007. J Heart Lung Transplant. 2007;26(8):769-81.

233. Perrier-Melo RJ, Figueira F, Guimaraes GV, Costa MDC. High-Intensity Interval Training in Heart Transplant Recipients: A Systematic Review with Meta-Analysis. Arq Bras Cardiol. 2018;110(2):188-94.

234. Anderson L, Nguyen TT, Dall CH, Burgess L, Bridges C, Taylor RS. Exercisebased cardiac rehabilitation in heart transplant recipients. Cochrane Database Syst Rev. 2017;4:CD012264.

235. Braith RW, Welsch MA, Mills RM, Jr., Keller JW, Pollock ML. Resistance exercise prevents glucocorticoid-induced myopathy in heart transplant recipients. Med Sci Sports Exerc. 1998;30(4):483-9.

236. Braith RW, Mills RM, Welsch MA, Keller JW, Pollock ML. Resistance exercise training restores bone mineral density in heart transplant recipients. J Am Coll Cardiol. 1996;28(6):1471-7.

237. Richard R, Verdier JC, Duvallet A, Rosier SP, Leger P, Nignan A, et al. Chronotropic competence in endurance trained heart transplant recipients: heart rate is not a limiting factor for exercise capacity. J Am Coll Cardiol. 1999;33(1):192-7.

238. Nytroen K, Rustad LA, Aukrust P, Ueland T, Hallen J, Holm I, et al. Highintensity interval training improves peak oxygen uptake and muscular exercise capacity in heart transplant recipients. Am J Transplant. 2012;12(11):3134-42.

239. Haykowsky M, Eves N, Figgures L, McLean A, Koller M, Taylor D, et al. Effect of exercise training on $\mathrm{VO} 2$ peak and left ventricular systolic function in recent cardiac transplant recipients. Am J Cardiol. 2005;95(8):1002-4.

240. Kobashigawa JA. Postoperative management following heart transplantation. Transplant Proc. 1999;31(5):2038-46.

241. Rosenbaum AN, Kremers WK, Schirger JA, Thomas RJ, Squires RW, Allison TG, et al. Association Between Early Cardiac Rehabilitation and Long-term Survival in Cardiac Transplant Recipients. Mayo Clin Proc. 2016;91(2):149-56.

242. Haykowsky M, Taylor D, Kim D, Tymchak W. Exercise training improves aerobic capacity and skeletal muscle function in heart transplant recipients. Am J Transplant. 2009;9(4):734-9.

243. Kobashigawa JA, Leaf DA, Lee N, Gleeson MP, Liu H, Hamilton MA, et al. A controlled trial of exercise rehabilitation after heart transplantation. $\mathrm{N}$ Engl J Med. 1999;340(4):272-7. 
244. Dall CH, Snoer M, Christensen S, Monk-Hansen T, Frederiksen M, Gustafsson $\mathrm{F}$, et al. Effect of high-intensity training versus moderate training on peak oxygen uptake and chronotropic response in heart transplant recipients: a randomized crossover trial. Am J Transplant. 2014;14(10):2391-9.

245. Nytroen K, Yardley M, Rolid K, Bjorkelund E, Karason K, Wigh JP, et al. Design and rationale of the HITTS randomized controlled trial: Effect of High-intensity Interval Training in de novo Heart Transplant Recipients in Scandinavia. Am Heart J. 2016;172:96-105.

246. Herdy AH, Ritt LE, Stein R, Araujo CG, Milani M, Meneghelo RS, et al. Teste Cardiopulmonar de Exercício: Fundamentos, Aplicabilidade e Interpretação. Arq Bras Cardiol. 2016;107(5):467-81.

247. Cowie A, Buckley J, Doherty P, Furze G, Hayward J, Hinton S, et al. Standards and core components for cardiovascular disease prevention and rehabilitation. Heart. 2019;105(7):510-5.

248. Hamilton DM, Haennel RG. Validity and reliability of the 6-minute walk test in a cardiac rehabilitation population. J Cardiopulm Rehabil. 2000;20(3):156-64

249. ATS Committee on Proficiency Standards for Clinical Pulmonary Function Laboratories. ATS statement: guidelines for the six-minute walk test. Am J Respir Crit Care Med. 2002;166(1):111-7.

250. Laursen PB, Jenkins DG. The scientific basis for high-intensity interval training: optimising training programmes and maximising performance in highly trained endurance athlets. Sports Med. 2002;32(1):53-73.

251. Grupper A, Gewirtz H, Kushwaha S. Reinnervation post-heart transplantation. Eur Heart J. 2018;39(20):1799-806.

252. Borg GA. Psychophysical bases of perceived exertion. Med Sci Sports Exerc. 1982:14(5):377-81.

253. Jones CJ, Rikli RE, Beam WC. A 30-s chair-stand test as a measure of lower body strength in community-residing older adults. Res Q Exerc Sport. 1999;70(2):113-9.

254. Takatori K, Matsumoto D, Okada Y, Nakamura J, Shomoto K. Effect of intensive rehabilitation on physical function and arterial function in community-dwelling chronic stroke survivors. Top Stroke Rehabil. 2012;19(5):377-83

255. Rosique-Esteban N, Babio N, Diaz-Lopez A, Romaguera D, Alfredo Martinez J, Sanchez VM, et al. Leisure-time physical activity at moderate and high intensity is associated with parameters of body composition, muscle strength and sarcopenia in aged adults with obesity and metabolic syndrome from the PREDIMED-Plus study. Clin Nutr. 2019;38(3):1324-31.

256. Telenius EW, Engedal K, Bergland A. Inter-rater reliability of the Berg Balance Scale, $30 \mathrm{~s}$ chair stand test and $6 \mathrm{~m}$ walking test, and construct validity of the Berg Balance Scale in nursing home residents with mild-tomoderate dementia. BMJ Open. 2015;5(9):e008321.

257. Colvin-Adams M, Smith JM, Heubner BM, Skeans MA, Edwards LB, Waller CD, et al. OPTN/SRTR 2013 Annual Data Report: heart. Am J Transplant. 2015;15 (Suppl 2):1-28.

258. Colvin-Adams M, Smithy JM, Heubner BM, Skeans MA, Edwards LB, Waller C, et al. OPTN/SRTR 2012 Annual Data Report: heart. Am J Transplant. 2014;14 (Suppl 1):113-38.

259. Wu YT, Chien CL, Chou NK, Wang SS, Lai JS, Wu YW. Efficacy of a home-based exercise program for orthotopic heart transplant recipients. Cardiology. 2008;111(2):87-93.

260. Bernardi L, Radaelli A, Passino C, Falcone C, Auguadro C, Martinelli L, et al. Effects of physical training on cardiovascular control after heart transplantation. Int J Cardiol. 2007;118(3):356-62.

261. Tegtbur U, Busse MW, Jung K, Pethig K, Haverich A. Time course of physical reconditioning during exercise rehabilitation late after heart transplantation. J Heart Lung Transplant. 2005;24(3):270-4.
262. Karapolat H, Eyigor S, Zoghi M, Yagdi T, Nalbantgil S, Durmaz B, et al. Effects of cardiac rehabilitation program on exercise capacity and chronotropic variables in patients with orthotopic heart transplant. Clin Res Cardiol. 2008;97(7):449-56.

263. de Lima JB, Ferrari F, Stein R. Reabilitação nos pacientes submetidos a transplante cardíaco - parte III: Recomendações para treinamento póstransplante cardíaco. Rev DERC. 2019;25(2):38-44.

264. de Lima JB, Ferrari F, Stein R. Reabilitação nos pacientes submetidos a transplante cardíaco - parte I. Rev DERC. 2018;24(4):132-4.

265. de Lima JB, Ferrari F, Stein R. Reabilitação nos pacientes submetidos a transplante cardíaco - parte II: treinamento pós-transplante cardíaco. Rev DERC. 2019;25(1):10-3.

266. Saberi S, Wheeler M, Bragg-Gresham J, Hornsby W, Agarwal PP, Attili A, et al. Effect of Moderate-Intensity Exercise Training on Peak Oxygen Consumption in Patients With Hypertrophic Cardiomyopathy: A Randomized Clinical Trial. JAMA. 2017:317(13):1349-57.

267. Klempfner R, Kamerman T, Schwammenthal E, Nahshon A, Hay I, Goldenberg I, et al. Efficacy of exercise training in symptomatic patients with hypertrophic cardiomyopathy: results of a structured exercise training program in a cardiac rehabilitation center. Eur J Prev Cardiol. 2015;22(1):13-9

268. Elliott PM, Anastasakis A, Borger MA, Borggrefe M, Cecchi F, Charron P, et al. 2014 ESC Guidelines on diagnosis and management of hypertrophic cardiomyopathy: the Task Force for the Diagnosis and Management of Hypertrophic Cardiomyopathy of the European Society of Cardiology (ESC). Eur Heart J. 2014;35(39):2733-79.

269. Pelliccia A, Solberg EE, Papadakis M, Adami PE, Biffi A, Caselli S, et al Recommendations for participation in competitive and leisure time sport in athletes with cardiomyopathies, myocarditis, and pericarditis: position statement of the Sport Cardiology Section of the European Association of Preventive Cardiology (EAPC). Eur Heart J. 2019;40(1):19-33.

270. Ruwald AC, Marcus F, Estes NA 3rd, Link M, McNitt S, Polonsky B et al. Association of competitive and recreational sport participation with cardiac events in patients with arrhythmogenic right ventricular cardiomyopathy: results from the North American multidisciplinary study of arrhythmogenic right ventricular cardiomyopathy. Eur Heart J. 2015;36(27):1735-43.

271. Gersh BJ, Maron BJ, Bonow RO, Dearani JA, Fifer MA, Link MS, et al. 2011 ACCF/AHA guideline for the diagnosis and treatment of hypertrophic cardiomyopathy: executive summary: a report of the American College of Cardiology Foundation/American Heart Association Task Force on Practice Guidelines. Circulation. 2011;124(24):2761-96.

272. Watkins H, Ashrafian H, Redwood C. Inherited cardiomyopathies. N Engl Med. 2011;364(17):1643-56

273. Syed IS, Glockner JF, Feng D, Araoz PA, Martinez MW, Edwards WD, et al Role of cardiac magnetic resonance imaging in the detection of cardiac amyloidosis. JACC Cardiovasc Imaging. 2010;3(2):155-64.

274. Harris KM, Spirito P, Maron MS, Zenovich AG, Formisano F, Lesser JR, et al. Prevalence, clinical profile, and significance of left ventricular remodeling in the end-stage phase of hypertrophic cardiomyopathy. Circulation. 2006;114(3):216-25

275. Maron BJ, Casey SA, Hauser RG, Aeppli DM. Clinical course of hypertrophic cardiomyopathy with survival to advanced age. J Am Coll Cardiol. 2003:42(5):882-8.

276. Ghorayeb N, Stein R, Daher DJ, Silveira ADD, Ritt LEF, Santos D, et al. Atualização da Diretriz em Cardiologia do Esporte e do Exercício da Sociedade Brasileira de Cardiologia e da Sociedade Brasileira de Medicina do Exercício e Esporte - 2019. Arq Bras Cardiol. 2019;112(3):326-68.

277. Elliott PM, Gimeno JR, Thaman R, Shah J, Ward D, Dickie S, et al. Historical trends in reported survival rates in patients with hypertrophic cardiomyopathy. Heart. 2006;92(6):785-91. 
278. Sorajja P, Nishimura RA, Gersh BJ, Dearani JA, Hodge DO, Wiste HJ, et al. Outcome of mildly symptomatic or asymptomatic obstructive hypertrophic cardiomyopathy: a long-term follow-up study. J Am Coll Cardiol. 2009;54(3):234-41.

279. Maron MS, Rowin EJ, Olivotto I, Casey SA, Arretini A, Tomberli $B$, et al. Contemporary Natural History and Management of Nonobstructive Hypertrophic Cardiomyopathy. J Am Coll Cardiol. 2016;67(12):1399-409.

280. Dias KA, Link MS, Levine BD. Exercise Training for Patients With Hypertrophic Cardiomyopathy: JACC Review Topic of the Week. J Am Coll Cardiol. 2018;72(10):1157-65.

281. Sorajja P, Allison T, Hayes C, Nishimura RA, Lam CS, Ommen SR. Prognostic utility of metabolic exercise testing in minimally symptomatic patients with obstructive hypertrophic cardiomyopathy. Am J Cardiol. 2012;109(10):1494-8.

282. Maragiannis D, Alvarez PA, Ghosn MG, Chin K, Hinojosa JJ, Buergler JM, et al. Left ventricular function in patients with hypertrophic cardiomyopathy and its relation to myocardial fibrosis and exercise tolerance. Int J Cardiovasc Imaging. 2018;34(1):121-9.

283. Maron BJ, Udelson JE, Bonow RO, Nishimura RA, Ackerman MJ, Estes NA 3rd, et al. Eligibility and Disqualification Recommendations for Competitive Athletes With Cardiovascular Abnormalities: Task Force 3: Hypertrophic Cardiomyopathy, Arrhythmogenic Right Ventricular Cardiomyopathy and Other Cardiomyopathies, and Myocarditis: A Scientific Statement From the American Heart Association and American College of Cardiology. Circulation. 2015;132(22):e273-80.

284. Hindieh W, Adler A, Weissler-Snir A, Fourey D, Harris S, Rakowski H. Exercise in patients with hypertrophic cardiomyopathy: A review of current evidence, national guideline recommendations and a proposal for a new direction to fitness. J Sci Med Sport. 2017;20(4):333-8.

285. Sheikh N, Papadakis M, Schnell F, Panoulas V, Malhotra A, Wilson M, et al. Clinical Profile of Athletes With Hypertrophic Cardiomyopathy. Circ Cardiovasc Imaging. 2015;8(7):e003454.

286. Pelliccia A, Maron BJ, Spataro A, Proschan MA, Spirito P. The upper limit of physiologic cardiac hypertrophy in highly trained elite athletes. N Engl J Med. 1991;324(5):295-301.

287. Rowin EJ, Maron BJ, Olivotto I, Maron MS. Role of Exercise Testing in Hypertrophic Cardiomyopathy. JACC Cardiovasc Imaging. 2017;10(11):1374-86

288. Sasanuma N, Takahashi K, Yamauchi S, Itani Y, Tanaka T, Mabuchi S, et al. A five-year follow-up of a patient with fulminant myocarditis who underwent a stepwise and goal-oriented individualized comprehensive cardiac rehabilitation program. J Cardiol Cases. 2015;11(6):160-3.

289. Milani M. Exame em destaque: Teste Cardiopulmonar. Jornal do DERC. $2019 ; 1(5): 9$.

290. Yanagi H, Shindo N. Effects of exercise therapy on polymyositis complicated by post-myocarditis cardiomyopathy: A case report. J Rehabil Med. 2017;49(3):282-5.

291. Corrado D, Basso C, Judge DP. Arrhythmogenic Cardiomyopathy. Circ Res. 2017;121(7):784-802.

292. Kirchhof P, Fabritz L, Zwiener M, Witt H, Schafers M, Zellerhoff S, et al. Age- and training-dependent development of arrhythmogenic right ventricular cardiomyopathy in heterozygous plakoglobin-deficient mice. Circulation. 2006;114(17):1799-806.

293. James CA, Bhonsale A, Tichnell C, Murray B, Russell SD, Tandri H, et al. Exercise increases age-related penetrance and arrhythmic risk in arrhythmogenic right ventricular dysplasia/cardiomyopathy-associated desmosomal mutation carriers. J Am Coll Cardiol. 2013;62(14):1290-7.

294. Wang W, Orgeron G, Tichnell C, Murray B, Crosson J, Monfredi O, et al. Impact of Exercise Restriction on Arrhythmic Risk Among Patients With Arrhythmogenic Right Ventricular Cardiomyopathy. J Am Heart Assoc. 2018;7(12).pii e008843.
295. Towbin JA, Lorts A, Jefferies JL. Left ventricular non-compaction cardiomyopathy. Lancet. 2015;386(9995):813-25.

296. Sedaghat-Hamedani F, Haas J, Zhu F, Geier C, Kayvanpour E, Liss M, et al. Clinical genetics and outcome of left ventricular non-compaction cardiomyopathy. Eur Heart J. 2017;38(46):3449-60.

297. Hotta VT, Tendolo SC, Rodrigues ACT, Fernandes F, Nastari L, Mady C. Limitations in the Diagnosis of Noncompaction Cardiomyopathy by Echocardiography. Arq Bras Cardiol. 2017;109(5):483-8.

298. Thavendiranathan P, Dahiya A, Phelan D, Desai MY, Tang WH. Isolated left ventricular non-compaction controversies in diagnostic criteria, adverse outcomes and management. Heart. 2013;99(10):681-9.

299. Ganga HV, Thompson PD. Sports participation in non-compaction cardiomyopathy: a systematic review. Br J Sports Med. 2014;48(20):1466-71.

300. Gati S, Chandra N, Bennett RL, Reed M, Kervio G, Panoulas VF, et al. Increased left ventricular trabeculation in highly trained athletes: do we need more stringent criteria for the diagnosis of left ventricular noncompaction in athletes? Heart. 2013;99(6):401-8.

301. Caselli S, Ferreira D, Kanawati E, Di Paolo F, Pisicchio C, Attenhofer Jost C, et al. Prominent left ventricular trabeculations in competitive athletes: A proposal for risk stratification and management. Int J Cardiol. 2016;223:590-5.

302. Tarasoutchi F, Montera MW, Grinberg M, Pineiro DJ, Sanchez CR, Bacelar AC, et al. Diretriz Brasileira de Valvopatias - SBC 2011/ I Diretriz Interamericana de Valvopatias - SIAC 2011. Arq Bras Cardiol. 2011;97(5 Suppl 1):1-67.

303. Baumgartner H, Falk V, Bax JJ, De Bonis M, Hamm C, Holm PJ, et al. 2017 ESC/EACTS Guidelines for the management of valvular heart disease. Eur Heart J. 2017;38(36):2739-91.

304. Nishimura RA, Otto CM, Bonow RO, Carabello BA, Erwin J 3rd, Guyton RA, et al. 2014 AHA/ACC Guideline for the Management of Patients With Valvular Heart Disease: executive summary: a report of the American College of Cardiology/American Heart Association Task Force on Practice Guidelines. Circulation. 2014;129(23):2440-92.

305. Sibilitz KL, Berg SK, Tang LH, Risom SS, Gluud C, Lindschou J, et al. Exercise-based cardiac rehabilitation for adults after heart valve surgery. Cochrane Database Syst Rev. 2016;3:CD010876.

306. Sibilitz KL, Berg SK, Rasmussen TB, Risom SS, Thygesen LC, Tang L, et al. Cardiac rehabilitation increases physical capacity but not mental health after heart valve surgery: a randomised clinical trial. Heart. 2016;102(24):1995-2003.

307. Lund K, Sibilitz KL, Berg SK, Thygesen LC, Taylor RS, Zwisler AD. Physical activity increases survival after heart valve surgery. Heart. 2016;102(17):1388-95.

308. Tamuleviciute-Prasciene E, Drulyte K, Jurenaite G, Kubilius R, BjarnasonWehrens B. Frailty and Exercise Training: How to Provide Best Care after Cardiac Surgery or Intervention for Elder Patients with Valvular Heart Disease. Biomed Res Int. 2018;2018:9849475.

309. Anand A, Harley C, Visvanathan A, Shah ASV, Cowell J, MacLullich A, et al. The relationship between preoperative frailty and outcomes following transcatheter aortic valve implantation: a systematic review and metaanalysis. Eur Heart J Qual Care Clin Outcomes. 2017;3(2):123-32.

310. Kehler DS, Stammers AN, Tangri N, Hiebert B, Fransoo R, Schultz ASH, et al. Systematic review of preoperative physical activity and its impact on postcardiac surgical outcomes. BMJ Open. 2017;7(8):e015712.

311. DeLarochelliere H, Urena M, Amat-Santos IJ, Ribeiro HB, Allende R, Laflamme L, et al. Effect on outcomes and exercise performance of anemia in patients with aortic stenosis who underwent transcatheter aortic valve replacement. Am J Cardiol. 2015;115(4):472-9.

312. Lacombe SP, LaHaye SA, Hopkins-Rosseel D, Ball D, Lau W. Identifying patients at low risk for activity-related events: the RARE Score. J Cardiopulm Rehabil Prev. 2014;34(3):180-7. 
313. Pierard LA, Lancellotti P. Stress testing in valve disease. Heart. 2007:93(6):766-72.

314. Bissessor N, Stewart R, Zeng I, Ellyet K, Kolbe J, Kerr A. Comparing Cardiopulmonary Exercise Testing with Standard Exercise Treadmill Testing in Chronic Mixed Heart Valve Disease. Heart, Lung and Circulation. 2007;16(Suppl 2):S57-S8.

315. Leclerc K. Cardiopulmonary exercise testing: A contemporary and versatile clinical tool. Cleve Clin J Med. 2017;84(2):161-8.

316. Guazzi M, Bandera F, Ozemek C, Systrom D, Arena R. Cardiopulmonary Exercise Testing: What Is its Value? J Am Coll Cardiol. 2017;70(13):1618-36.

317. Travensolo C, Polito M. Testes de Degrau para Avaliação da Capacidade de Exercício em Pacientes com Doenças Cardíacas: Revisão da Literatura. Rev Bras Cardiol. 2014;27(6):445-53.

318. de Carvalho EEV, Costa DC, Crescêncio JC, De Santi GL, Papa V, F. M, etal. Insuficiência Cardíaca : Comparação Entre o Teste de Caminhada de Seis Minutos e o Teste Cardiopulmonar. Arq Bras Cardiol. 2011;97(1):59-64.

319. Pulz C, Diniz RV, Alves AN, Tebexreni AS, Carvalho AC, de Paola $\mathrm{AA}$, et al. Incremental shuttle and six-minute walking tests in the assessment of functional capacity in chronic heart failure. Can J Cardiol. 2008;24(2):131-5.

320. Oliveira MF, Zanussi G, Sprovieri B, Lobo DM, Mastrocolla LE, Umeda, II, et al. Alternatives to Aerobic Exercise Prescription in Patients with Chronic Heart Failure. Arq Bras Cardiol. 2016;106(2):97-104.

321. Meneghelo RS, Araújo CGS, Stein R, Mastrocolla LE, Albuquerque PF, Serra SM. III Diretrizes da Sociedade Brasileira de Cardiologia sobre Teste Ergométrico. Arq Bras Cardiol. 2010;95(5 Suppl 1):1-26.

322. Picano E, Pibarot $P$, Lancellotti P, Monin JL, Bonow RO. The emerging role of exercise testing and stress echocardiography in valvular heart disease. J Am Coll Cardiol. 2009;54(24):2251-60.

323. Lancellotti P, Dulgheru R, Go YY, Sugimoto T, Marchetta S, Oury C, et al. Stress echocardiography in patients with native valvular heart disease. Heart. 2018;104(10):807-13

324. Iung B, Baron G, Butchart EG, Delahaye F, Gohlke-Barwolf C, Levang $\mathrm{OW}$, et al. A prospective survey of patients with valvular heart disease in Europe: The Euro Heart Survey on Valvular Heart Disease. Eur Heart J. 2003;24(13):1231-43.

325. Pascual I, Munoz-Garcia AJ, Lopez-Otero D, Avanzas P, Jimenez-Navarro MF, Cid-Alvarez B, et al. Transcatheter aortic valve implantation in very elderly patients: immediate results and medium term follow-up. J Geriatr Cardiol. 2015;12(4):340-5.

326. Kortlandt F, Velu J, Schurer R, Hendriks T, Van den Branden B, Bouma B, et al. Survival After MitraClip Treatment Compared to Surgical and Conservative Treatment for High-Surgical-Risk Patients With Mitral Regurgitation. Circ Cardiovasc Interv. 2018;11(6):e005985.

327. Vigorito C, Abreu A, Ambrosetti M, Belardinelli R, Corra U, Cupples M, et al. Frailty and cardiac rehabilitation: A call to action from the EAPC Cardiac Rehabilitation Section. Eur J Prev Cardiol. 2017;24(6):577-90.

328. Voller H, Salzwedel A, Nitardy A, Buhlert H, Treszl A, Wegscheider K. Effect of cardiac rehabilitation on functional and emotional status in patients after transcatheter aortic-valve implantation. Eur J Prev Cardiol. 2015;22(5):568-74

329. Osnabrugge RL, Arnold SV, Reynolds MR, Magnuson EA, Wang K, Gaudiani VA, et al. Health status after transcatheter aortic valve replacement in patients at extreme surgical risk: results from the CoreValve U.S. trial. JACC Cardiovasc Interv. 2015;8(2):315-23.

330. Okoh AK, Chauhan D, Kang N, Haik N, Merlo A, Cohen M, et al. The impact of frailty status on clinical and functional outcomes after transcatheter aortic valve replacement in nonagenarians with severe aortic stenosis. Catheter Cardiovasc Interv. 2017;90(6):1000-6.
331. Ribeiro GS, Melo RD, Deresz LF, Dal Lago P, Pontes MR, Karsten M. Cardiac rehabilitation programme after transcatheter aortic valve implantation versus surgical aortic valve replacement: Systematic review and metaanalysis. Eur J Prev Cardiol. 2017;24(7):688-97.

332. Mijnarends DM, Schols JM, Meijers JM, Tan FE, Verlaan S, Luiking YC, et al. Instruments to assess sarcopenia and physical frailty in older people living in a community (care) setting: similarities and discrepancies. J Am Med Dir Assoc. 2015;16(4):301-8.

333. Bonow RO, Nishimura RA, Thompson PD, Udelson JE, American Heart Association E, Arrhythmias Committee of Council on Clinical Cardiology CoCDiYCoC, et al. Eligibility and Disqualification Recommendations for Competitive Athletes With Cardiovascular Abnormalities: Task Force 5: Valvular Heart Disease: A Scientific Statement From the American Heart Association and American College of Cardiology. Circulation. 2015;132(22):e292-7.

334. Gati S, Malhotra A, Sharma S. Exercise recommendations in patients with valvular heart disease. Heart. 2019;105(2):106-10.

335. Lemon J, Edelman S, Kirkness A. Avoidance behaviors in patients with implantable cardioverter defibrillators. Heart Lung. 2004;33(3):176-82.

336. Thomas SA, Friedmann E, Kelley FJ. Living with an implantable cardioverter-defibrillator: a review of the current literature related to psychosocial factors. AACN Clin Issues. 2001;12(1):156-63.

337. Lampert R, Cannom D, Olshansky B. Safety of sports participation in patients with implantable cardioverter defibrillators: a survey of heart rhythm society members. J Cardiovasc Electrophysiol. 2006;17(1):11-5.

338. Bajaj RR, Biswas A, Oh P, Alter DA. Safety of implantable cardioverter defibrillators in exercise therapy and cardiac rehabilitation: a systematic review and meta-analysis. Can J Cardiol. 2015;31(10):S264-S5.

339. Jung MH, Gustafsson F. Exercise in heart failure patients supported with a left ventricular assist device. J Heart Lung Transplant. 2015;34(4):489-96.

340. Isaksen K, Morken IM, Munk PS, Larsen AI. Exercise training and cardiac rehabilitation in patients with implantable cardioverter defibrillators: a review of current literature focusing on safety, effects of exercise training, and the psychological impact of programme participation. Eur J Prev Cardiol. 2012;19(4):804-12

341. Pandey A, Parashar A, Moore C, Ngo C, Salahuddin U, Bhargava M, et al. Safety and Efficacy of Exercise Training in Patients With an Implantable Cardioverter-Defibrillator: A Meta-Analysis. JACC Clin Electrophysiol. 2017;3(2):117-26.

342. Alswyan AH, Liberato ACS, Dougherty CM. A Systematic Review of Exercise Training in Patients With Cardiac Implantable Devices. J Cardiopulm Rehabil Prev. 2018;38(2):70-84.

343. Lampert R, Olshansky B, Heidbuchel H, Lawless C, Saarel E, Ackerman $M$, et al. Safety of sports for athletes with implantable cardioverterdefibrillators: results of a prospective, multinational registry. Circulation. 2013;127(20):2021-30

344. Lampert R, Olshansky B, Heidbuchel H, Lawless C, Saarel E, Ackerman $M$, et al. Safety of Sports for Athletes With Implantable CardioverterDefibrillators: Long-Term Results of a Prospective Multinational Registry. Circulation. 2017:135(23):2310-2.

345. Davids JS, McPherson CA, Earley C, Batsford WP, Lampert R. Benefits of cardiac rehabilitation in patients with implantable cardioverter-defibrillators: a patient survey. Arch Phys Med Rehabil. 2005;86(10):1924-8

346. Pathak RK, Elliott A, Middeldorp ME, Meredith M, Mehta AB, Mahajan R, et al. Impact of CARDIOrespiratory FITness on Arrhythmia Recurrence in Obese Individuals With Atrial Fibrillation: The CARDIO-FIT Study. J Am Coll Cardiol. 2015;66(9):985-96.

347. Billman GE. Aerobic exercise conditioning: a nonpharmacological antiarrhythmic intervention. J Appl Physiol (1985). 2002;92(2):446-54. 
348. Hossri CAC, Felicioni SP, Lourenço UR. Exercise Testing in Patients with Cardiac Implantable Electronic Devices. Rev Bras Cardiol. 2014;27(3):217-27.

349. Cenik F, Schoberwalter D, Keilani M, Maehr B, Wolzt M, Marhold M, et al. Neuromuscular electrical stimulation of the thighs in cardiac patients with implantable cardioverter defibrillators. Wien Klin Wochenschr. 2016;128(21-22):802-8.

350. Pachón EIM. Interferência dos monitores de pulso pessoais nos portadores de marcapasso definitivo e desfibriladores. Reblampa. 2004;17(1):11-7.

351. Mizzaci C, Mastrocolla LE, Pineli S. Tutorial básico de marcapasso. Rev DERC. 2016;22(2):38-9.

352. Mizzaci C, Mastrocolla LE, Ruchler R, Buglia S. Tutorial básico de marcapasso - parte II: Wenckebach eletrônico (Wenckebach do marcapasso). Rev DERC. 2016;22(1):110-1.

353. Miracapillo G, Costoli A, Addonisio L, Breschi M, Pasquinelli K, Gemignani $\mathrm{L}$, et al. Early mobilization after pacemaker implantation. J Cardiovasc Med (Hagerstown). 2006;7(3):197-202.

354. Quittan M, Sochor A, Wiesinger GF, Kollmitzer J, Sturm B, Pacher R, et al. Strength improvement of knee extensor muscles in patients with chronic heart failure by neuromuscular electrical stimulation. Artif Organs. 1999;23(5):432-5

355. Parissis J, Farmakis D, Karavidas A, Arapi S, Filippatos G, Lekakis J. Functional electrical stimulation of lower limb muscles as an alternative mode of exercise training in chronic heart failure: practical considerations and proposed algorithm. Eur J Heart Fail. 2015;17(12):1228-30.

356. Banerjee P, Caulfield B, Crowe L, Clark AL. Prolonged electrical muscle stimulation exercise improves strength, peak VO2, and exercise capacity in patients with stable chronic heart failure. J Card Fail. 2009;15(4):319-26.

357. Aboyans V, Ricco JB, Bartelink ML, Bjorck M, Brodmann M, Cohner T, et al. [2017 ESC Guidelines on the Diagnosis and Treatment of Peripheral Arterial Diseases, in collaboration with the European Society for Vascular Surgery (ESVS)]. Kardiol Pol. 2017;75(11):1065-160.

358. Fowkes FG, Rudan D, Rudan I, Aboyans V, Denenberg JO, McDermott $\mathrm{MM}$, et al. Comparison of global estimates of prevalence and risk factors for peripheral artery disease in 2000 and 2010: a systematic review and analysis. Lancet. 2013;382(9901):1329-40.

359. Duff S, Mafilios MS, Bhounsule P, Hasegawa JT. The burden of critical limb ischemia: a review of recent literature. Vasc Health Risk Manag. 2019;15:187-208

360. Xu D, Zou L, Xing Y, Hou L, Wei Y, Zhang J, et al. Diagnostic value of anklebrachial index in peripheral arterial disease: a meta-analysis. Can J Cardiol. $2013 ; 29(4): 492-8$

361. Aboyans V, Criqui MH, Abraham P, Allison MA, Creager MA, Diehm C, et al. Measurement and interpretation of the ankle-brachial index: a scientific statement from the American Heart Association. Circulation. 2012;126(24):2890-909.

362. Kithcart AP, Beckman JA. ACC/AHA Versus ESC Guidelines for Diagnosis and Management of Peripheral Artery Disease: JACC Guideline Comparison. J Am Coll Cardiol. 2018;72(22):2789-801.

363. Gerhard-Herman MD, Gornik HL, Barrett C, Barshes NR, Corriere MA, Drachman DE, et al. 2016 AHA/ACC Guideline on the Management of Patients With Lower Extremity Peripheral Artery Disease: Executive Summary: A Report of the American College of Cardiology/American Heart Association Task Force on Clinical Practice Guidelines. Circulation. 2017;135(12):e686-e725.

364. Stivalet O, Paisant A, Belabbas D, Omarjee L, Le Faucheur A, Landreau $P$, et al. Exercise testing criteria to diagnose lower extremity peripheral artery disease assessed by computed-tomography angiography. PLoS One. 2019;14(6):e0219082.

365. Lane R, Ellis B, Watson L, Leng GC. Exercise for intermittent claudication. Cochrane Database Syst Rev. 2014(7):CD000990.
366. Fokkenrood HJ, Bendermacher BL, Lauret GJ, Willigendael EM, Prins MH, Teijink JA. Supervised exercise therapy versus non-supervised exercise therapy for intermittent claudication. Cochrane Database Syst Rev. 2013(8):CD005263.

367. Gommans LN, Fokkenrood HJ, van Dalen HC, Scheltinga MR, Teijink JA, Peters RJ. Safety of supervised exercise therapy in patients with intermittent claudication. J Vasc Surg. 2015;61(2):512-8 e2.

368. Bermingham SL, Sparrow K, Mullis R, Fox M, Shearman C, Bradbury A, et al. The cost-effectiveness of supervised exercise for the treatment of intermittent claudication. Eur J Vasc Endovasc Surg. 2013;46(6):707-14.

369. Al-Jundi W, Madbak K, Beard JD, Nawaz S, Tew GA. Systematic review of home-based exercise programmes for individuals with intermittent claudication. Eur J Vasc Endovasc Surg. 2013;46(6):690-706.

370. Back M, Jivegard L, Johansson A, Nordanstig J, Svanberg T, Adania UW, et al. Home-based supervised exercise versus hospital-based supervised exercise or unsupervised walk advice as treatment for intermittent claudication: a systematic review. J Rehabil Med. 2015;47(9):801-8.

371. Lauret GJ, Fakhry F, Fokkenrood HJ, Hunink MG, Teijink JA, Spronk S. Modes of exercise training for intermittent claudication. Cochrane Database Syst Rev. 2014(7):CD009638.

372. Jakubseviciene E, Vasiliauskas D, Velicka L, Kubilius R, Milinaviciene $\mathrm{E}$, Vencloviene J. Effectiveness of a new exercise program after lower limb arterial blood flow surgery in patients with peripheral arterial disease: a randomized clinical trial. Int J Environ Res Public Health. 2014;11(8):7961-76.

373. Kruidenier LM, Nicolai SP, Rouwet EV, Peters RJ, Prins MH, Teijink JA. Additional supervised exercise therapy after a percutaneous vascular intervention for peripheral arterial disease: a randomized clinical trial. J Vasc Interv Radiol. 2011;22(7):961-8.

374. Malgor RD, Alahdab F, Elraiyah TA, Rizvi AZ, Lane MA, Prokop LJ, et al. A systematic review of treatment of intermittent claudication in the lower extremities. J Vasc Surg. 2015;61(3 Suppl):54S-73S.

375. Murphy TP, Cutlip DE, Regensteiner JG, Mohler ER, Cohen DJ, Reynolds $M R$, et al. Supervised exercise versus primary stenting for claudication resulting from aortoiliac peripheral artery disease: six-month outcomes from the claudication: exercise versus endoluminal revascularization (CLEVER) study. Circulation. 2012;125(1):130-9.

376. Murphy TP, Cutlip DE, Regensteiner JG, Mohler ER 3rd, Cohen DJ, Reynolds MR, et al. Supervised exercise, stent revascularization, or medical therapy for claudication due to aortoiliac peripheral artery disease: the CLEVER study. J Am Coll Cardiol. 2015;65(10):999-1009.

377. Klaphake S, Buettner S, Ultee KH, van Rijn MJ, Hoeks SE, Verhagen HJ. Combination of endovascular revascularization and supervised exercise therapy for intermittent claudication: a systematic review and metaanalysis. J Cardiovasc Surg (Torino). 2018;59(2):150-7.

378. Saratzis A, Paraskevopoulos I, Patel S, Donati T, Biasi L, Diamantopoulos A, et al. Supervised Exercise Therapy and Revascularization for Intermittent Claudication: Network Meta-Analysis of Randomized Controlled Trials. JACC Cardiovasc Interv. 2019;12(12):1125-36.

379. Arya S, Khakharia A, Binney ZO, DeMartino RR, Brewster LP, Goodney PP, et al. Association of Statin Dose With Amputation and Survival in Patients With Peripheral Artery Disease. Circulation. 2018;137(14):1435-46.

380. CAPRIE Steering Committee. A randomised, blinded, trial of clopidogrel versus aspirin in patients at risk of ischaemic events (CAPRIE). CAPRIE Steering Committee. Lancet. 1996;348(9038):1329-39.

381. Harwood AE, Smith GE, Cayton T, Broadbent E, Chetter IC. A Systematic Review of the Uptake and Adherence Rates to Supervised Exercise Programs in Patients with Intermittent Claudication. Ann Vasc Surg. 2016;34:280-9.

382. Lane R, Harwood A, Watson L, Leng GC. Exercise for intermittent claudication. Cochrane Database Syst Rev. 2017;12:CD000990.

Este é um artigo de acesso aberto distribuído sob os termos da licença de atribuição pelo Creative Commons 